\title{
MCNP: Neutron Benchmark Problems
}

Daniel J. Whalen

David A. Cardon

Jennifer L. Uhle

John S. Hendricks 


\section{DISCLAIMER}

This report was prepared as an account of work sponsored by an agency of the United States Government. Neither the United States Government nor any agency Thereof, nor any of their employees, makes any warranty, express or implied, or assumes any legal liability or responsibility for the accuracy, completeness, or usefulness of any information, apparatus, product, or process disclosed, or represents that its use would not infringe privately owned rights. Reference herein to any specific commercial product, process, or service by trade name, trademark, manufacturer, or otherwise does not necessarily constitute or imply its endorsement, recommendation, or favoring by the United States Government or any agency thereof. The views and opinions of authors expressed herein do not necessarily state or reflect those of the United States Government or any agency thereof. 


\section{DISCLAIMER}

Portions of this document may be illegible in electronic image products. Images are produced from the best available original document. 


\title{
MCNP: NEUTRON BENCHMARK PROBLEMS
}

by

\author{
Daniel J. Whalen \\ David A. Cardon \\ Jennifer L. Uhle \\ John S. Hendricks
}

\begin{abstract}
The recent widespread and increased use of radiation transport codes has produced greater user and institutional demand for assurances that such codes give correct results. Responding to these requirements for code validation, the general purpose Monte Carlo transport code MCNP has been tested on criticality, pulsed sphere, and shielding neutron problem families. Results for each were compared to experimental data. MCNP successfully predicted the experimental results of all three families within the expected data and statistical uncertainties. These successful predictions demonstrate that MCNP can successfully model a broad spectrum of neutron transport problems.
\end{abstract}




\section{INTRODUCTION}

\section{A. The MCNP Benchmark Project}

This document is the second in a series of reports benchmarking the MCNP ${ }^{1}$ Monte Carlo computer code. The first document, LA-12196, ${ }^{2}$ demonstrated that MCNP accurately models analytic problems and a wide variety of photon experiments. This report demonstrates that MCNP also models a wide variety of neutron problems well.

For the most part, both this report and its companion report, LA-12196, model the same problems chosen to benchmark the COG Monte Carlo code ${ }^{3}$ developed at Lawrence Livermore National Laboratory. The criticality problems reported here are the only serious departures from the set chosen for the COG benchmarks. The COG benchmark set represents a wide variety of radiation transport problems. Furthermore, the COG results provide an indication of what constitutes acceptable accuracy. The calculation of $k_{\text {eff }}$ for criticality is considered unacceptable if it deviates more than a fraction of a percent from measurements. But for a deep penetration shielding problem, an answer within a factor of two of the experiment is considered reasonable. In all cases presented here, the MCNP calculated results were as good as or better than those of COG and as accurate as could be reasonably expected in a numerical simulation.

\section{B. Problem Overview}

All three families of the neutron benchmark problems presented here were the focus of experimental study. Benchmark one is a set of neutron pulsed-sphere experiments conducted at Lawrence Livermore National Laboratory in the late sixties. These pulsed-sphere experiments were used to validate neutron transport codes (such as SORS or TART) then in operation at Livermore. In these experiments, a nearly-isotropic pulsed deuterium-tritium (D-T) neutron source was placed in the

1 Judith F. Briesmeister, Editor, "MCNP - A General Monte Carlo Code for Neutron and Photon Transport, Version 3A," Los Alamos National Laboratory report LA-7396-M, Rev. 2 (1986).

2 Daniel J. Whalen, David E. Hollowell, and John S. Hendricks, "MCNP: Photon Benchmark Problems," Los Alamos National Laboratory report LA-12196 (1991).

3 Thomas P. Wilcox, Jr., and Edward M. Lent, "COG - A Particle Transport Code Designed to Solve the Boltzmann Equation for Deep Penetration (Shielding) Problems," Vol. 4, "Benchmark Problems," Lawrence Livermore National Laboratory report M-221-4 (12/2/88). 
centers of spheres of several different diameters and compositions. The time-offlight energy spectrum of the neutrons leaving a sphere at a given angle was then measured. Thomas Wilcox and Edward Lent used these pulsed-sphere studies to benchmark the LLNL COG Monte Carlo code in 1987. These experiments were chosen for simulation because they involve neutron scattering over a wide range of energies in many different materials. MCNP was used to compute the neutron spectra of these experiments, and its results were compared to the experimental data.

Benchmark two is one of a series of neutron shielding experiments performed by Santoro et al. at Oak Ridge National Laboratory between 1980 and 1985 . These experiments were designed to simulate the D- $\mathrm{T}$ fusion neutron spectrum at the first wall of a hypothetical fusion reactor. In these experiments a nearly-isotopic $\mathrm{D}$-T neutron source was placed at one end of an iron pipe. The source and pipe were imbedded in a concrete block shield, and a detector outside the source/shield assembly measured the energy spectra of the neutrons and photons leaving the assembly. The different experiments of this series tested various shielding configurations. MCNP was used to model three stainless steel and polyethylene shielding arrangements. This problem was chosen for study because it involves streaming and deep penetration - a formidable variance reduction task. It also involves neutroninduced photon production and coupled neutron-photon transport.

Benchmark three is a family of critical assembly experiments. These experiments measured the neutron multiplication in several different fissionable systems. Four types of critical assemblies were studied:

1. Fast neutron systems

2. Low-enrichment systems

3. Reflected-neutron systems

4. Interacting systems

These criticals were chosen as benchmarks because they are straightforward and test MCNP's criticality eigenvalue estimators. These three neutron benchmarks are summarized in Tables 1 and 2. 
TABLE 1

\title{
DESCRIPTION OF MCNP NEUTRON BENCHMARK PROBLEMS
}

\author{
Problem \\ Number Subcategory \\ Description \\ Energy Range \\ 1 \\ 2 \\ 3 \\ A pulsed D-T neutron source which is nearly \\ isotropic is placed at the centers of spheres \\ a-p of various radii and compositions. The time- \\ of-flight spectrum of the neutrons leaving \\ the spheres is measured. \\ A D-T neutron source is placed at one end \\ of an iron pipe. The pipe and source are \\ imbedded in a concrete shield block, with \\ the other end of the pipe open to the air. \\ The energy spectra of the neutrons and photons \\ penetrating steel and polyethylene are measured. \\ This experiment simulates the neutron \\ spectrum at the first wall of a hypothetical \\ fusion reactor. \\ Four types of critical assemblies were \\ experimented with: \\ a \\ Fast Neutron Systems \\ 1. Godiva: bare uranium sphere $\left(93.71 \%{ }^{235} \mathrm{U}\right)$ \\ 2. Jezebel: bare plutonium sphere - \\ two cases: $95.5 \%{ }^{239} \mathrm{Pu}$ \\ and $80 \%{ }^{239} \mathrm{Pu}$ \\ $1.6-15.2 \mathrm{MeV}$ \\ 15.2 MeV to thermal \\ (neutrons) \\ $15.2 \mathrm{MeV}$ to $1 \mathrm{keV}$ \\ (secondary photons) \\ b Low Enrichment systems \\ 1. uranium cylinder: $10.9 \%{ }^{235} \mathrm{U}$ \\ 2. uranium cylinder: $14.11 \%{ }^{235} \mathrm{U}$ \\ c Reflected Neutron Systems \\ 1. uranium sphere $\left(93.5 \%{ }^{235} \mathrm{U}\right)$ surrounded by graphite \\ 2. uranium sphere $\left(97.6 \%{ }^{235} \mathrm{U}\right)$ surrounded by water \\ d Interacting Units \\ 1. three ${ }^{235} \mathrm{U}$ cylinders \\ 2. $3 \times 3$ array of plutonium fuel rods
}


TABLE 2

DESCRIPTION OF MCNP NEUTRON BENCHMARK PROBLEMS

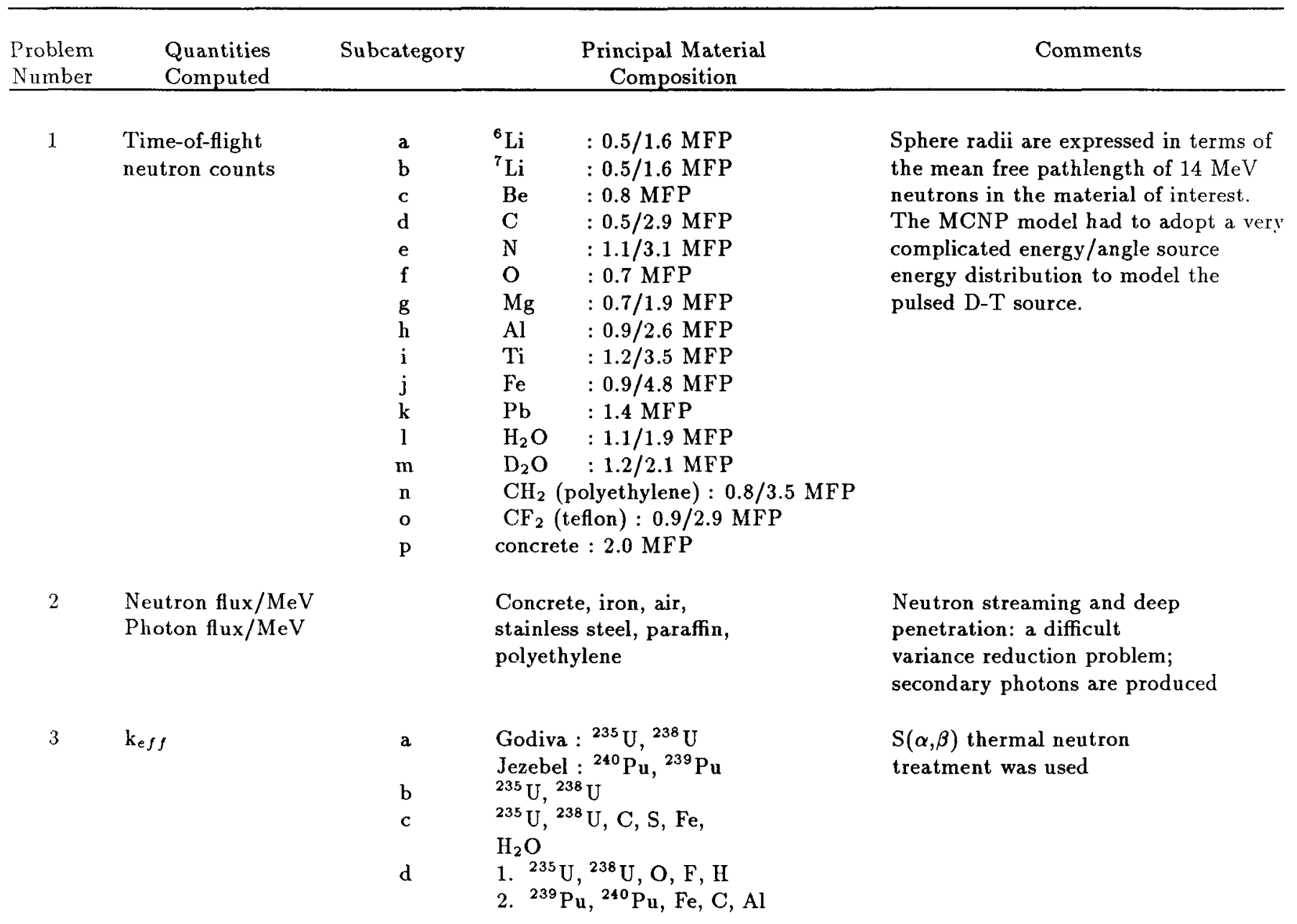




\section{BENCHMARK PROBLEM ONE: PULSED SPHERES}

\section{A. Problem History}

In the 1960s researchers at Lawrence Livermore National Laboratory initiated the pulsed spheres program to study nuclear cross sections and to validate neutron transport codes such as SORS and TART. In these experiments a pulsed source of approximately $14-\mathrm{MeV}$ neutrons was placed in the centers of spheres of various materials. The time-of-flight spectrum of the neutrons leaving each sphere was then measured. The pulsed spheres are ideal for benchmarking a code such as MCNP because of the relative simplicity of their geometry and experimental data.

\section{B. Experimental Setup}

1. Neutron Source and Target Assembly. The $T(d, n)^{4}$ He reaction was used to create a nearly isotropic source of $14-\mathrm{MeV}$ neutrons. The Livermore Insulated Core Transformer (ICT) accelerator directed $400-\mathrm{keV} \mathrm{D}+$ ions at a tritium-loaded titanium target located approximately at the center of a cubical 12.2 meter (40-ft) target pit. The target was a thin tritiated titanium disk $1.2 \mathrm{~cm}$ in diameter. The disk was held in place by a low mass structure made primarily of aluminum and stainless steel. Solid spheres of various materials were constructed. Each had a narrow hole from the outside to the center into which the target assembly could be inserted. Spherical containers with very thin walls were used for liquid materials. Neutron detectors were placed at 30 and 120 degrees with respect to the beam line at distances ranging from $752 \mathrm{~cm}$ to $975 \mathrm{~cm}$ (see Figs. 1, 2, and 3).

In the center-of-mass frame the $\mathrm{T}(\mathrm{d}, \mathrm{n})^{4} \mathrm{He}$ reaction is isotropic. However, in the laboratory frame the intensity and energy are slightly higher in the direction of the deuteron beam than in the opposite direction. The intensity and most probable energy as a function of angle are known. ${ }^{4}$

2. Neutron Detection. Two types of neutron detectors were used: the $\mathrm{Pi}$ lot B detector and the NE213. Both detectors were operated at a neutron bias of

4 C. Wong, J. D. Anderson, P. Brown, L. F. Hansen, J. L. Kammerdiener, C. Logan, and B. Pohl, "Livermore Pulsed Sphere Program: Program Summary Through July 1971", Lawrence Livermore National Laboratory report UCRL-51144 Rev. 1 (1972), p. 7. 


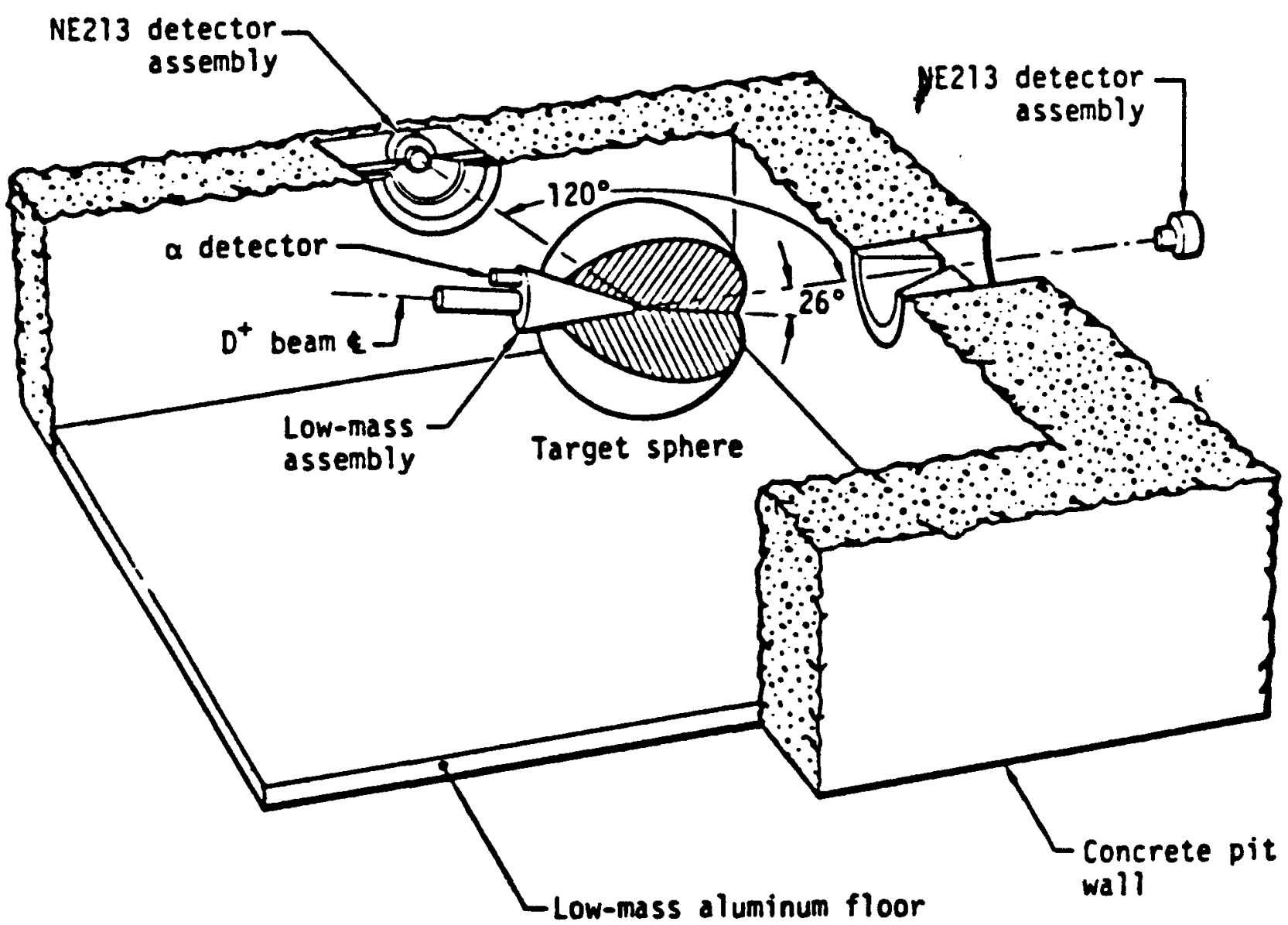

Fig. 1. Time-of-flight geometry of the target sphere and collimated neutron detector in the Livermore pulsed sphere experiments. (Figure taken from Ref. 4.) 


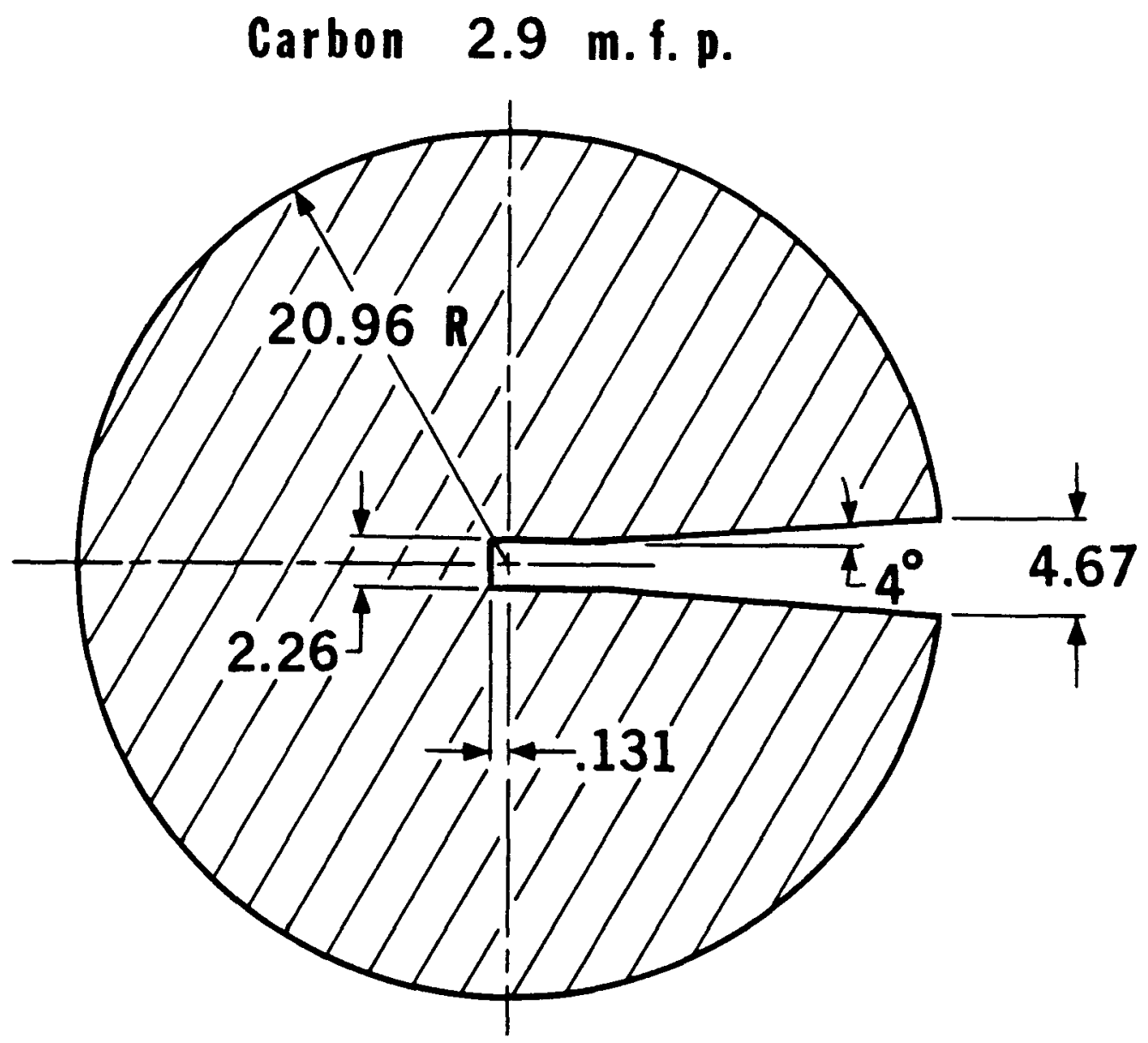

Fig. 2. Diagram showing the specifications of a solid carbon sphere used in the Livermore pulsed sphere experiments. Spheres of other materials were similarly constructed. (Figure taken from Ref. 18.) 


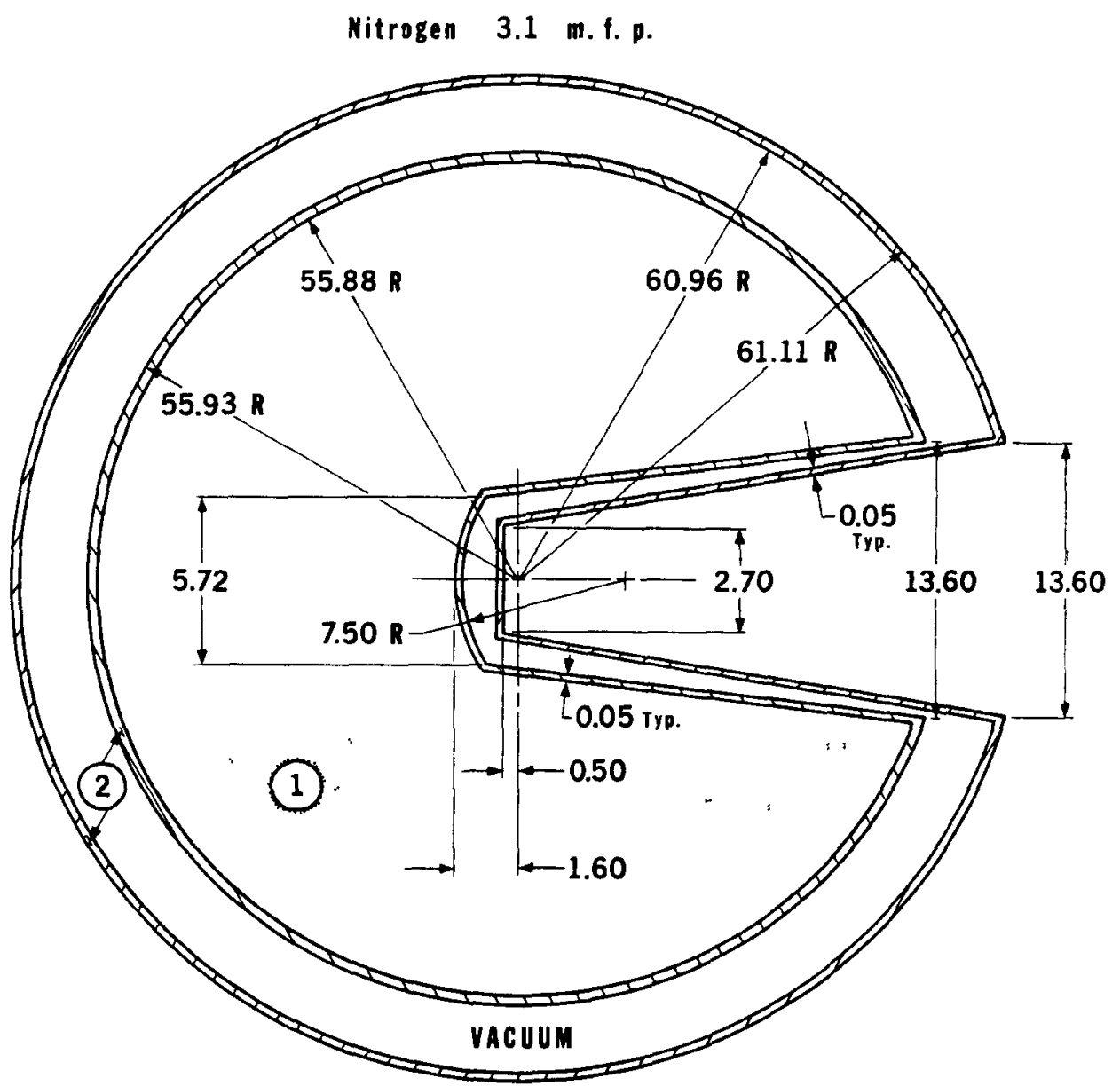

All Dimensions in Centimeters

\begin{tabular}{c|c|c|c} 
Zone & Density $\left(\mathrm{g} / \mathrm{cm}^{3}\right)$ & Material & Atomic \% \\
\hline 1 & 0.808 & Liquid N $_{2}$ & 100.0 \\
\hline 2 & 7.9 & $\mathrm{Fe}$ & 68.6 \\
& & $\mathrm{Cr}$ & 20.0 \\
& & $\mathrm{Ni}$ & 8.4 \\
& & $\mathrm{Si}$ & 2.0 \\
& & $\mathrm{Mn}$ & 1.0
\end{tabular}

Fig. 3. Diagram showing the specifications of the 3.1 mean free path liquid nitrogen sphere used in the Livermore pulsed sphere experiments. Similarly constructed spheres were used for other liquid materials. (Figure taken from Ref. 18.) 
1.6 MeV. ${ }^{5,6,7}$ Response functions for both detectors at this bias have been measured. $^{8,9}$ The detector response functions were not unfolded from the published experimental data.

3. Data. With a sphere of material surrounding the neutron source, the number of detected counts per 2-ns time bin was recorded starting at the beginning of a neutron pulse. The data were then divided by the total number of neutrons recorded from a pulse without the sphere in place. This normalization made the results independent of the accelerator beam intensity.

\section{MCNP Problem Model}

The MCNP input files for three representative pulsed sphere problem models are in the Appendix in Tables A1-A3.

1. Geometry. The MCNP geometry centers the simulated spherical target assembly at the origin. The spherical assembly is modeled to include the hole into which the tritiated titanium target is inserted in the real experiment (see Fig. 4). The shape and size of the holes vary from material to material. Hence, each input file contains geometry descriptions specific to the sphere being modeled. The spherical target assembly is surrounded by a sphere with a radius of 1000 $\mathrm{cm}$. The region outside the spherical target assembly and inside the large sphere is specified to be air with a standard density of $.001288-\mathrm{g} / \mathrm{cm}^{3}$. The region outside the large sphere is neglected.

$\overline{5}$ L. F. Hansen, J. D. Anderson, E. Goldberg, J. Kammerdiener, E. Plechaty, and C. Wong, "Predictions for Neutron Transport in Air, Based on Integral Measurements in Nitrogen and Oxygen at $14 \mathrm{MeV}$," Nuclear Science and Engineering 40, 262-282 (1970), p. 263.

6 Marion L. Stelts, John D. Anderson, Luisa F. Hansen, Ernest F. Plechaty, and Calvin Wong, "Spectra of Fast Neutrons from Water Pulsed with 14-MeV Neutrons," Nuclear Science and Engineering 46, 53-56 (1971), p. 54.

7 Luisa F. Hansen, John D. Anderson, Eugene Goldberg, Ernest F. Plechaty, Marion L. Stelts, and Calvin Wong, "Time Spectra from Spheres Pulsed with 14-MeV Neutrons," Nuclear Science and Engineering 35, 227-239 (1969), p. 228.

8 Wong et al., pp. 14 and 16.

9 W. Webster and C. Wong, "Measurement of the Neutron Emission Spectra from Spheres of N, O, W, U-235, U-238, and Pu-239, Pulsed by 14-MeV Neutrons," Lawrence Livermore National Laboratory report UCID-17332 (December 15, 1976), p. 10. 


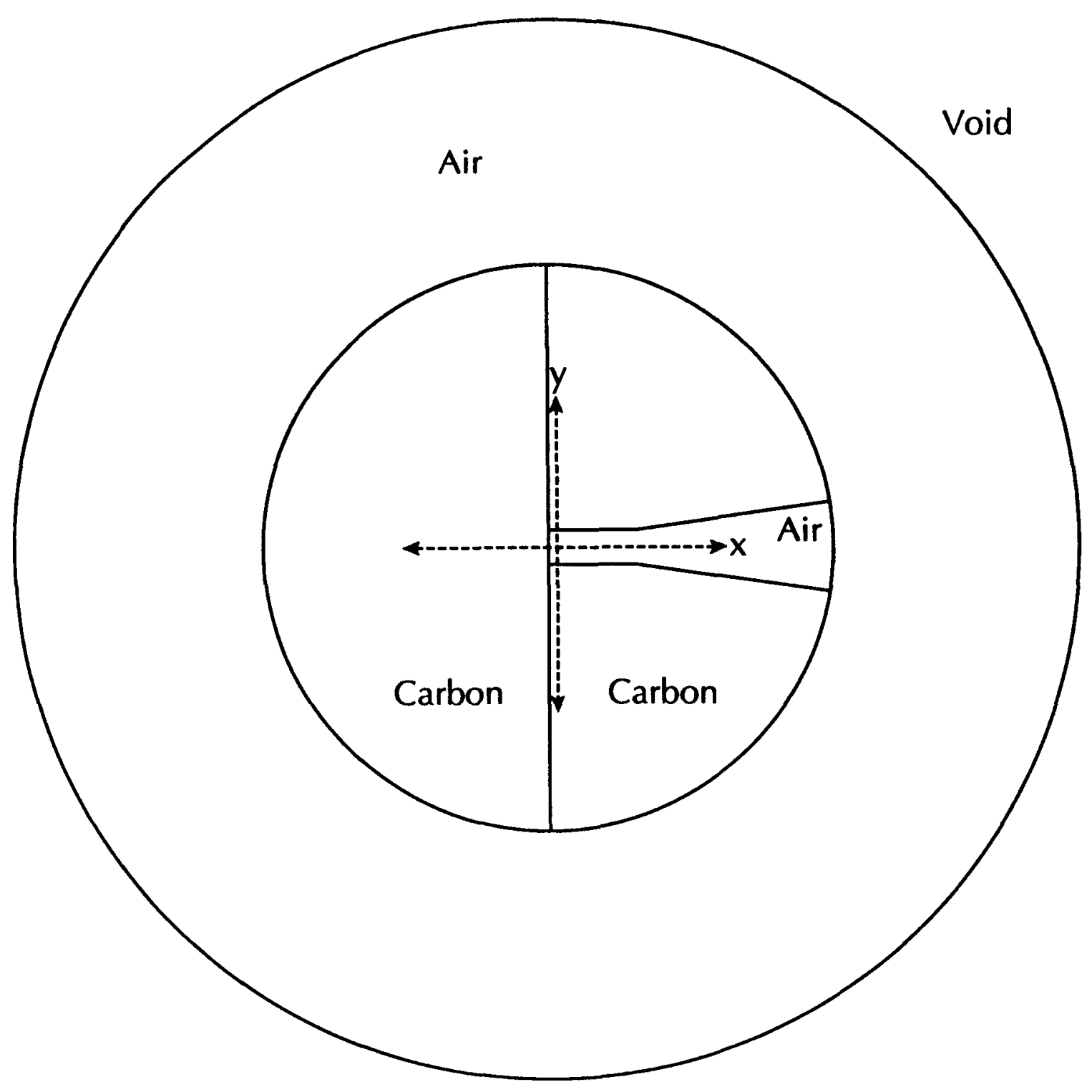

Fig. 4. Cell geometry used for the 2.9 m.f.p. carbon sphere (not to scale). The cell geometries for the other MCNP pulsed sphere calculations are similar. 
When the reported dimensions, density, and mass were in conflict, the mass was assumed to be correct. For example, the MCNP model uses an artificially high density for the stainless steel containers in the lithium pulsed sphere experiment to preserve both the reported dimensions and the reported mass.

2. Low Mass Target Assembly. The aluminum-stainless steel structure which holds the titanium-tritide target in place is not included in the model because its mass is small compared to the mass of most of the spherical assemblies. To see if this structure should be included in the models for smaller spheres, a detailed MCNP model of this assembly was created for the $.9 \mathrm{mfp}$ iron sphere, but the results were within a percent of the results without the assembly. Therefore, the simpler model has been used in all the pulsed sphere calculations. Also, the room in which the experiment was performed has not been modeled because its effect is assumed to be insignificant.

3. Neutron Source. The most complicated aspect of the MCNP pulsed sphere model is the neutron source specification. The MCNP neutron source produces the intensity and most probable energy as a function of angle. At 0 degrees with respect to the deuteron beam, the most likely neutron energy is $15.11 \mathrm{MeV}$, and the energy decreases monotonically as a function of the angle to a value of $13.20 \mathrm{MeV}$ at 180 degrees. The intensity also decreases monotonically as a function of angle where intensity is normalized so that $I=1.00$ at 0 degrees and $I=.87$ at 180 degrees. The source description, therefore, requires several probability distributions. First, the direction of a neutron is specified on the source definition (SDEF) card with the entries

$$
\mathrm{DIR}=\mathrm{D} 1 \mathrm{VEC}=-1 \quad 0 \quad 0 .
$$

The polar angle of a source particle is measured with respect to the vector VEC which points in the direction of the negative $\mathrm{x}$ axis. DIR is a variable whose value is the cosine of the angle between the vector VEC and the initial direction of the particle. D1 is a probability distribution defined by the entries on the source information (SI1) and the source probability (SP1) cards. Therefore, distribution 1 is constructed to sample the cosines of the polar angles of the particle's initial direction. The entries on the SI1 card are the cosines of the angles at which the intensity is known. The SP1 card's entries are the intensities corresponding to the angles whose cosines appear on the SI1 card. MCNP linearly interpolates between 
the points specified in the SI1 and SP1 cards to form a probability density function from which the values of the cosine are sampled.

The energy is specified on the SDEF card with the entry

$$
\mathrm{ERG}=\mathrm{FDIR}=\mathrm{D} 2,
$$

meaning that the values of energy are chosen from probability distribution 2 which itself depends on the already chosen direction. Because the energy distribution depends on the direction distribution, a dependent source (DS2) card must be used. The DS2 card's entries include the cosines of every five degrees where each cosine value is followed by the number of another distribution from which the final energy is taken. For example, the first few entries on the DS2 card are

$$
\text { DS2 Q -.99619 } 180-.98481175-.96593170 \ldots \text { etc. }
$$

If a value of the cosine is chosen lying between -.98481 and - .96593 (which are the cosines of 170 and 165 degrees), then the energy will be chosen from distribution 170. Distribution 170 samples uniformly between the most likely energies at 165 and 170 degrees. The energy distributions referred to on the DS2 card above are from the DS2 card on the input file and are numbered according to the angles from 5 to 180 degrees at intervals of 5 degrees. The angular dependence of energy and intensity given in the reference ${ }^{10}$ is only accurate to two decimal places. An additional digit was added to these figures by analytically calculating the energy and intensity of an isotropic source moving with respect to the laboratory frame. The values from this analytic calculation were fixed to match the measured energy exactly at 0 and 180 degrees. The recalculated values with three decimal places exactly match the reported values upon truncating or rounding to two places. The final energy spectrum produced by MCNP more closely resembles the actual energy spectrum when the additional digits are used than when they are not.

The actual neutron source is a $.6 \mathrm{~cm}$ radius titanium tritide disk. Therefore, in the MCNP model the neutrons originate on a disk with $.6 \mathrm{~cm}$ radius. This is specified by including

$$
\mathrm{RAD}=\mathrm{D} 3 \mathrm{SUR}=100
$$

10 Wong et al., p. 7. 
on the source definition card along with the corresponding probability definition

SI3 H 0.6

SP3 D -21 1 .

The SP3 distribution guarantees that MCNP will uniformly sample the area on a disk of radius $.6 \mathrm{~cm}$ centered at the origin. This disk is located on surface 100 which is a plane perpendicular to the $\mathrm{x}$ axis at the origin.

4. Cross-Section Libraries. ENDF/B-V was used whenever available, including for all major nuclides. Preliminary ENDF/B-VI was also used for nitrogen (see discussion below).

5. Detectors and Data. Because the MCNP model is symmetric with respect to the $\mathrm{x}$-axis, a ring detector about the $\mathrm{x}$-axis was used to calculate the flux at a given polar angle and distance from the detector. The detector response functions were not folded out of the experimental data. Therefore, the MCNP model uses a detector energy (DE) card and a dose function (DF) card which weight the tallies depending on the energy of the detected neutron. The response functions for both the Pilot B and NE213 detectors for a bias at $1.6 \mathrm{MeV}$ neutron energy were modeled by specifying various energy values on the $\mathrm{DE}$ card and the corresponding values of the detector response functions on the DF card. ${ }^{11,12}$

Because the experimental results are given in terms of (particles/ns)/(particles detected without the sphere), the MCNP results must be properly normalized. The MCNP tallies give flux/(source particle). Thus, the problem must be rerun with the solid sphere replaced by air to find (flux without sphere in place)/(source particle). The former value is divided by the latter to give values comparable to the experimental results.

6. Special Techniques. Most of the pulsed sphere models contain no variance reduction techniques. However, through trial and error, it was discovered that the MCNP figure of merit for some of the sphere problems with larger radii could be improved by dividing the spherical cell at the origin into several concentric shells. The importance was then increased as the distance from the center of the sphere increased. For the iron sphere with a 4.8 mean free path radius, this increase

11 Ibid, p. 14, 16.

12 Webster et al., p. 10. 
significantly improved the figure of merit. Another technique that improved the run time for all of the input files was to include an energy cutoff at $1.6 \mathrm{MeV}$. This cutoff prevented MCNP from tracking particles whose energies dropped below the detector's sensitivity threshold.

\section{Results and Discussion}

1. MCNP Results. The experimental results and computed results are compared in both plots and tables. Table 3 summarizes the results of the pulsed sphere calculations. For each material the normalized number of counts was integrated in time bins that correspond roughly to neutron energies of $12-16 \mathrm{MeV}$ and $2-16 \mathrm{MeV}$. It is convenient to discuss the results in this manner because the neutron detectors were not located the same distance from the center of the sphere in each experiment. Determination of the time bins was based on the time a particle of the given energy would take to travel from the center of the sphere to the detector without collision. The table lists the ratio of the calculated value to the experimental value in each energy (time) bin. The results are quite good for most materials. However, there are several notable exceptions, one of which is nitrogen.

With the recent release of the ENDF/B-VI cross sections for nitrogen, it is interesting to compare the results of nitrogen pulsed sphere calculations using both the old and new cross sections. Table 4 contains information for nitrogen spheres with 1.1, 3.1, and 7.7 mean free path radii. Time bins were chosen that correspond roughly to energies of 2-5 MeV, $5-10 \mathrm{MeV}, 10-13 \mathrm{MeV}$, and 13-16 MeV. In general, the agreement between calculated results and experiment is significantly better with the ENDF/B-VI cross sections than it is with the ENDF/B-V cross sections.

The second comparison uses time bins at intervals of 2-ns as in the experiment. Thus, rather than comparing integrated numbers of counts over a broad time range, we compare count rates. Plots of the computed count rate are superimposed on

plots of the experimental count rate for comparison of their shapes. This was done for nitrogen, carbon, iron, water, and concrete. See Figs. 5-10.

Note that each of the plots for nitrogen (Figs. 5 and 6) contains two calculated curves: one generated with ENDF/B-V cross sections and one generated with ENDF/B-VI cross sections. The curves generated using ENDF/B-VI cross sections have a better shape and do not exhibit the nonphysical bump at about 210 nanoseconds that is present in the curves generated with the ENDF/B-V cross sections. 
TABLE 3

RATIO OF CALCULATED TO EXPERIMENTAL VALUES FOR THE NUMBER OF NEUTRONS DETECTED IN EACH ENERGY RANGE ${ }^{13}$

\begin{tabular}{|c|c|c|c|}
\hline Material & $\underline{\mathrm{mfp}}$ & $12-16 \mathrm{MeV}$ & 2-16 MeV \\
\hline \multirow[t]{2}{*}{${ }^{6} \mathrm{Li}$} & 0.5 & .981 & .981 \\
\hline & 1.6 & 1.019 & 1.030 \\
\hline \multirow[t]{2}{*}{${ }^{7} \mathrm{Li}$} & 0.5 & .990 & .985 \\
\hline & 1.6 & 1.017 & 1.008 \\
\hline $\mathrm{Be}$ & 0.8 & .937 & .997 \\
\hline \multirow[t]{2}{*}{$\mathrm{C}$} & 0.5 & .974 & .990 \\
\hline & 2.9 & .950 & .973 \\
\hline \multirow[t]{2}{*}{$\mathrm{N}$} & 1.1 & .866 & .950 \\
\hline & 3.1 & .812 & .972 \\
\hline $\mathrm{O}$ & 0.7 & .921 & .988 \\
\hline \multirow[t]{2}{*}{$\mathrm{Mg}$} & 0.7 & 1.046 & 1.033 \\
\hline & 1.9 & .994 & .960 \\
\hline \multirow[t]{2}{*}{$\mathrm{Al}$} & 0.9 & .940 & .948 \\
\hline & 2.6 & .786 & .839 \\
\hline \multirow[t]{2}{*}{$\mathrm{Ti}$} & 1.2 & 1.069 & .992 \\
\hline & 3.5 & 1.077 & .930 \\
\hline \multirow[t]{2}{*}{$\mathrm{Fe}$} & 0.9 & 1.006 & 1.006 \\
\hline & 4.8 & .937 & .948 \\
\hline $\mathrm{Pb}$ & 1.4 & .873 & .851 \\
\hline \multirow[t]{2}{*}{$\mathrm{H}_{2} \mathrm{O}$} & 1.1 & .881 & .946 \\
\hline & 1.9 & .961 & 1.066 \\
\hline \multirow[t]{2}{*}{$\mathrm{D}_{2} \mathrm{O}$} & 1.2 & .865 & .914 \\
\hline & 2.1 & .983 & 1.025 \\
\hline \multirow[t]{2}{*}{$\mathrm{CH}_{2}$} & 0.8 & .973 & .999 \\
\hline & 3.5 & .884 & .969 \\
\hline \multirow[t]{2}{*}{$\mathrm{CF}_{2}$} & 0.9 & .957 & .976 \\
\hline & 2.9 & .766 & .782 \\
\hline Concrete & 2.0 & .987 & 1.041 \\
\hline
\end{tabular}

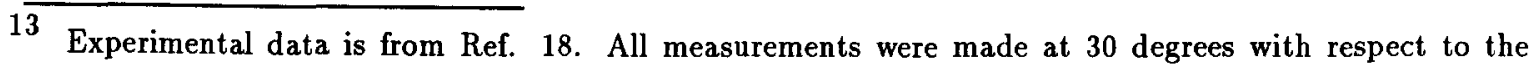
deuteron beam except the concrete measurement which was made at 120 degrees. 


\section{RATIO OF THE CALCULATED TO EXPERIMENTAL VALUES FOR NITROGEN USING ENDF/B-V AND ENDF/B-VI CROSS SECTIONS ${ }^{14}$}

\begin{tabular}{lcr} 
& \multicolumn{2}{c}{ Nitrogen 1.1 M.F.P } \\
Energy $(\mathrm{MeV})$ & $5 /$ meas. & $6 /$ meas. \\
& & \\
$13-16$ & .872 & .910 \\
$10-13$ & 1.049 & 1.195 \\
$5-10$ & 1.309 & 1.271 \\
$2-5$ & 1.309 & 1.084 \\
Total & .959 & .975 \\
& & \\
& Nitrogen 3.1 M.F.P \\
Energy $(\mathrm{MeV})$ & $5 /$ meas. \\
$13-16$ & .815 & $6 /$ meas. \\
$10-13$ & .826 & .899 \\
$5-10$ & 1.194 & 1.015 \\
$2-5$ & 1.278 & 1.189 \\
Total & .976 & 1.105 \\
& & 1.009 \\
& Nitrogen 7.7 M.F.P. \\
Energy $(\mathrm{MeV})$ & & \\
$13-16$ & $5 /$ meas. & $6 /$ meas. \\
$10-13$ & .713 & .868 \\
$5-10$ & .677 & .911 \\
$2-5$ & 1.004 & 1.040 \\
Total & 1.124 & 1.006 \\
& .931 & .973 \\
& & \\
& & \\
& & \\
& & \\
& & \\
& &
\end{tabular}




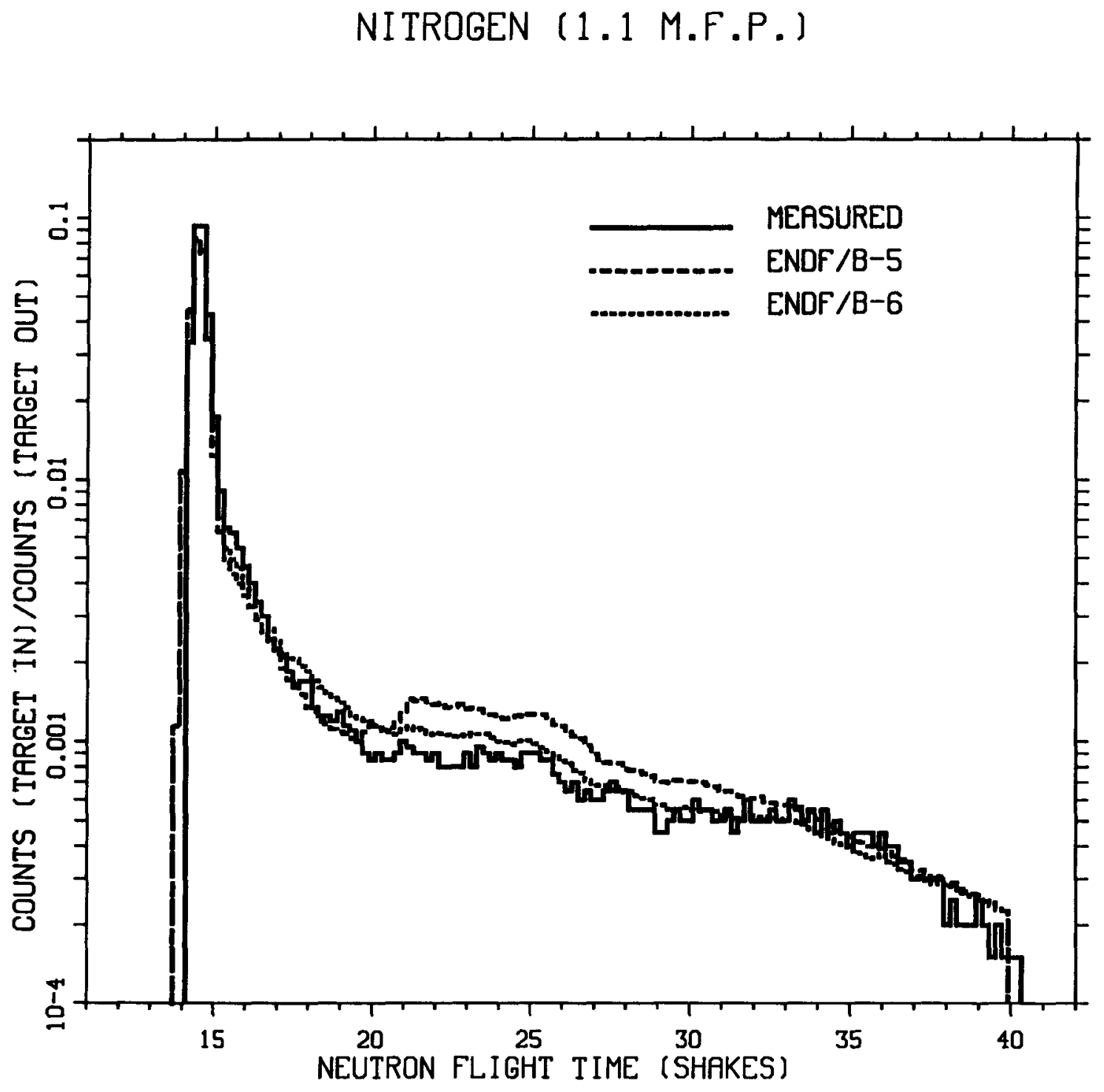

Fig. 5. Plot of experimental and calculated count rates as a function of time for a nitrogen sphere with 1.1 mean free path radius. The detector was located $763.3 \mathrm{~cm}$ from the center of the sphere at 30 degrees with respect to the deuteron beam $(1$ shake $=10 \mathrm{~ns})$. 


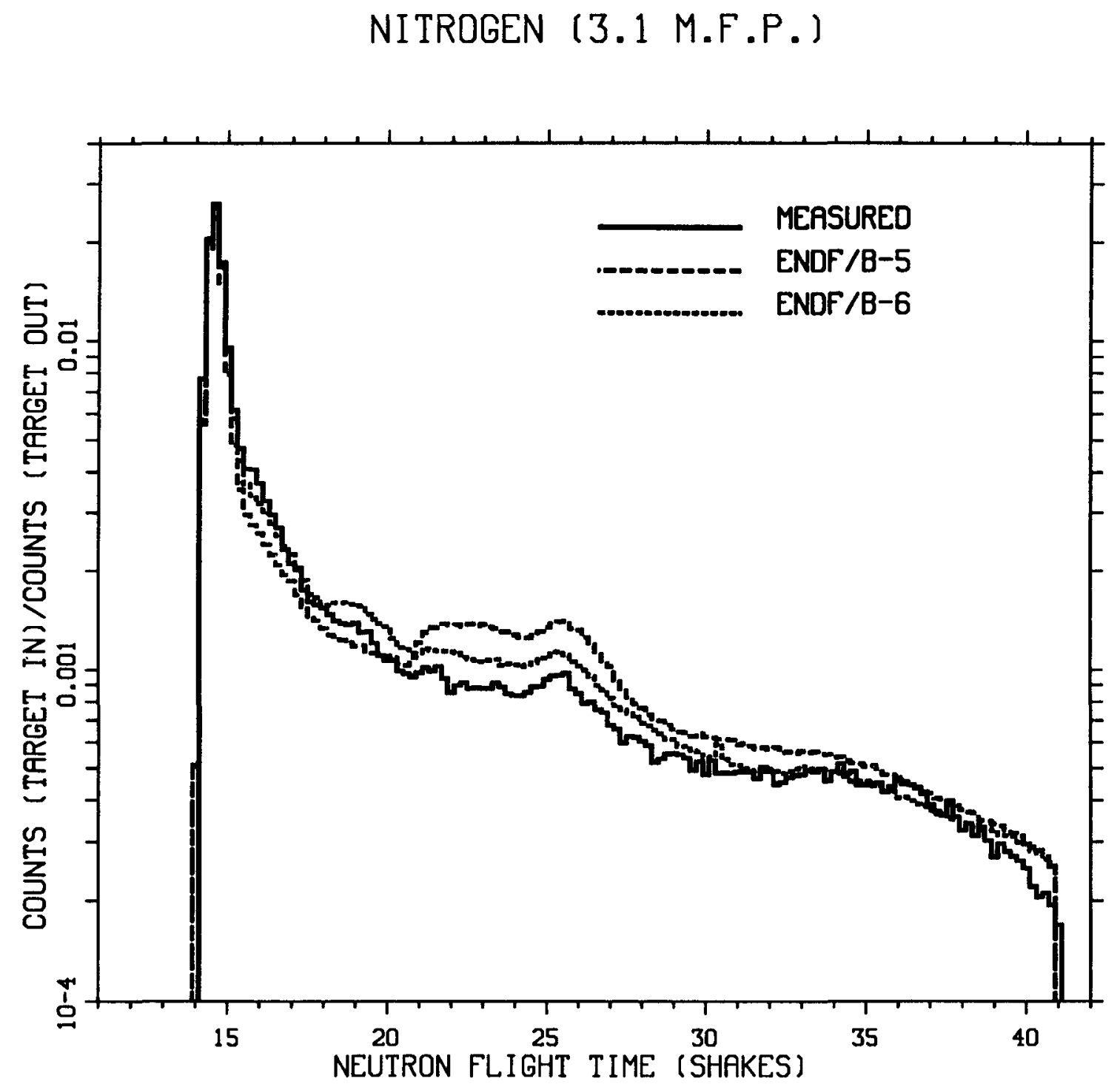

Fig. 6. Plot of experimental and calculated count rates as a function of time for a nitrogen sphere with 3.1 mean free path radius. The detector was located $765.2 \mathrm{~cm}$ from the center of the sphere at 30 degrees with respect to the deuteron beam ( 1 shake $=10 \mathrm{~ns})$. 
CARBON (0.5 M.F.P.)

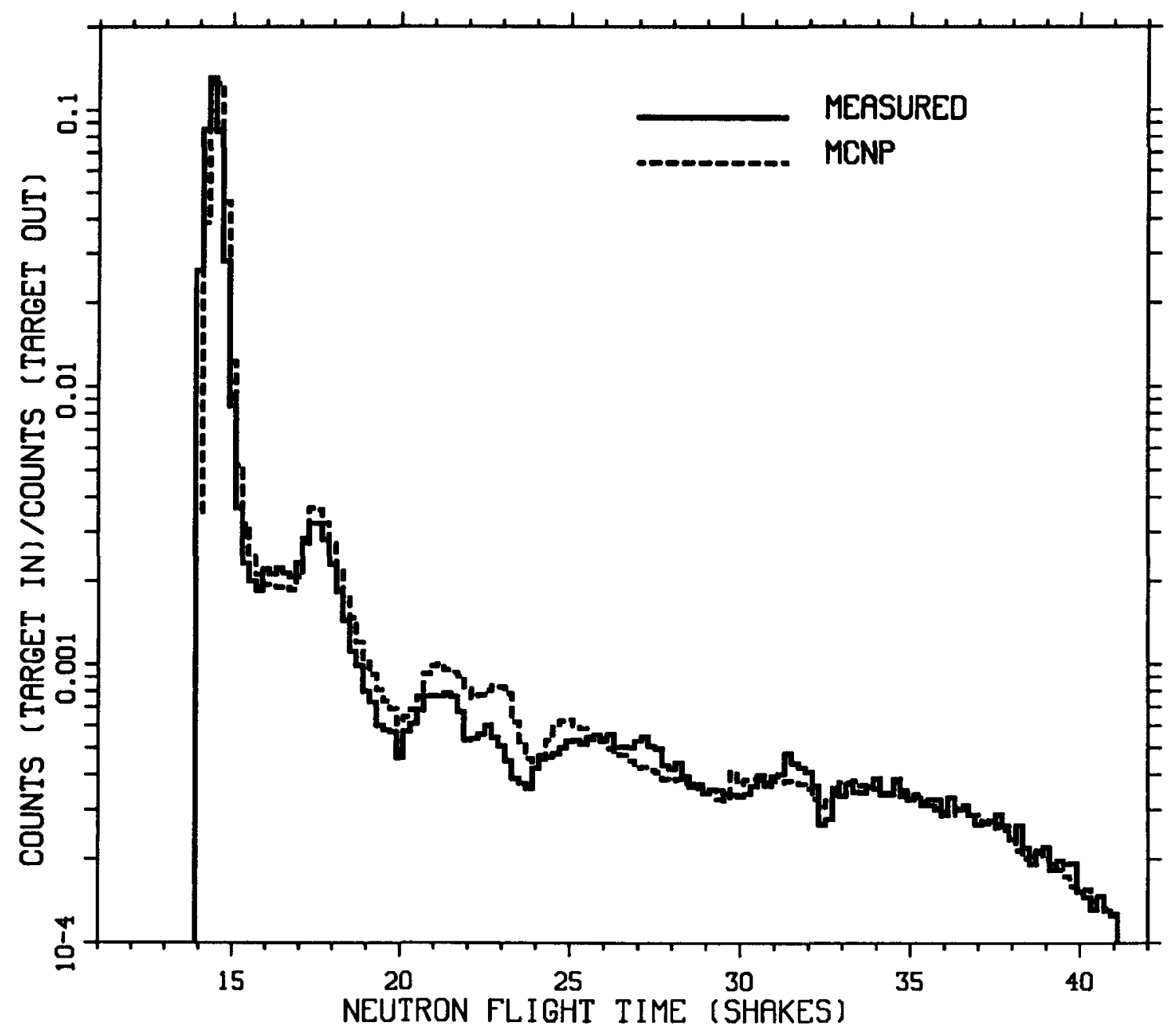

Fig. 7. Plot of experimental and calculated count rates as a function of time for a carbon sphere with 0.5 mean free path radius. The detector was located $766 \mathrm{~cm}$ from the center of the sphere at 30 degrees with respect to the deuteron beam $(1$ shake $=10 \mathrm{~ns})$. 
IRON (0.9 M.F.P.)

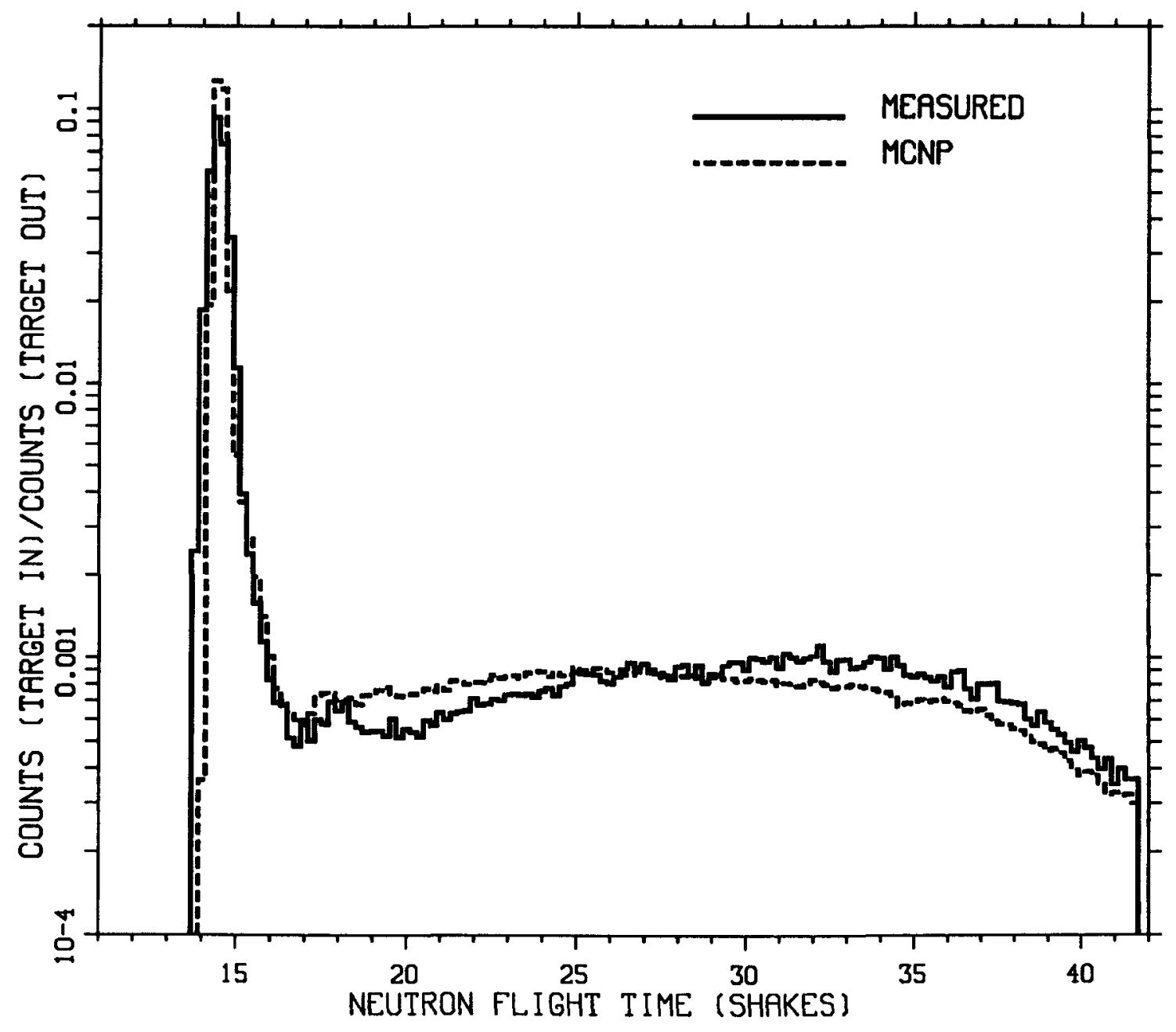

Fig. 8. Plot of experimental and calculated count rates as a function of time for an iron sphere with 0.9 mean free path radius. The detector was located $766 \mathrm{~cm}$ from the center of the sphere at 30 degrees with respect to the deuteron beam $(1$ shake $=10 \mathrm{~ns})$. 
WATER (1.1 M.F.P.)

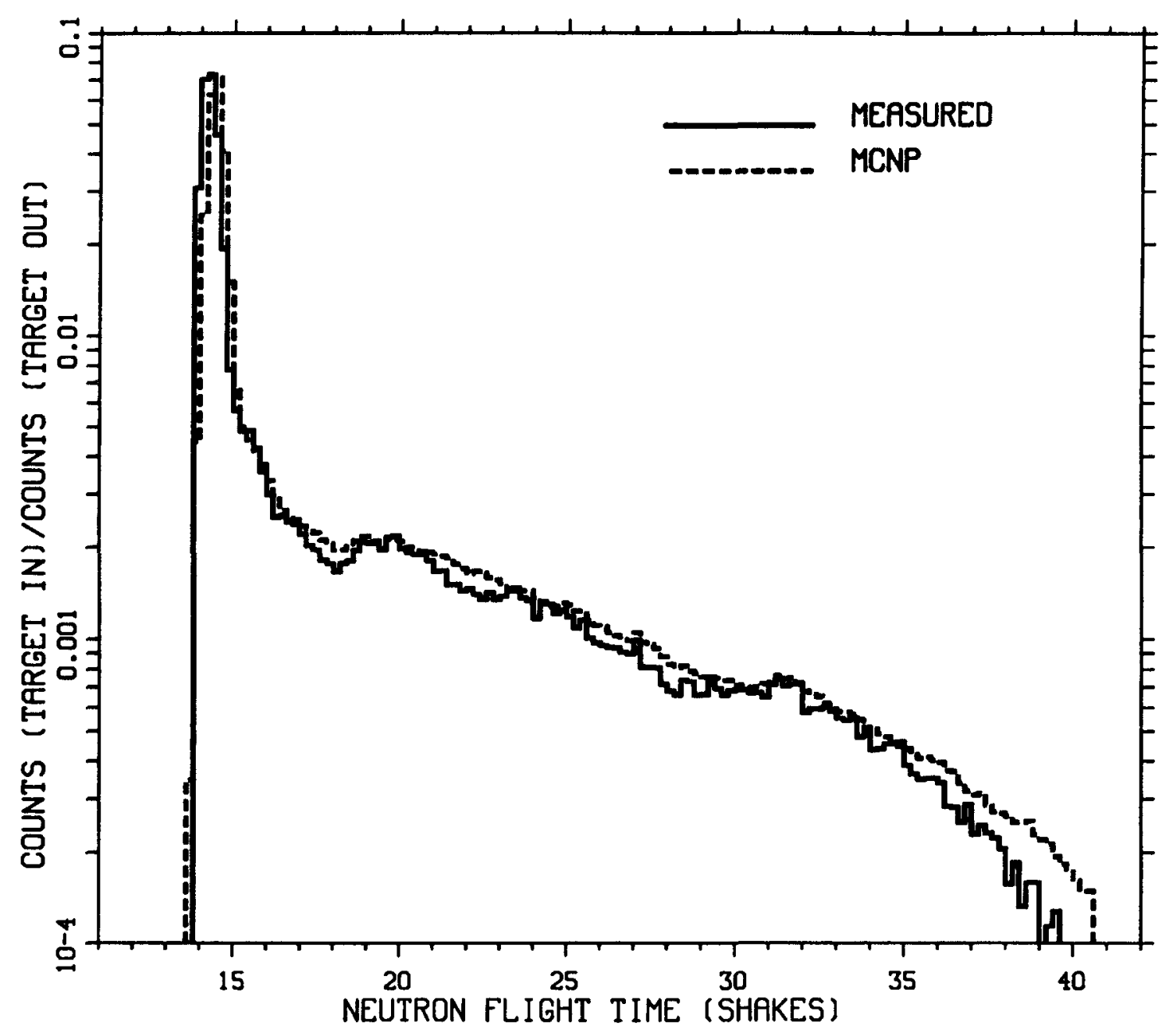

Fig. 9. Plot of experimental and calculated count rates as a function of time for a water sphere with 1.1 mean free path radius. The detector was located $754 \mathrm{~cm}$ from center of sphere at 30 degrees with respect to the deuteron beam ( 1 shake $=10 \mathrm{~ns})$. 
CONCRETE (2.0 M.F.P.)

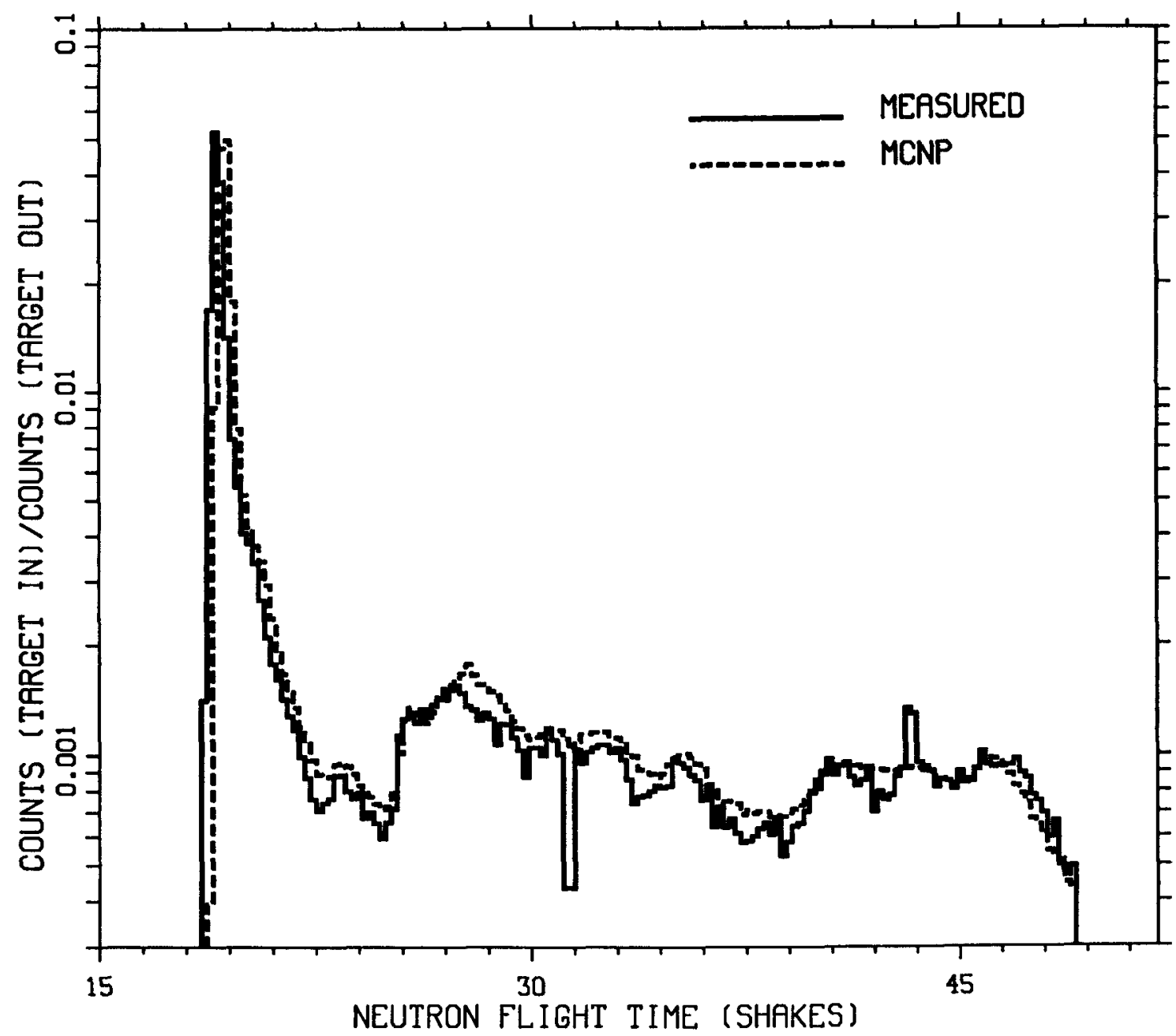

Fig. 10. Plot of experimental and calculated count rates as a function of time for a concrete sphere with 2.0 mean free path radius. The detector was located $975.4 \mathrm{~cm}$ from the center of the sphere at 120 degrees with respect to the deuteron beam ( 1 shake $=10 \mathrm{~ns})$. 


\section{E. Conclusion}

In cases where MCNP and the measurement disagree, it is reasonable to believe that the disagreement is due to cross section uncertainties as was shown for nitrogen. Also, the disagreements are consistent with those reported for other calculation/experiment comparisons. ${ }^{15,16}$ On the basis of the data presented in Tables 3 and 4 and in Figs. 5-10, it is reasonable to conclude that MCNP accurately predicts pulsed sphere results for a wide range of materials.

\section{BENCHMARK PROBLEM TWO: FUSION SHIELDING}

\section{A. Problem History and Description}

How well fusion reactor shields will protect reactor components from radiation damage will have a significant impact on the costs of fusion energy systems. Benchmark two (one of a series of related fusion shielding experiments) was devised and performed by Santoro et al. at Oak Ridge National Laboratory in 1980 to test how well transport codes can predict fusion shield performance. ${ }^{17}$ This experiment simulated the deuterium-tritium (D-T) neutron spectrum that would exist at the first wall of a fusion reactor. The experiment also simulated the secondary photon spectrum that would be produced from neutron interactions within this first wall.

The experimental arrangement for this shielding benchmark is shown in Fig. $11 .^{18}$ A flat target disk of titanium tritide was positioned at one end of a cylindrical iron duct along its axis. This iron duct, in turn, was imbedded inside a concrete block as shown in Fig. 11. One end of the iron pipe opened to the air outside the concrete block, whereas the other end was capped by an iron can (which held the target assembly). The iron can modified the neutron spectrum from the titanium

15 Wilcox and Lent, pp. 48-49.

16 G. P. Estes, R. C. Little, R. E. Seamon, P. D. Soran, "Air Transport in Connection with the HiroshimaNagasaki Dose Reevaluation Effort," Los Alamos National Laboratory report LA-9369-MS (July 1982), UC-11 and UC-34c.

17 Philip F. Rose and Robert W. Roussin, editors, "Shielding Benchmark Compilation," Vol. 2, Brookhaven National Laboratory report BNL-19302 (1983), p. S-5.

18 R. T. Santoro, R. G. Alsmiller, J. M. Barnes, and G. T. Chapman, "Calculation of Neutron and GammaRay Spectra for Fusion Reactor Shield Design: Comparison with Experiment," Nuclear Science and Engineering 78, 259-272 (1981), p. 260. 


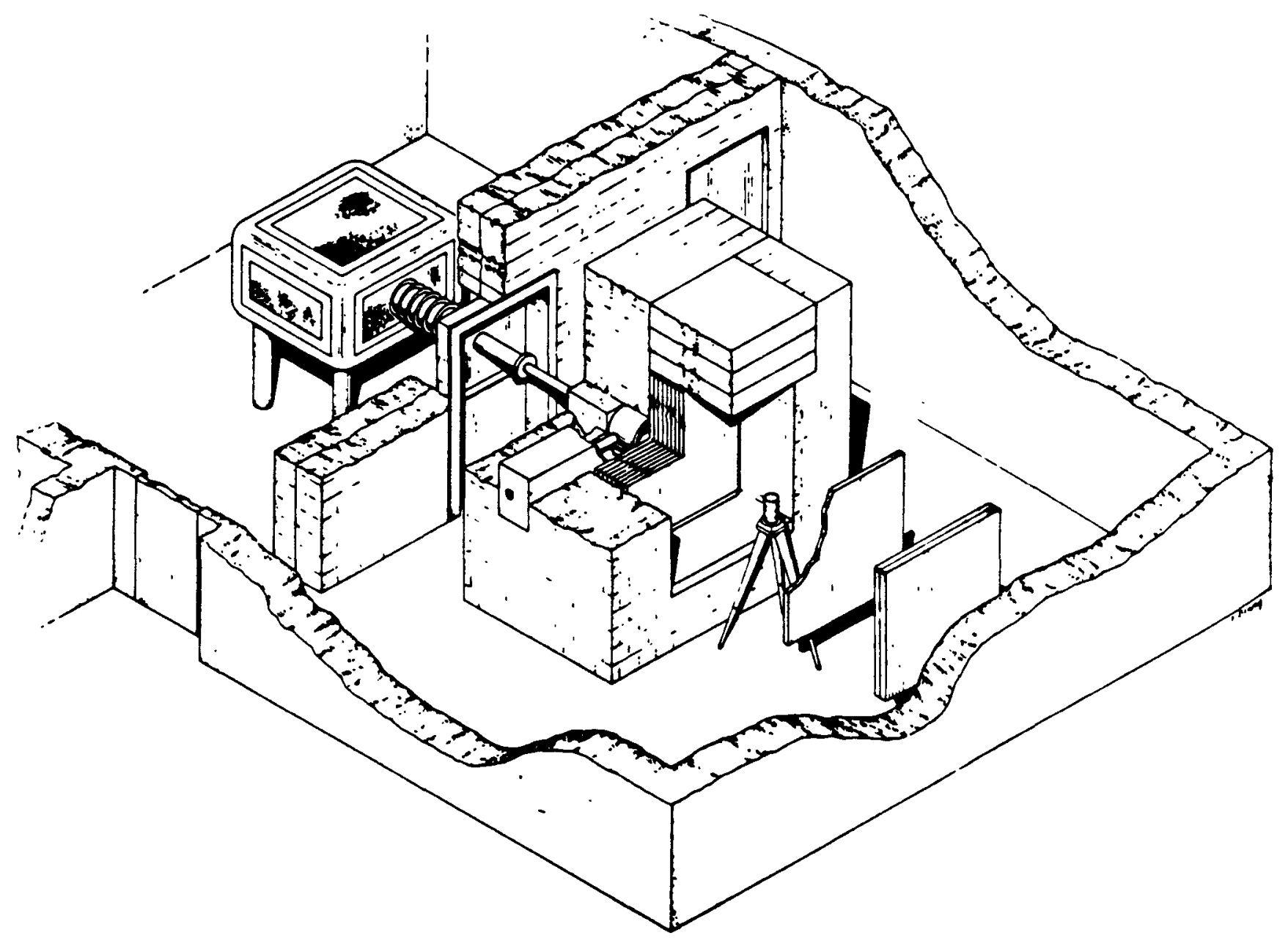

Fig. 11. Artist's rendition of the experimental facility. 
target to produce the desired neutron energy profile. A deuteron beam (from the accelerator and beamline shown in Fig. 11) struck the target disk and produced a nearly-isotropic source of $14-\mathrm{MeV}$ neutrons inside the duct by the $\mathrm{T}(\mathrm{d}, \mathrm{n})^{4} \mathrm{He}$ reaction.

Neutron and gamma detectors were placed at several different positions outside the concrete block beyond the open end of the duct. These detectors measured the energy spectra of the neutrons and secondary photons streaming from the duct and concrete assembly. A stainless steel plate was placed between the detectors and the wall to minimize backscatter from the walls, which otherwise would have distorted the spectra the experimenters were attempting to simulate. A neutron/gamma shield was then placed inside the concrete block (see Fig. 11). This shield assembly covered the open end of the iron duct.

Several different shield assemblies were studied in this experiment for their attenuation of the neutron and photon spectra leaving the concrete block. ${ }^{19}$ MCNP was used to compute these spectra for the three shield assemblies shown in Fig. 12. The neutron spectrum was computed for one on-axis detector position in configuration 1. Both neutron and photon spectra were computed for on- and off-axis detector positions in configurations 3 and 7 (see Table 5). The fusion shielding experiment was chosen for an MCNP benchmark for several reasons.

First, this experiment was submitted to the 1983 Cross Section Evaluation Working Group Benchmark Report and consequently was very well documented. Next, this experiment is a challenging streaming and deep-penetration shielding problem which heavily tests MCNP's variance reduction abilities. Finally, this experiment has a neutron source that is difficult to model accurately, and the experimental data had response functions folded into them. These complications challenged MCNP's source-modeling and tally-modification features. MCNP's predictions for the neutron and gamma spectra in this problem compared favorably to the corresponding experimental data.

\section{B. MCNP Problem Model}

1. MCNP Geometry/Cell Subdivision. The experimental arrangement of the ORNL fusion shielding problem is shown from different angles in Figs. 13 to $15 .^{20}$ The dimensions in these diagrams allow a complete and unambiguous MCNP

$\begin{array}{ll}19 & \text { Rose et al., p. S-15. } \\ 20 & \text { Ibid, pp. S-6 to S-8. }\end{array}$ 

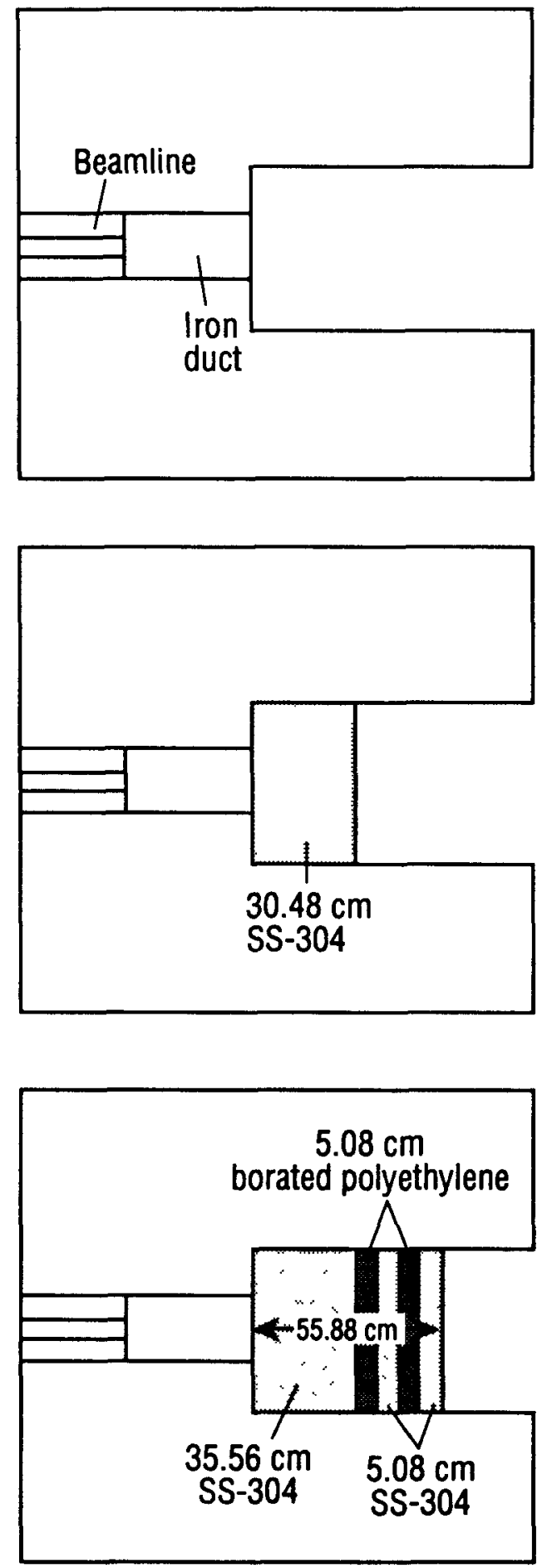

Fig. 12. The three shielding configurations modeled by MCNP. 
TABLE 5

MCNP DETECTOR TALLY POSITIONS*

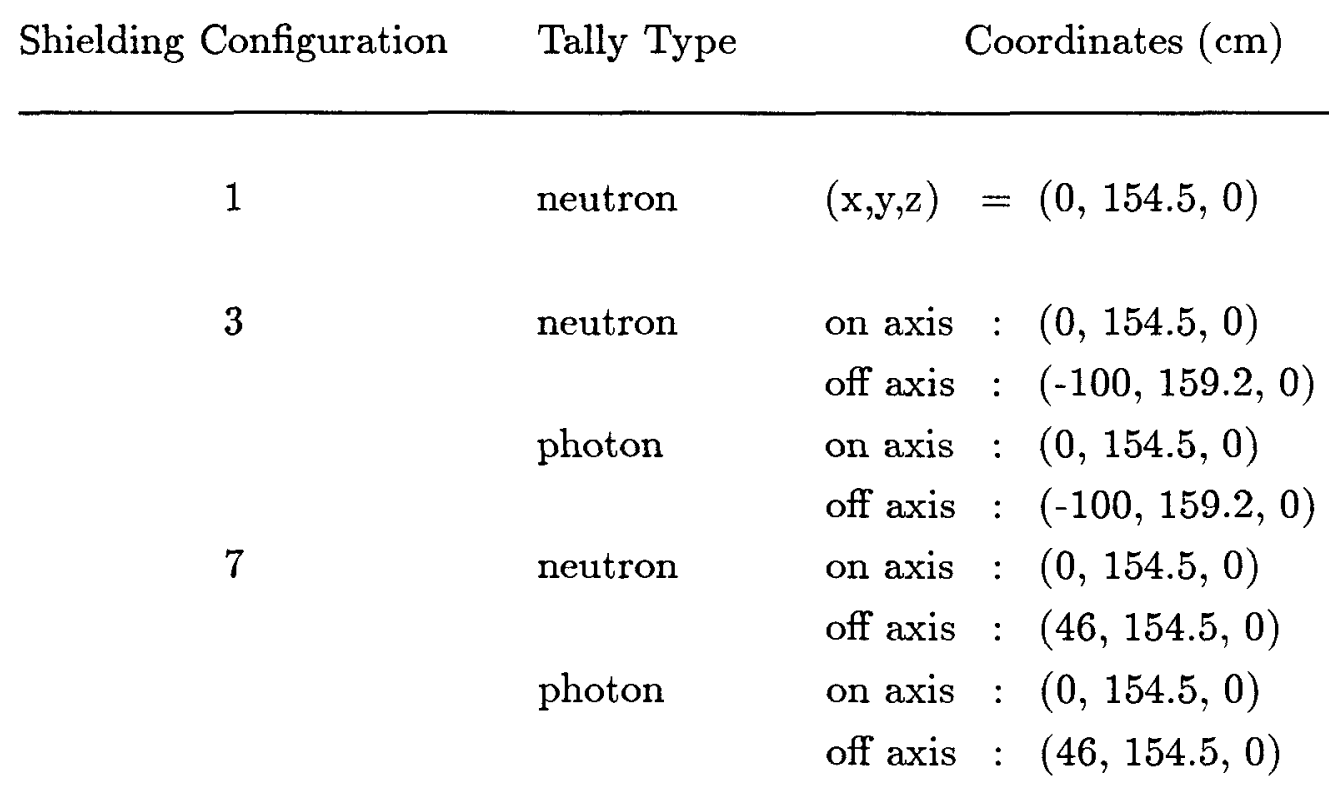

*The coordinates listed here are relative to the neutron source in the MCNP reference coordinate system. The detector coordinates in the MCNP input files are relative to the reference coordinate system origin. 


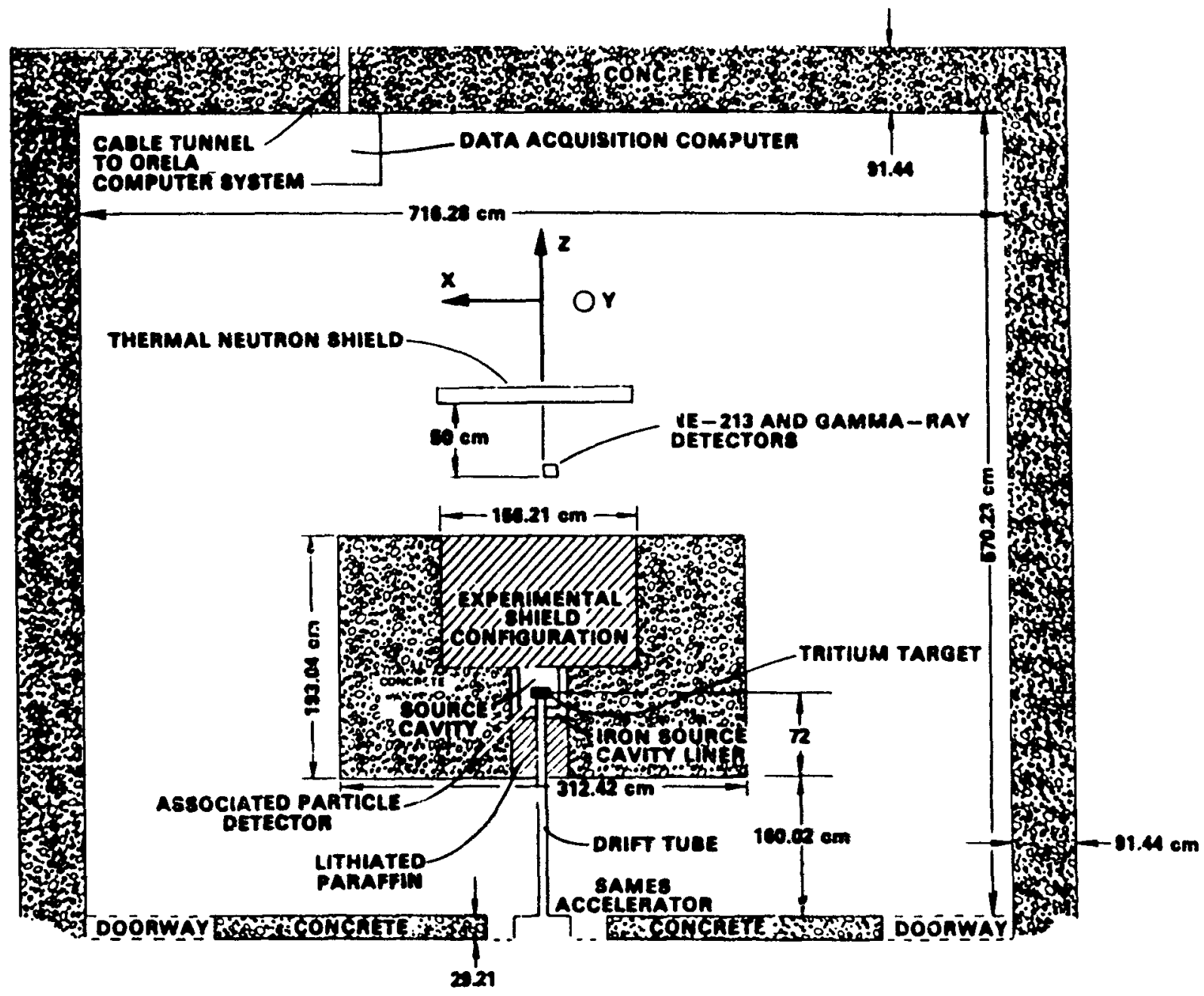

Fig. 13. Horizontal schematic of the experimental enclosure (drawing not to scale). 


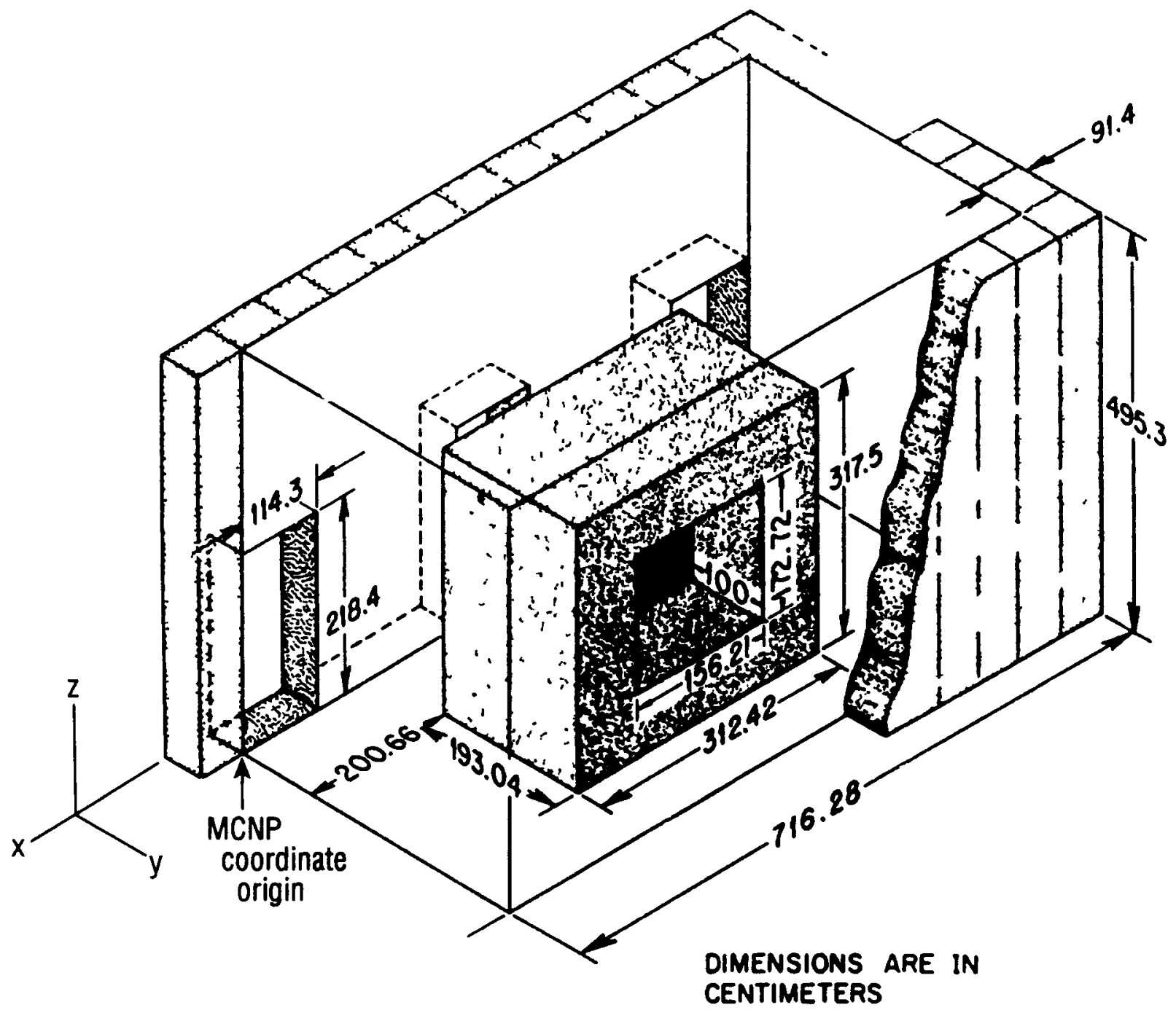

Fig. 14. Three-dimensional view of the experimental enclosure (drawing not to scale). 

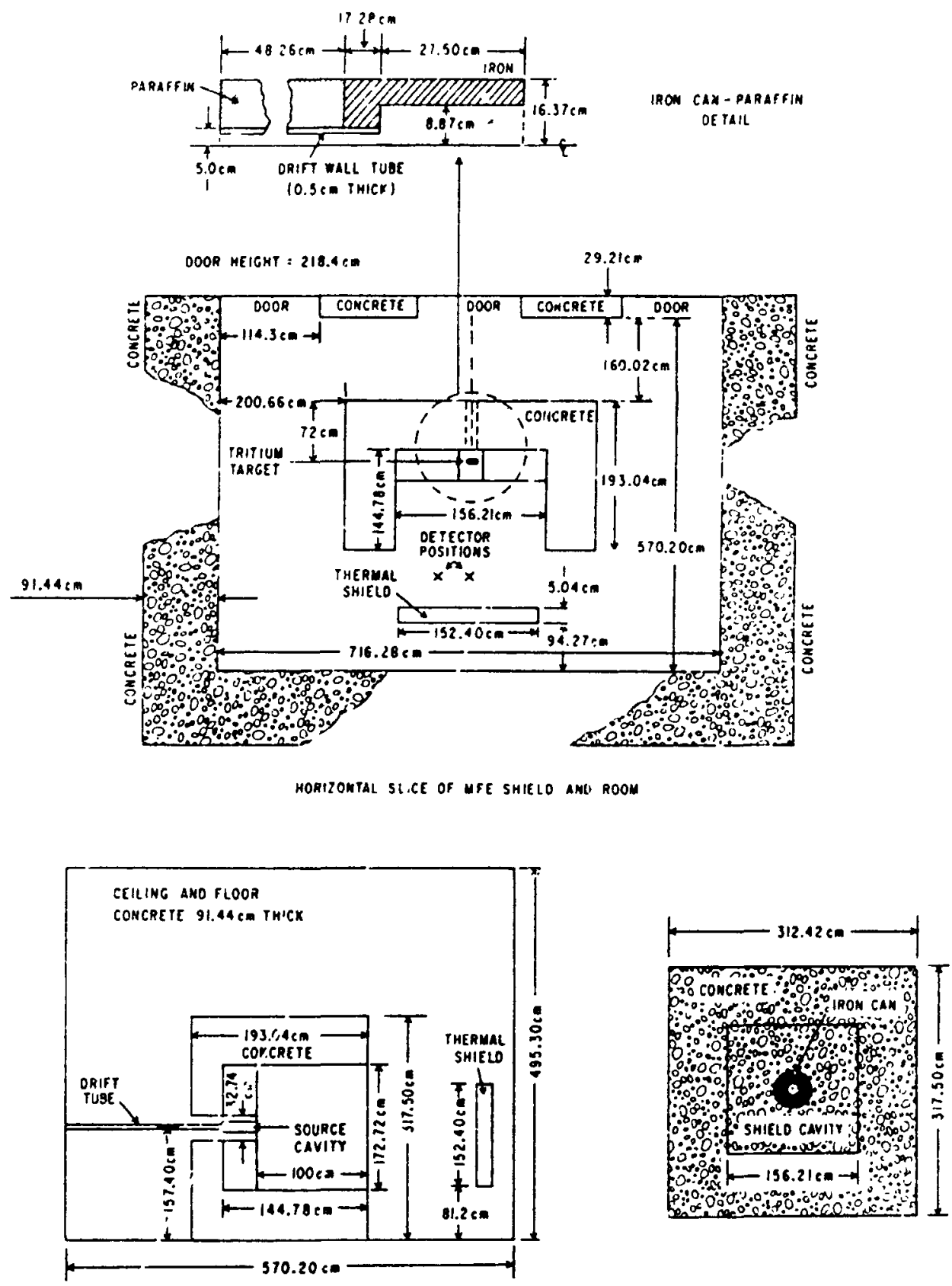

VERTICAL SLICE OF HFE SHIELO AMO ROOW

FRONT VIEV OF SOURCE CAM AMO SHELO

Fig. 15. Additional schematics of the experimental enclosure (drawing not to scale). 
geometry of the experiment. The MCNP geometry used in the problem model exactly modeled every detail of the arrangement depicted in Figs. 13 to 15 with a few minor exceptions:

- only the beamline inside the concrete block was included in the geometry - the segment of beamline between the rear wall and the back of the concrete block was ignored.

- the neutron source disk was centered in the iron source can/iron duct assembly - the disk was simply suspended along the assembly axis because no further description of the source was provided. The MCNP source used in this benchmark is identical to that used in benchmark one except for the target radius.

- the MCNP geometry reference coordinate system had a different orientation than that used by the ORNL experimenters in their benchmark report (see Fig. 14). Whenever detector coordinates or component locations are specified in this report, they are in terms of the MCNP coordinate system.

The MCNP geometry of this experiment was subdivided into 175 cells. These cells were all rectangular blocks or slabs, cylinders, or cylindrical shells, and are fully described in the problem input files in Tables A4 and A5 in the Appendix.

2. Material Compositions/Code Tallies. The materials present in the fusion shielding experiment were concrete, air, iron, SS-304 stainless steel, lithiated paraffin, and borated polyethylene. The elemental composition (and atom density of each elemental component) of each material is shown in Table. $6 .^{21}$ Where these materials were present in the experiment is seen in Figs. 12-15. ENDF/B-V cross sections were used whenever available.

Point detector (F5) photon and neutron flux tallies were then placed in the MCNP geometry at positions corresponding to where actual fluxes were measured in the experiment. The detector locations for the three shielding configurations that were modeled are listed in Table 5 . These tallies were modified to incorporate the gaussian experimental detector response. The FT GEB a b tally modification feature in MCNP allows such an energy-dependent gaussian to be folded into tally estimates, where the FWHM is of the form

21 Ibid, p. S-11. 
TABLE 6

COMPOSITION OF MATERIALS USED IN THE

MCNP SHIELDING BENCHMARK MODEL

Nuclide

Number Density

(atom/barn-cm)

Concrete Air Iron $\quad$ SS-304 BP* LP $^{* *}$

\begin{tabular}{|c|c|c|c|c|c|}
\hline $\mathrm{H}$ & $7.86 \times 10^{-3}$ & & & $7.13 \times 10^{-2}$ & $5.926 \times 10^{-2}$ \\
\hline B-10 & & & & $4.87 \times 10^{-4}$ & \\
\hline B-11 & & & & $1.97 \times 10^{-3}$ & \\
\hline $\mathrm{C}$ & & & & $3.41 \times 10^{-2}$ & $3.338 \times 10^{-2}$ \\
\hline $\mathrm{N}$ & & $3.64 \times 10^{-5}$ & & & \\
\hline $\mathrm{O}$ & $4.39 \times 10^{-2}$ & $9.74 \times 10^{-6}$ & & $3.64 \times 10^{-3}$ & $1.125 \times 10^{-2}$ \\
\hline $\mathrm{Na}$ & $1.05 \times 10^{-3}$ & & & & \\
\hline $\mathrm{Mg}$ & $1.40 \times 10^{-4}$ & & & & \\
\hline $\mathrm{Al}$ & $2.39 \times 10^{-3}$ & & & & \\
\hline $\mathrm{Si}$ & $1.58 \times 10^{-2}$ & & & & \\
\hline $\mathrm{K}$ & $6.90 \times 10^{-4}$ & & & & \\
\hline $\mathrm{Ca}$ & $2.92 \times 10^{-3}$ & & & & \\
\hline $\mathrm{Cr}$ & & & $1.77 \times 10^{-2}$ & & \\
\hline $\mathrm{Mn}$ & & & $1.77 \times 10^{-3}$ & & \\
\hline $\mathrm{Fe}$ & $3.10 \times 10^{-4}$ & $8.48 \times 10^{-2}$ & $6.02 \times 10^{-2}$ & & \\
\hline $\mathrm{Ni}$ & & & $7.83 \times 10^{-3}$ & & \\
\hline $\mathrm{Li}-6$ & & & & & $5.565 \times 10^{-4}$ \\
\hline $\mathrm{Li}-7$ & & & & & $6.944 \times 10^{-3}$ \\
\hline
\end{tabular}

* $\mathrm{BP}=$ Borated Polyethylene

${ }^{* *} \mathrm{LP}=$ Lithiated Paraffin 


$$
F W H M=a+b \sqrt{E}
$$

where $\mathrm{E}$ is the energy of the particle (in $\mathrm{MeV}$ ).

However, the experimental gaussian detector responses had a different form. For the neutron detector, ${ }^{22}$

$$
F W H M=\sqrt{0.03 E^{2}+0.08 E} \quad(\mathrm{E} \text { in } \mathrm{MeV})
$$

while for the photon detector,

$$
F W H M=\sqrt{0.017 E^{2}+0.0288 E} \quad(\mathrm{E} \text { in } \mathrm{MeV})
$$

Therefore, it was necessary to slightly alter MCNP to accept a user-input gaussian energy broadening of the form

$$
F W H M=\sqrt{a E^{2}+b E} \quad(\mathrm{E} \text { in } \mathrm{MeV})
$$

through the FT GEB a b option. How this was done is shown in the patch input file in Table A6 of the Appendix.

Neutron and photon spectra were computed in separate runs, even though when both spectra were computed, they were done at the same position. Separate computations were done for two reasons. First, a neutron spectrum could be calculated in one tenth the CPU time of a photon spectrum. The experimental detector energy cutoffs for neutrons and photons were $.85 \mathrm{MeV}$ and $.75 \mathrm{MeV}$, respectively. ${ }^{23}$ MCNP could terminate neutron histories below the $.85 \mathrm{MeV}$ cutoff and compute an accurate spectrum. To compute photon spectra, the low-energy neutron histories had to be included because they could still produce photons above the $.75 \mathrm{MeV}$ cutoff through nuclear reactions. Transporting these low-energy neutrons greatly increased the running time of the problem. Second, it was easier to separately optimize the neutron and photon variance reduction techniques.

3. Variance Reduction. Efficiently simulating the fusion shielding experiment required using strong variance reduction techniques because the model has 22 Ibid, pp. S-12 to S-13.

23 Ibid, p. S-13. 
streaming and the deep penetration of neutrons and photons into several shielding materials. Each problem was run several times with the MCNP weight window generator $^{24}$ to produce a good set of variance reduction weight windows. After two or three such iterations, the figure of merit of each problem increased by a factor of ten or more, which enabled MCNP to converge to low-variance tally results reasonably quickly.

\section{Results and Discussion}

The experimental data and MCNP results for the neutron and photon spectra for shielding configurations 1, 3, and 7 are shown in Figs. 16-24. In each figure, the MCNP results (solid line) appear with the experimental upper bound data (short dash line) and experimental lower bound data (long dash line). The experimental upper and lower bound data is listed in tabular form in BNL-19302. ${ }^{25}$ Agreement between the experimental data and MCNP in the on- and off-axis neutron spectra for all three configurations is good except for between 7.5 and $9.5 \mathrm{MeV}$ where the computational unfolding routines that were used to process the experimental data produce a nonphysical dip in the neutron spectra.

The agreement between MCNP and the experimental data in the photon spectra is not as good as in the neutron spectra, most likely because the neutron-induced photon production cross sections are not well known. Also, processing routines again produce nonphysical fluctuation in the spectra (especially evidenced by the negative flux in Fig. 23). In spite of this, MCNP predicts the main features of the photon spectra well. The $50 \%$ or so agreement between MCNP and the measured data is excellent for a deep penetration problem.

\footnotetext{
24 T. E. Booth and J. S. Hendricks, "Importance Estimation in Forward Monte Carlo Calculations", Nuclear Technology/Fusion, 5(1), 90, (1984).

25 Rose et al., pp. S-31 to S-56.
} 


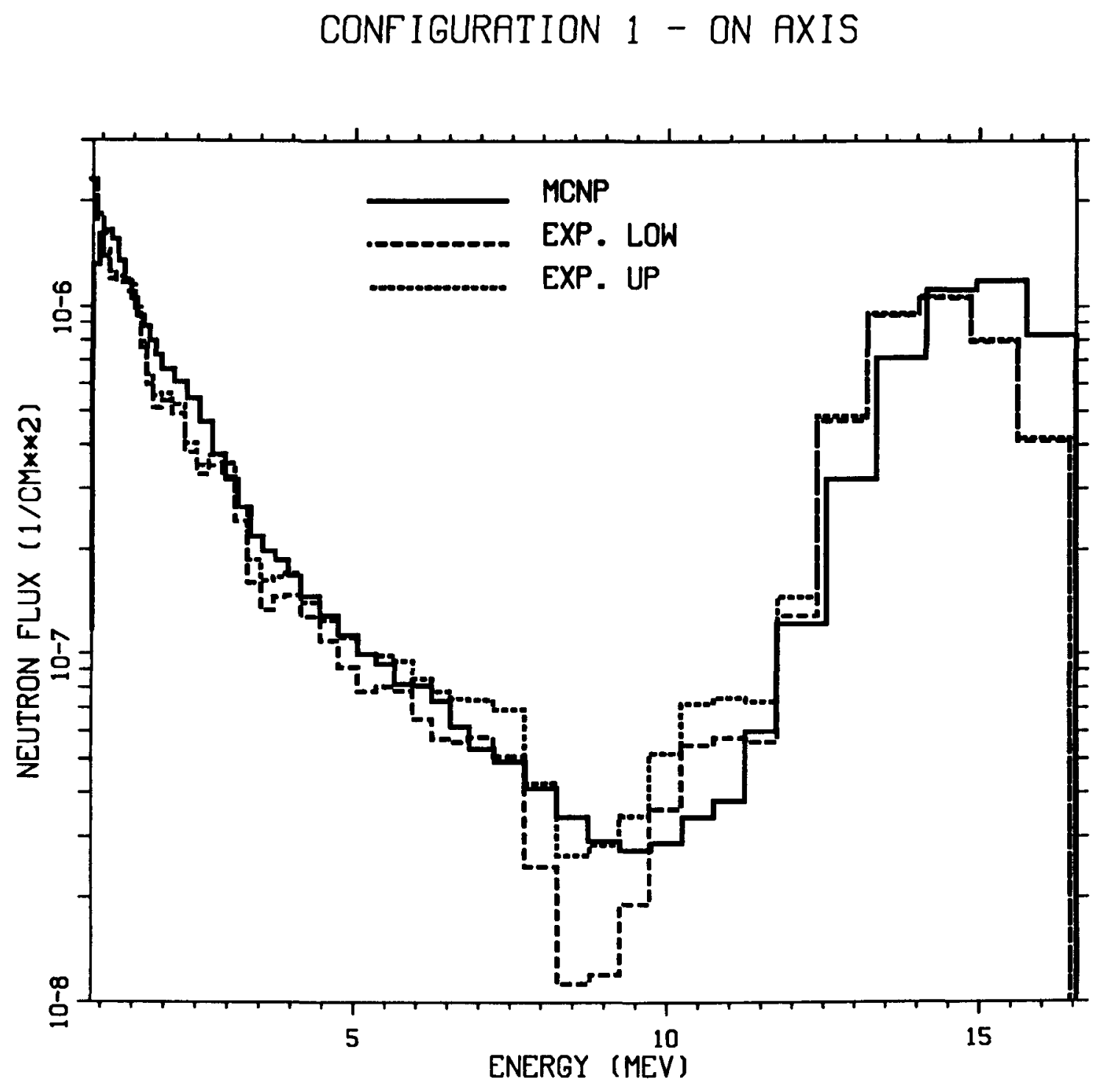

Fig. 16. Neutron spectra for configuration 1: on-axis. 


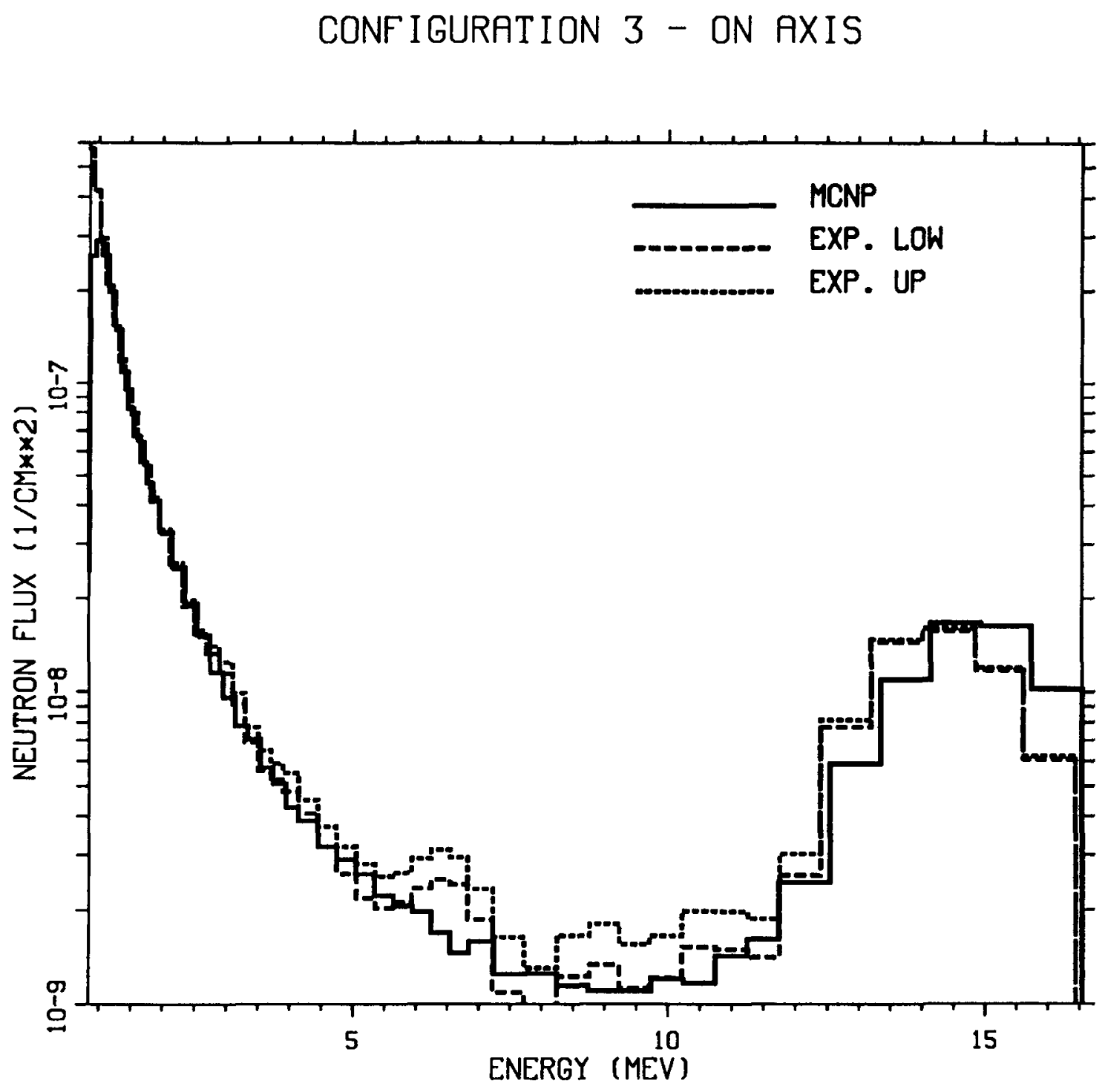

Fig. 17. Neutron spectra for configuration 3: on-axis. 


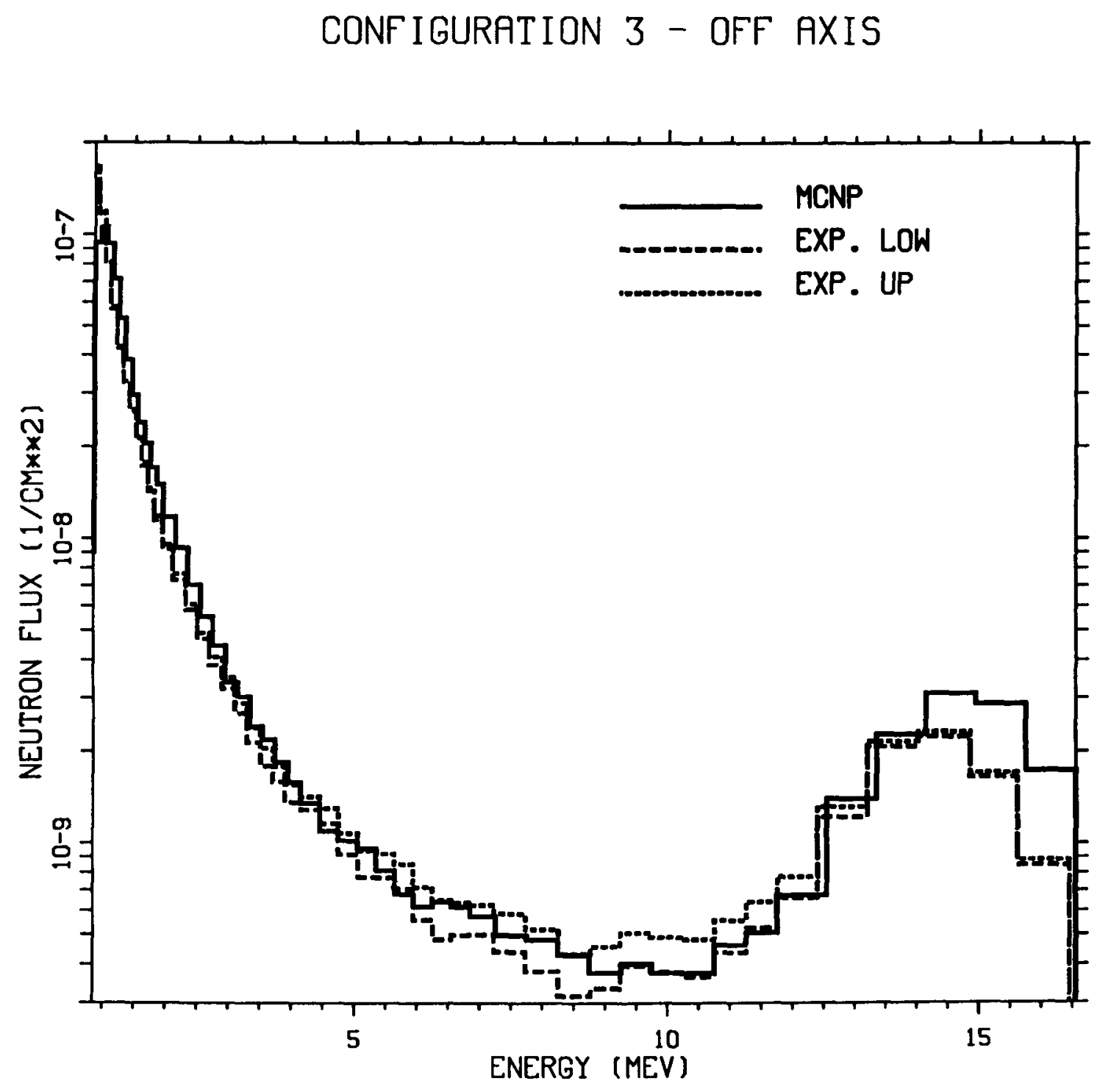

Fig. 18. Neutron spectra for configuration 3: off-axis. 
CONFIGURATION 7 - ON AXIS

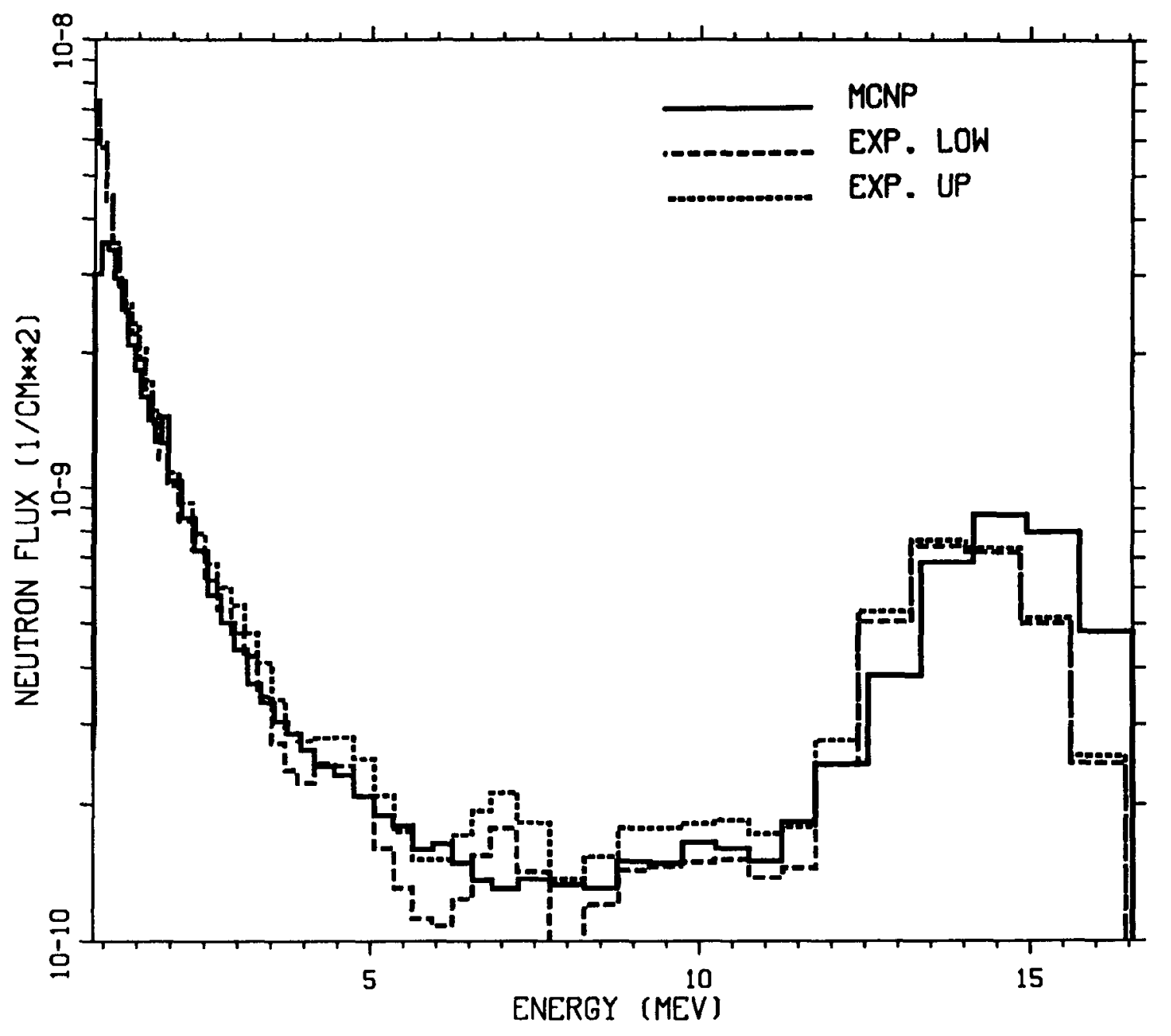

Fig. 19. Neutron spectra for configuration 7: on-axis. 
CONF IGURATION 7 - OFF AXIS

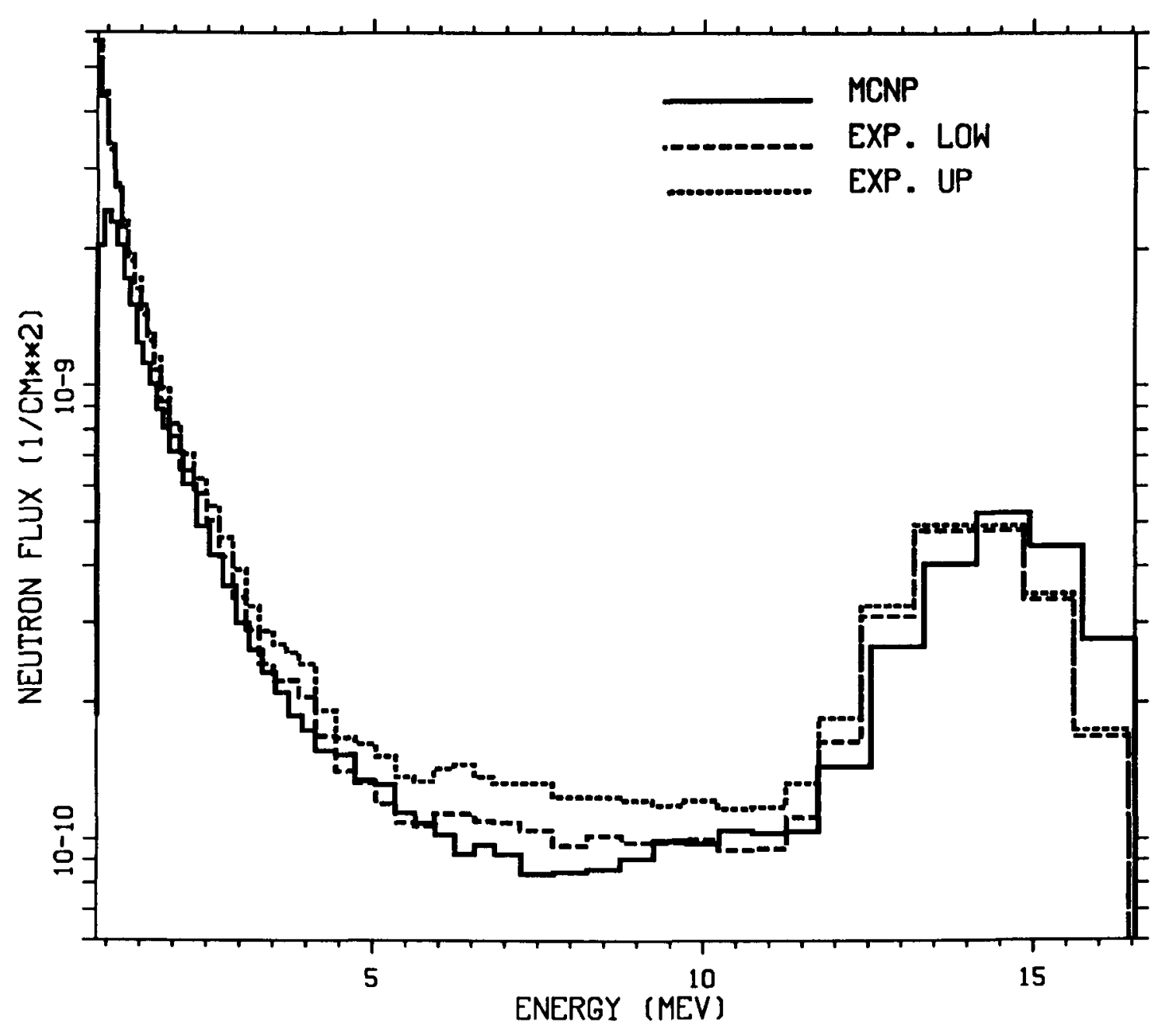

Fig. 20. Neutron spectra for configuration 7: off-axis. 
CONF IGURATION 3 - ON AXIS

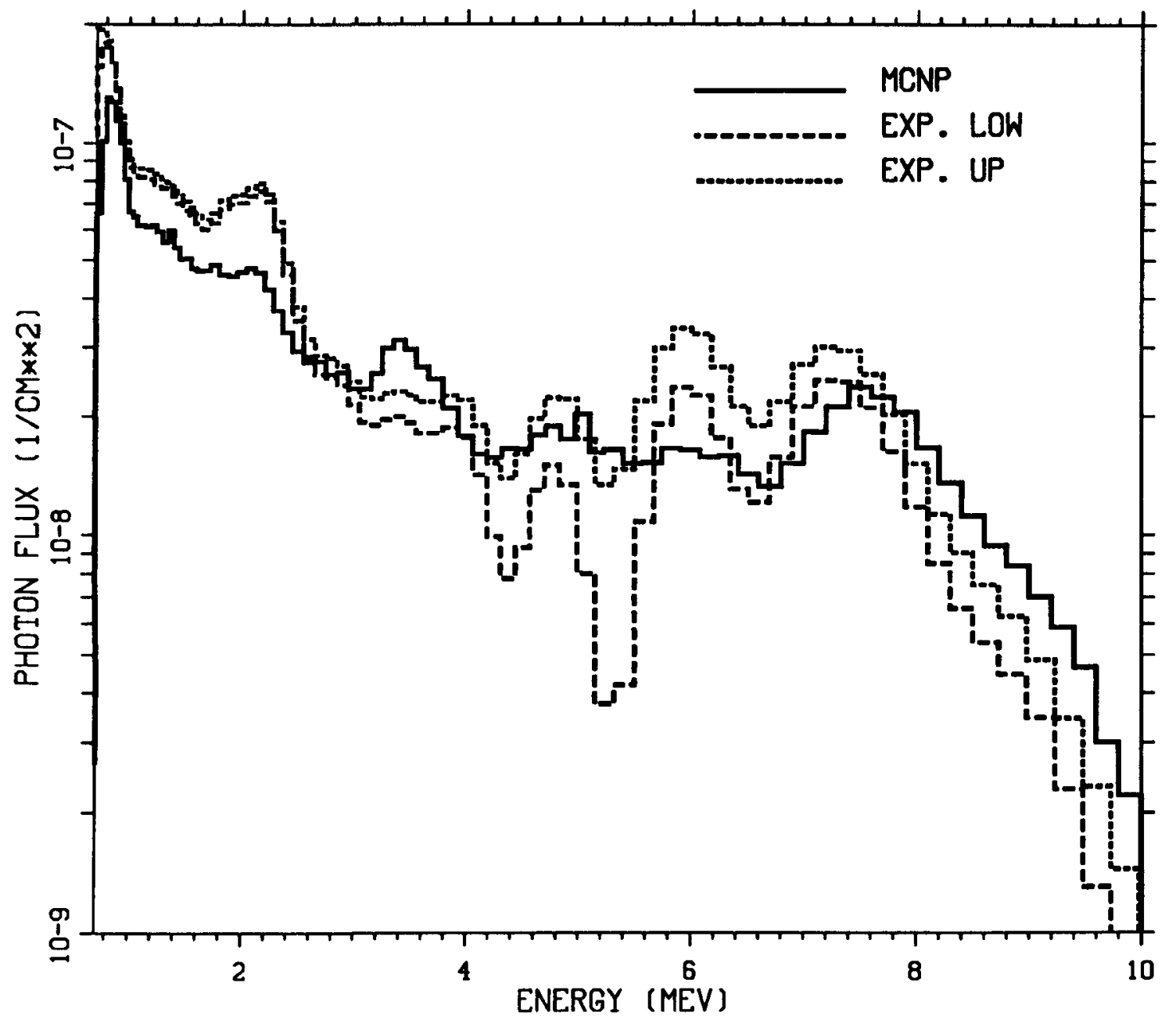

Fig. 21. Photon spectra for configuration 3: on-axis. 
CONFIGURATION 3 - OFF AXIS

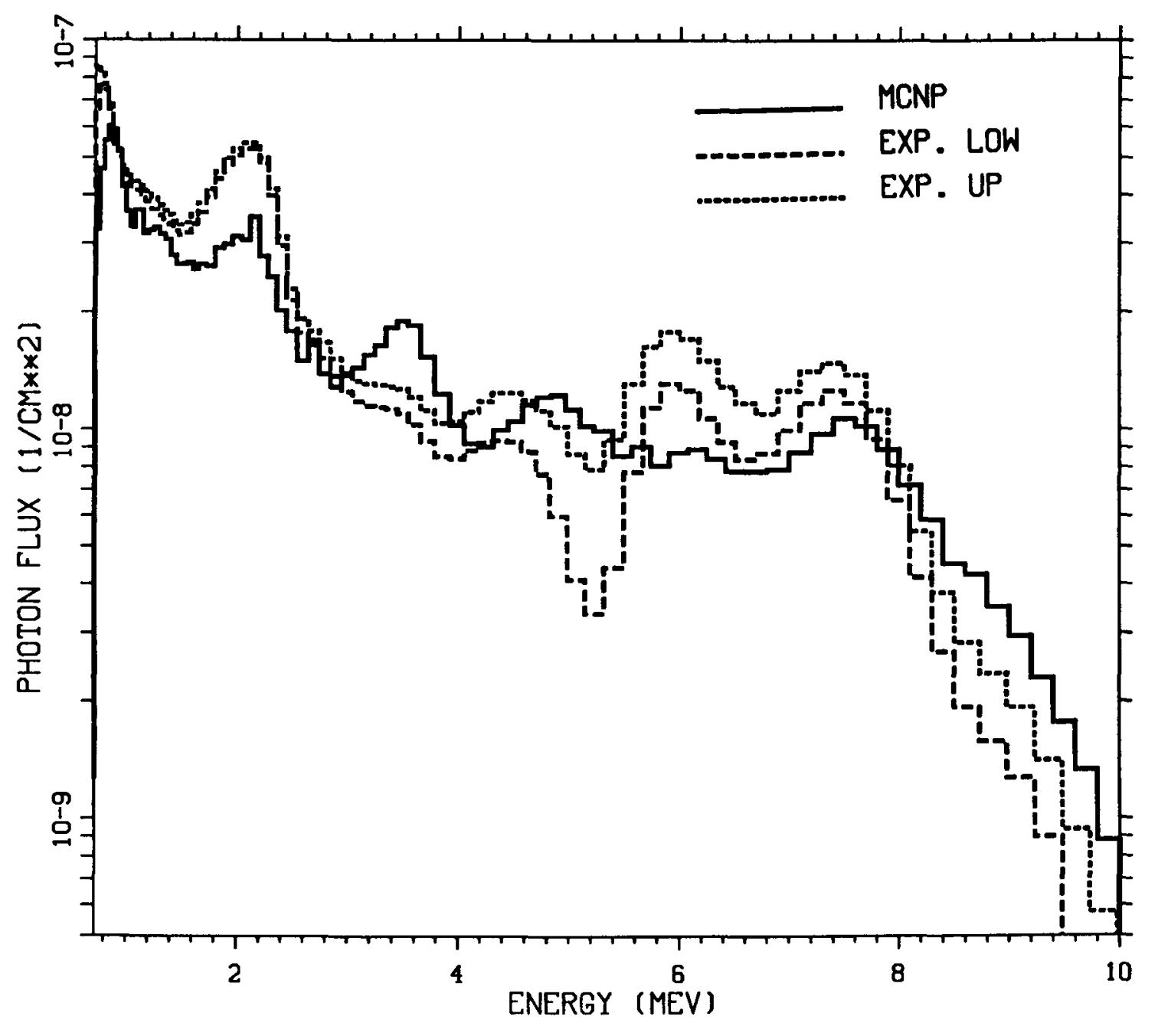

Fig. 22. Photon spectra for configuration 3: off-axis. 
CONFIGURATION 7 - ON AXIS

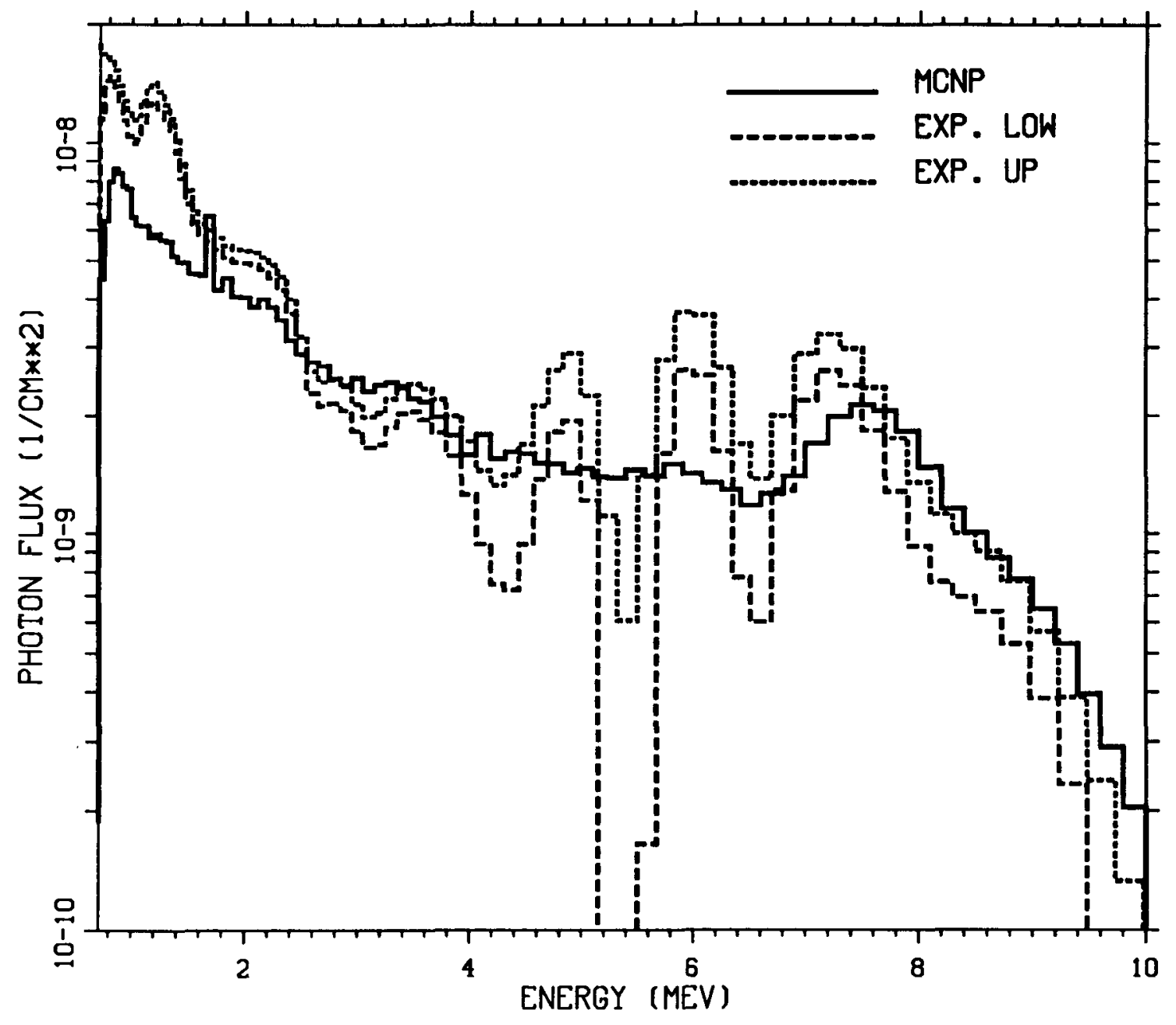

Fig. 23. Photon spectra for configuration 7: on-axis. 
CONFIGURATION 7 - OFF AXIS

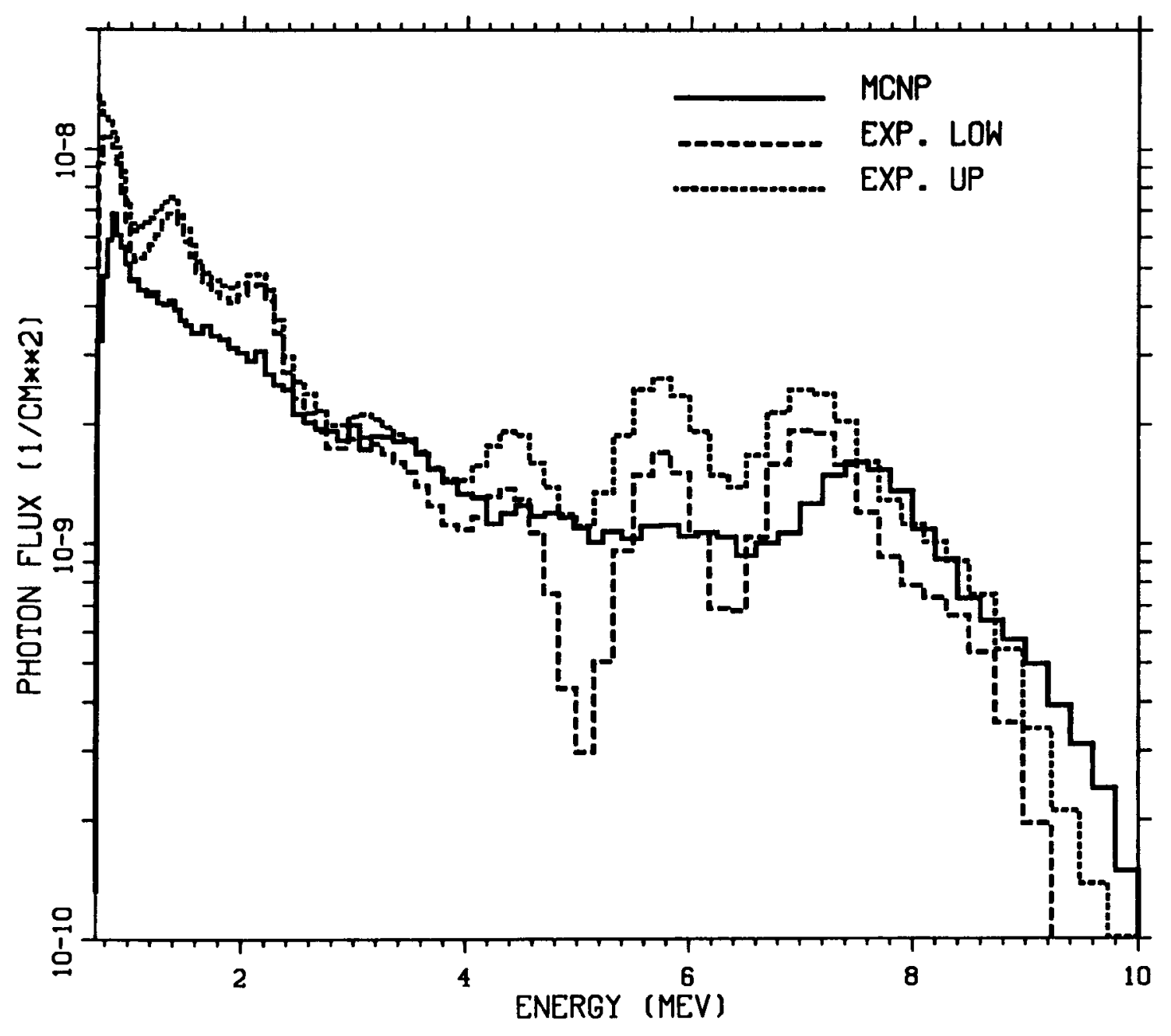

Fig. 24. Photon spectra for configuration 7: off-axis. 


\section{BENCHMARK PROBLEM THREE: CRITICAL ASSEMBLIES}

\section{A. Problem History}

Nuclear criticality has been one of the most important measurements of nuclear systems since the Manhattan Project of World War II. The criticality of a given system is characterized by the multiplication factor, $k_{e f f} . \mathrm{k}_{e f f}$ is the ratio of the number of neutrons in two successive generations of a fission history and is the principal eigenvalue of the Boltzmann transport equation. If a system is critical, then $k_{\text {eff }}=1$, whereas a subcritical and a supercritical condition are characterized by $k_{\text {eff }}$ values less than and greater than 1 , respectively.

To determine MCNP's ability to calculate the multiplication factor of a critical configuration, nine experimental critical assemblies were analyzed. Each system was modeled, and the simulation results were compared to the experimental data. These nine experiments were carefully chosen so that a good percentage of criticality experimental types were represented in the study. Originally, the study was designed to examine the criticals run by $\mathrm{COG},{ }^{26}$ but many turned out to be computational models rather than experiments. Also, adequate documentation for the assemblies was not always available. Therefore, a different set of experiments was modeled, but the systems were similar to those evaluated in the COG document.

This set of nine experiments includes:

I. Fast Neutron Systems

1. Godiva

2. Jezebel (Pu-239 95.5\%)

3. Jezebel (Pu-239 80\%)

II. Low Enrichment

1. Uranium cylinder (U-235 10.9\%)

2. Uranium cylinder (U-235 14.11\%)

III. Reflected Systems

1. Graphite-tamped U sphere

2. Water reflected $U$ sphere

IV. Interacting Units

1. 3 cylinders of a $U$ solution

2. $3 \times 3$ array of $\mathrm{Pu}$ fuel rods

26 Wilcox and Lent, pp. 61-64. 
1. Criticality Source Modeling. The choice of criticality source parameter values depends on the settling rate of each problem, the system's dimensions, and the degree of fluctuation seen in the $k_{\text {eff }}$ values. For all runs, a $k_{\text {eff }}$ value of 1.0 was measured experimentally and was expected from the simulations. A relative error of .003 was assumed to be an acceptable fluctuation in the tally. Therefore, the simulations were run until the $k_{\text {eff }}$ value fluctuated about a constant mean value, and the values of subsequent cycles were then averaged until a 0.003 or less relative error was registered. Some simulations, such as Godiva and Jezebel, were allowed to run through more cycles than necessary if the geometry was simple and the computer time was available.

It was found that large geometries required approximately 10,000 initial particles per cycle to yield a converging $k_{\text {eff }}$ value, whereas small geometries with simple structural configurations quickly converged with approximately 3000 initial particles. Simple spherical geometries converged using a single source point centrally located, but the remaining systems required a distributed source defined by the SDEF option to yield a constant mean value in an appropriate number of cycles.

2. Cross-Section Libraries. Nuclide cross sections were taken from ENDF/B-V when possible.

3. Criticality Eigenvalue Selection. MCNP offers several options for the $k_{\text {eff }}$ value estimate. For this study, the combined average of the absorption, collision, and track-length estimator is quoted as the $k_{e f f}$ value. All estimates of $k_{e f f}$ are within $1 \%$ of the experimental critical value of 1.0 . Although a $1 \%$ difference in critical systems represents a large discrepancy in overall system behavior, general experimental error restricted the accuracy of the simulation to $1 \%$.

The following sections briefly describe the experimental designs and give the corresponding results of the MCNP simulations. Unless stated otherwise, enrichments, densities, and isotopic fractions are in mass rather than atom units. Further description of the geometries can be found in the cited references. Input files for all nine geometries are in Tables A7-A15 in the Appendix.

\section{B. Fast Neutron Systems}

1. Godiva. The specifications used to define a bare uranium sphere were taken from the data of G. E. Hansen and H. C. Paxton, which was originally generated at 
Los Alamos National Laboratory and then revised there in $1969 .{ }^{27}$ Lady Godiva, as the setup was called, is an example of a fast neutron critical system. It was a simple geometry, consisting of a $52.42 \mathrm{~kg}$ sphere of $\mathrm{U}$ (93.71)--93.71\% U-235 enriched. The density of the system was measured at $18.74 \mathrm{~g} / \mathrm{cm}^{3}$. These data correspond to a sphere of radius equal to $8.741 \mathrm{~cm}$. MCNP calculated a $k_{\text {eff }}$ value of 0.9976 with a corresponding relative error of $.0011 \%$.

2. Jezebel at 95.5\% Pu-239 Enrichment. Jezebel was similar to the Godiva experiment and was reevaluated by G. E. Hansen and H. C. Paxton at Los Alamos National Laboratory in $1969 .^{28}$ This system consisted of a bare plutonium sphere. Two different isotopic combinations of $\mathrm{Pu}-240$ and $\mathrm{Pu}-239$ were analyzeda $\mathrm{Pu}-239$ composition of $95.5 \%$ and one of $80 \%$. In both instances, the remaining material was $\mathrm{Pu}-240$. These are "fast" critical assemblies with a relatively hard spectrum.

The $95.5 \% \mathrm{Pu}-239$ system was a $17.02 \mathrm{~kg}$ sphere with a density of $15.61 \mathrm{~g} / \mathrm{cm}^{3}$ and a radius of $6.385 \mathrm{~cm}$. MCNP calculated a $k_{\text {eff }}$ value of $0.9986 \pm .0021$.

3. Jezebel at $80 \%$ Pu-239 Enrichment. The $80 \%$ enriched system had a critical mass of $19.46 \mathrm{~kg}$, a density of $15.73 \mathrm{~g} / \mathrm{cm}^{3}$ and a radius of $6.660 \mathrm{~cm}$. The simulation yielded a $k_{\text {eff }}$ value of $1.0075 \pm .0012$.

\section{Low Enrichment}

1. Uranium Cylinder at $\mathbf{1 0 . 9 \%}$ U-235 Enrichment. To determine MCNP's ability to effectively characterize the behavior of low enrichment systems, two simulations of experiments run by Paxton at LANL in $1975^{28}$ were performed. Both geometries were bare uranium cylinders, but they differed in uranium enrichments. The first was a cylinder of uranium enriched to $10.9 \% \mathrm{U}-235$, with a density of $18.63 \mathrm{~g} / \mathrm{cm}^{3}$, a height of $119.392 \mathrm{~cm}$, and a radius of $26.65 \mathrm{~cm}$. MCNP calculated the $\mathrm{k}_{\text {eff }}$ value of this system to be $1.0024 \pm .0013$.

2. Uranium Cylinder at $\mathbf{1 4 . 1 1 \%}$ U-235 Enrichment. The second system was enriched to $14.11 \% \mathrm{U}-235$ and had a density of $18.41 \mathrm{~g} / \mathrm{cm}^{3}$. The cylinder had

27 G. E. Hansen and H. C. Paxton, "Reevaluated Critical Specifications of Some Los Alamos Fast-Neutron Systems," Los Alamos National Laboratory report LA-4208 (1969).

28 H. C. Paxton, "Los Alamos Critical Data," Los Alamos National Laboratory report LA-3067-MS, Rev., (1975). 
a radius of $26.65 \mathrm{~cm}$ and a height of $44.239 \mathrm{~cm}$. The calculated $k_{e f f}$ value was $1.0003 \pm .0014$.

\section{Reflected Assemblies}

1. Graphite-Tamped Uranium Sphere. Two simulations of assemblies that were reflected by a tamping material were done. The first experiment, conducted by H. C. Paxton at LANL in $1975,{ }^{29}$ consisted of a uranium sphere reflected by a uniform layer of graphite. The sphere was composed of 93.5\%-enriched U-235 with a density of $18.8 \mathrm{~g} / \mathrm{cm}^{3}$. The reflecting layer was $5.1 \mathrm{~cm}$ of graphite. The reflector, with a density of $1.67 \mathrm{~g} / \mathrm{cm}^{3}$, consisted of $99.5 \%$ (by weight) carbon, $.34 \%$ iron, and $.16 \%$ sulfur. The $k_{e f f}$ value was calculated to be $0.9981 \pm .0010$.

2. Water-Reflected Uranium Sphere. The second reflected assembly was measured by Byers et al. at Los Alamos National Laboratory. ${ }^{30}$ The setup consisted of a $97.67 \%$-enriched uranium metal sphere immersed in a tank of water, which measured $30 \mathrm{~cm}$ in radius and $70 \mathrm{~cm}$ in height. The tank represented an effectively infinite water reflector. The sphere density, mass, and radius were $18.794 \mathrm{~g} / \mathrm{cm}^{3}$, $22.160 \mathrm{~kg}$, and $6.5537 \mathrm{~cm}$, respectively. The uranium composition in atoms $/ \mathrm{b}-\mathrm{cm}$ was $0.00053,0.04703,0.00010$, and 0.00049 for U-234, U-235, U-236, and U-238, respectively. The atomic densities of the hydrogen and oxygen in the water were 0.06679 and 0.03340 atoms/b-cm, respectively. The MCNP-calculated $k_{e f f}$ value of this geometry was $0.9956 \pm .0022$.

In both cases, the $\mathrm{S}(\alpha, \beta)$ thermal treatment was used. This treatment takes into account thermal neutron scattering by molecules, multiatomic molecules, and crystalline structures. To determine the effect of this treatment, the simulations were also run without the $\mathrm{S}(\alpha, \beta)$ thermal treatment. The $k_{e f f}$ value computed for the graphite-reflected sphere was $0.9851 \pm .0029$, whereas the $k_{e f f}$ of the waterreflected sphere was $1.0177 \pm .0017$. Obviously, the implementation of the $\mathrm{S}(\alpha, \beta)$ option radically affects the simulation results of reflected critical systems and should be used whenever possible.

29 Ibid.

30 C. C. Byers, et al., "Critical Measurements of a Water-Reflected Enriched Uranium Sphere," Transactions of the American Nuclear Society 27, 412-413 (1977). 


\section{E. Interacting Units}

1. Three Uranium Cylinders. Two interacting units were analyzed. The first experiment, performed by J. K. Fox and L. W. Gilley at Oak Ridge National Laboratory in $1959,{ }^{31}$ consisted of three unreflected aluminum cylinders containing $\mathrm{U}(93.2) \mathrm{O}_{2} \mathrm{~F}_{2}$ water solutions. The inside cylinder diameter and critical height measured 20.3 and $41.4 \mathrm{~cm}$, respectively. The aluminum container had a density of $2.71 \mathrm{~g} / \mathrm{cm}^{3}$ and was $0.15 \mathrm{~cm}$ thick. The three cylinders were set in an equilateral configuration with a surface separation of $0.38 \mathrm{~cm}$. The solution concentration parameters were $0.090 \mathrm{~g} \mathrm{U}-235 / \mathrm{cm}^{3}$ and a hydrogen to U-235 atomic ratio of 309 . Given this data, it was estimated that the solution density was approximately $1.131 \mathrm{~g} / \mathrm{cm}^{3}$ and consisted of $0.0021345 \mathrm{U}-235,0.00015382 \mathrm{U}-238,0.33383$ oxygen, 0.65930 hydrogen, and 0.0045756 fluorine in atoms/b-cm. MCNP calculated a $k_{e f f}$ value of $0.9991 \pm .0011$.

2. 3 x 3 Array of Plutonium Fuel Rods. The most complex setup of the series is a $3 \times 3$ array of $\mathrm{Pu}$ metal fuel rods. This experiment was performed by $\mathrm{H}$. F. Finn at Lawrence Livermore National Laboratory in $1971 .{ }^{32}$ In each rod, three cells of $\mathrm{Pu}$ were separated by aluminum inner spacers, and therefore, the system was effectively a $3 \times 3 \times 3$ array of Pu metal cells. Table 7 and Figs. 25, 26, and 27 specify the geometrical design and material specifications.

The overall arrangement was nine cylinders in a $3 \times 3$ configuration with a centerto-center spacing of $9.60 \mathrm{~cm}$ set on the surface of a table, modeled as a cylinder with a radius of $80 \mathrm{~cm}$. The assembly table consisted of 2 layers-the top and bottom layers were $2.54 \mathrm{~cm}$ of aluminum and $30 \mathrm{~cm}$ of steel, respectively. Because hundreds of bolt holes were used to fasten the fuel rods to the table, the density of the aluminum was reduced to $88 \%$ of its normal value and that of steel to only $7 \%$ of its normal value.

Figure 25 is a cross-sectional cut down the long axis of a cylindrical fuel element. The element consists of three cells of plutonium metal at a vertical center-to-center

31 J. K. Fox, L. W. Gilley, and E. R. Rohrer, "Critical Mass Studies, Part VIII. Aqueous Solutions of U 233 ," Oak Ridge National Laboratory report ORNL-2143 (1959).

32 H. F. Finn, N. L. Provost, O. C. Kolar, and G. A. Pierce, "Summary of Experimentally Determined Plutonium Array Critical Configurations," Lawrence Livermore National Laboratory report UCRL-51041 (1971). 
TABLE 7

MATERIAL SPECIFICATIONS FOR THE PLUTONIUM ARRAY (\% MASS)

\begin{tabular}{|c|c|c|c|c|c|c|}
\hline M1 & M2 & M3 & M4 & M5 & M6 & M7 \\
\hline $\mathrm{Cr} \quad .20$ & C $\quad .08$ & $\mathrm{~N} \quad 78.0$ & $\mathrm{Cr} \quad .10$ & $\mathrm{Cu} \quad .25$ & C .03 & Pu239 93.56 \\
\hline $\mathrm{Cu} \quad .25$ & Mn .37 & $\begin{array}{ll}0 & 21.0\end{array}$ & $\mathrm{Cu} \quad .25$ & $\mathrm{Fe} \quad .70$ & $\mathrm{Mn} .50$ & $240 \quad 5.97$ \\
\hline $\mathrm{Fe} \quad .70$ & $\mathrm{P} \quad .015$ & Ar 1.0 & $\mathrm{Fe} \quad .70$ & $\mathrm{Mg} 1.05$ & $\mathrm{P} \quad .005$ & $241 \quad .46$ \\
\hline $\mathrm{Mg} 1.0$ & S $\quad .025$ & & $\mathrm{Mg} 1.025$ & Mn 1.25 & $\mathrm{Si} \quad .33$ & $\begin{array}{ll}242 \quad .01\end{array}$ \\
\hline $\mathrm{Mn} .15$ & $\begin{array}{ll}\mathrm{Si} & .01\end{array}$ & & $\mathrm{Mn} .70$ & Si $\quad .30$ & S $\quad .009$ & \\
\hline $\mathrm{Si} \quad .60$ & Sn $\quad .30$ & & $\mathrm{Si} \quad .45$ & $\mathrm{Al} \quad 96.30$ & Sn .11 & \\
\hline $\mathrm{Ti} \quad .15$ & $\mathrm{Fe} \quad 99.2$ & & $\mathrm{Ti} \quad .075$ & & $\mathrm{Fe} \quad 35.54$ & \\
\hline \multirow[t]{4}{*}{ Al 96.7} & & & $\mathrm{Al} \quad 96.45$ & & Cr $\quad .07$ & \\
\hline & & & & & $\mathrm{Cu} 2.8$ & \\
\hline & & & & & $\mathrm{Mg} \quad .97$ & \\
\hline & & & & & $\mathrm{Al} \quad 59.45$ & \\
\hline
\end{tabular}




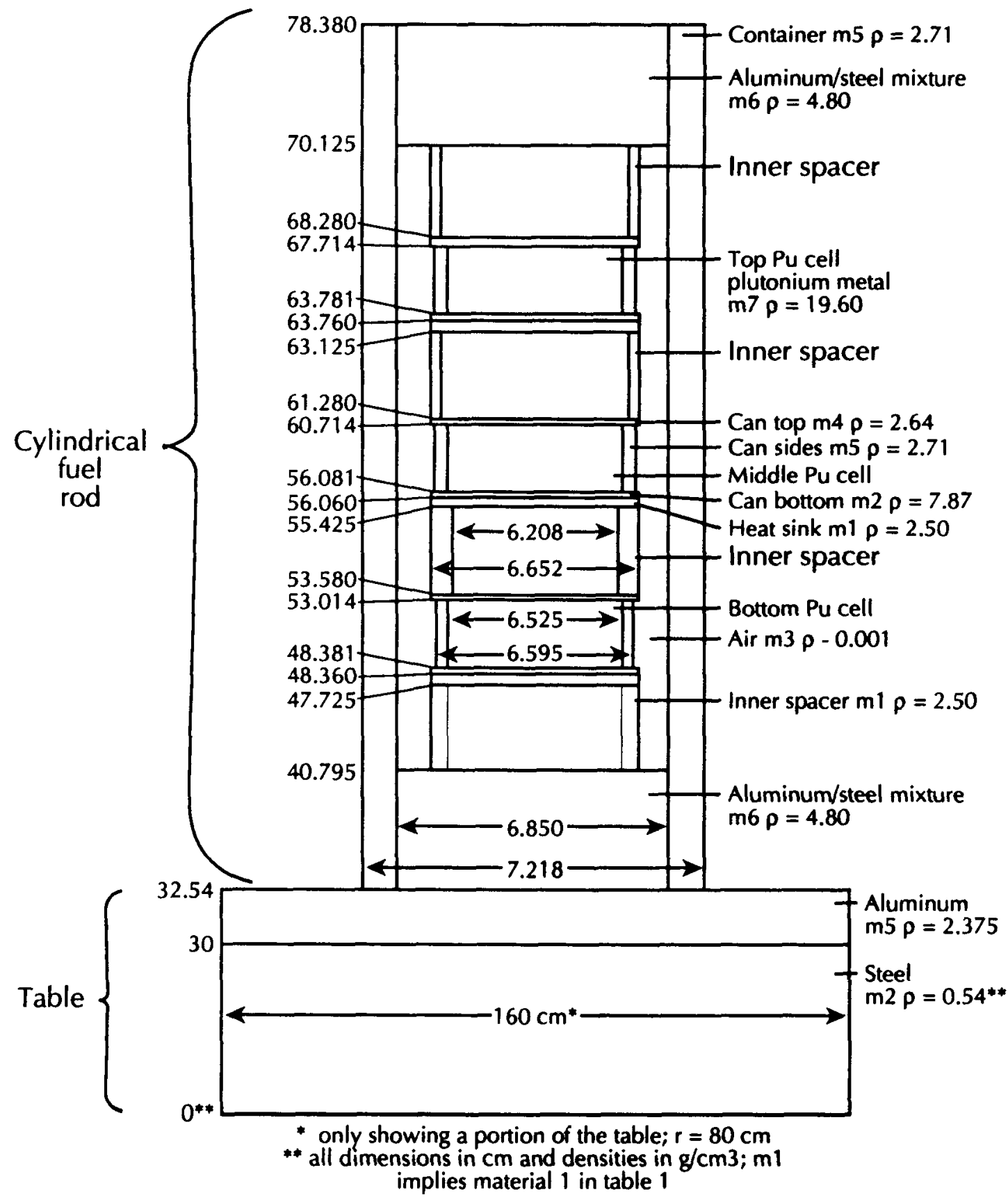

Fig. 25. Cross-sectional cut down the long axis of a cylindrical fuel element containing three cells of plutonium. 


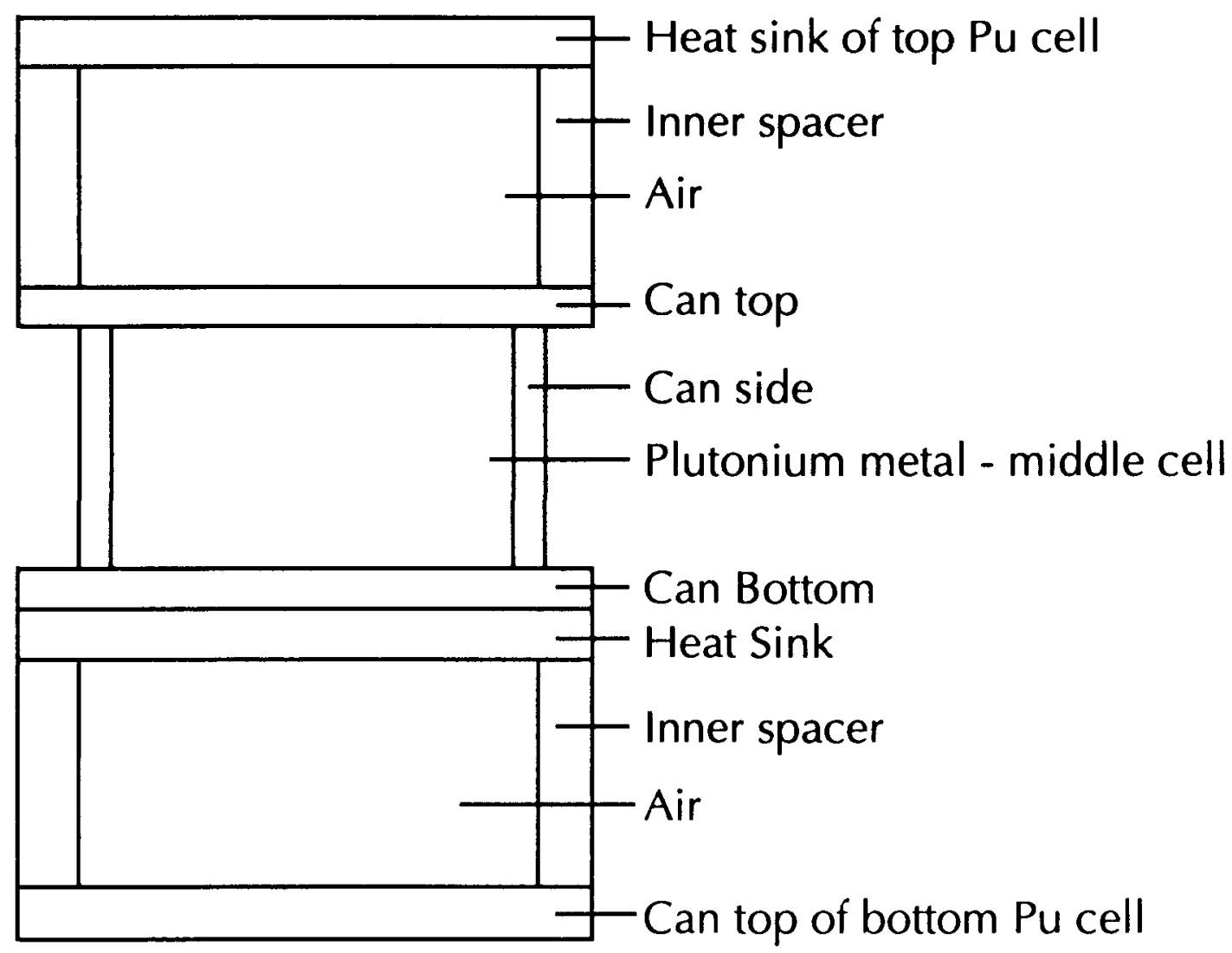

Fig. 26. Repeated structure. 


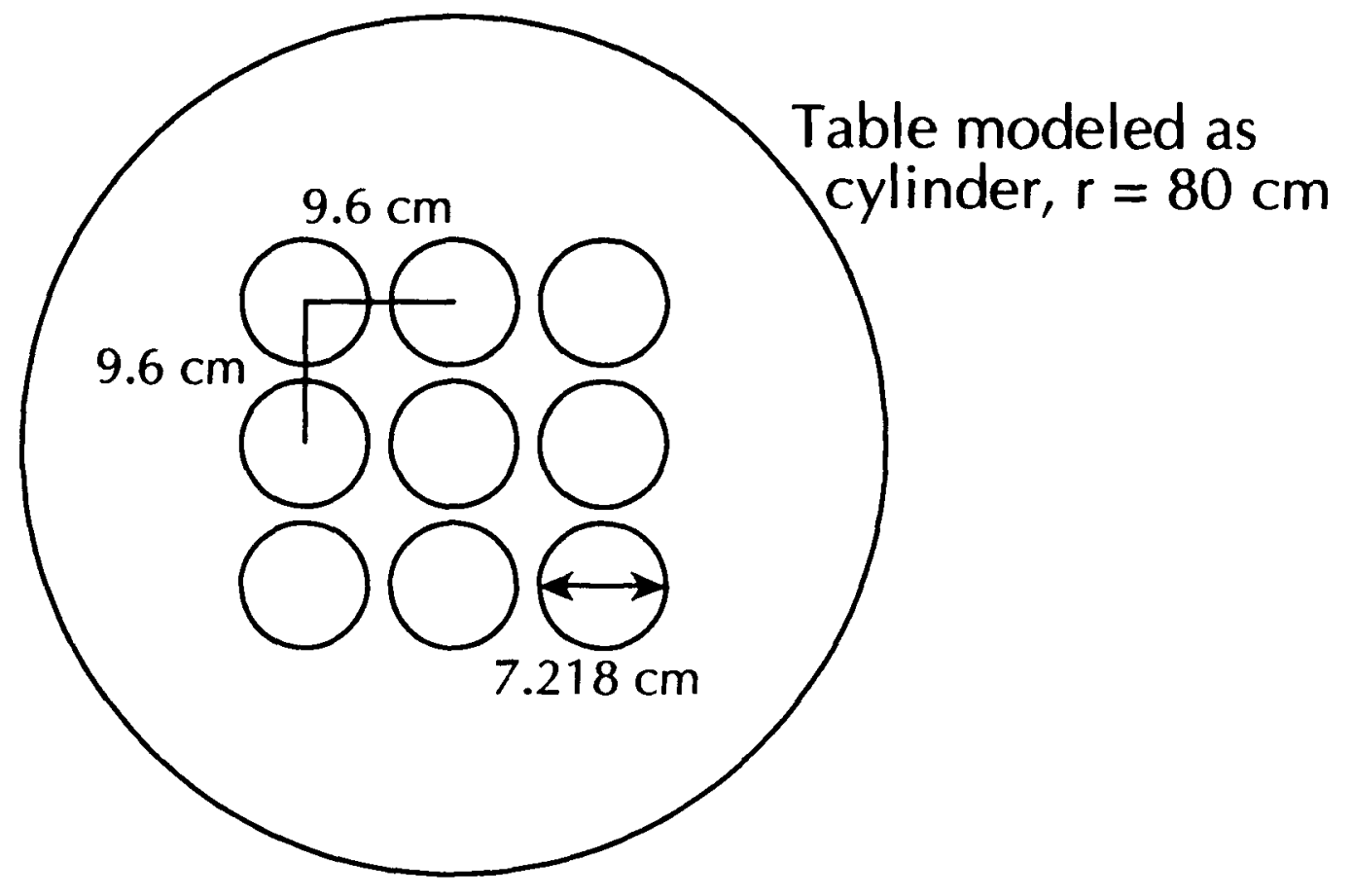

Fig. 27. Top view of the array, depicting the center-to-center separation of $9.6 \mathrm{~cm}$. 
spacing of $7.70 \mathrm{~cm}$. The structural integrity of the system arrangement was maintained by the aluminum inner spacers placed between the cells. The plutonium itself was contained in a box fabricated from various aluminum alloys and steel. This structure consisted of an aluminum can top and sides and a steel bottom. Below the can bottom rested an aluminum heat sink. The inner spacers were attached to the bottom of the top plutonium cell's heat sink and the top of the middle cell's can top. The middle and bottom cells were similarly connected. Inner spacers were also placed between the bottom plutonium cell and a region consisting of aluminum and steel, and they connected the top cell to a similar region, which served as the cap to the aluminum cylinder which encased the system. The region inside this cylinder surrounding the plutonium cells and subsequent supporting structures was filled with air.

Figure 26 explicitly shows a plutonium cell and its connection with the other two of the system. Figure 27 depicts the top view of the $3 \times 3$ array and table arrangement. Table 7 displays the material specifications of the system corresponding to the labels in Fig. 26. MCNP calculated the $k_{e f f}$ value at $1.0000 \pm .0019$. In comparison, COG published results of $0.991 \pm .0050$.

\section{SUMMARY}

Neutron pulsed sphere, shielding, and criticality problems have been run with MCNP4. These neutron problem families were chosen as benchmarks because they represent a broad spectrum of neutron transport problems and because some of them were also used to validate the COG Monte Carlo code. MCNP predicted the experimental results of all problems in these three families well. This evaluation convincingly demonstrates that MCNP can accurately model a wide class of neutron problems.

\section{REFERENCES}

1. Judith F. Briesmeister, Editor, "MCNP - A General Monte Carlo Code for Neutron and Photon Transport, Version 3A," Los Alamos National Laboratory report LA-7396-M, Rev. 2 (1986).

2. T. E. Booth and J. S. Hendricks, "Importance Estimation in Forward Monte Carlo Calculations", Nuclear Technology/Fusion, 5(1), 90 (1984). 
3. C. C. Byers, et al., "Critical Measurements of a Water-Reflected Enriched Uranium Sphere," Transactions of the American Nuclear Society 27, 412-413 (1977).

4. G. P. Estes, R. C. Little, R. E. Seamon, P. D. Soran, "Air Transport in Connection with the Hiroshima-Nagasaki Dose Reevaluation Effort," Los Alamos National Laboratory report LA-9369-MS (July 1982).

5. H. F. Finn, N. L. Provost, O. C. Kolar, and G. A. Pierce, "Summary of Experimentally Determined Plutonium Array Critical Configurations," Lawrence Livermore National Laboratory report UCRL-51041 (1971).

6. J. K. Fox, L. W. Gilley, and E. R. Rohrer, "Critical Mass Studies, Part VIII. Aqueous Solutions of U233," Oak Ridge National Laboratory report ORNL-2143 (1959).

7. G. E. Hansen and H. C. Paxton, "Reevaluated Critical Specifications of Some Los Alamos Fast-Neutron Systems," Los Alamos National Laboratory report LA-4208 (1969).

8. L. F. Hansen, J. D. Anderson, P. S. Brown, R. J. Howerton, J. L. Kammerdiener, C. M. Logan, E. F. Plechaty, and C. Wong, "Measurements and Calculations of the Neutron Spectra from Iron Bombarded with 14-MeV Neutrons," Nuclear Science and Engineering 51, 278-295 (1973).

9. L. F. Hansen, J. D. Anderson, E. Goldberg, J. Kammerdiener, E. Plechaty, and C. Wong, "Predictions for Neutron Transport in Air, Based on Integral Measurements in Nitrogen and Oxygen at $14 \mathrm{MeV}$, Nuclear Science and Engineering 40, 262-282 (1970).

10. Luisa F. Hansen, John D. Anderson, Eugene Goldberg, Ernest F. Plechaty, Marion L. Stelts, and Calvin Wong, "Time Spectra from Spheres Pulsed with 14-MeV Neutrons," Nuclear Science and Engineering 35, 227-239 (1969).

11. H. C. Paxton, "Los Alamos Critical Data," Los Alamos National Laboratory report LA-3067-MS, Rev. (1975).

12. Robert F. Rose and Robert W. Roussin, editors, "Shielding Benchmark Compilation," Vol. 2, Brookhaven National Laboratory report BNL-19302 (1983). 
13. R. T. Santoro, R. G. Alsmiller, J. M. Barnes, and G. T. Chapman, "Calculation of Neutron and Gamma-Ray Spectra for Fusion Reactor Shield Design: Comparison with Experiment," Nuclear Science and Engineering 78, 259-272 (1981).

14. Marion L. Stelts, John D. Anderson, Luisa F. Hansen, Ernest F. Plechaty, and Calvin Wong, "Spectra of Fast Neutrons from Water Pulsed with 14-MeV Neutrons," Nuclear Science and Engineering 46, 53-56 (1971).

15. W. Webster and C. Wong, "Measurement of the Neutron Emission Spectra from Spheres of N, O, W, U-235, U-238, and Pu-239, Pulsed by 14-MeV Neutrons," Lawrence Livermore National Laboratory report UCID-17332 (December 15,1976$)$.

16. Daniel J. Whalen, David E. Hollowell, and John S. Hendricks, "MCNP: Photon Benchmark Problems," Los Alamos National Laboratory report LA-12196 (1991).

17. Thomas P. Wilcox, Jr. and Edward M. Lent, "COG - A Particle Transport Code Designed to Solve the Boltzmann Equation for Deep-Penetration (Shielding) Problems," Volume 4, "Benchmark Problems," Lawrence Livermore National Laboratory report M-221-4 (December 2, 1988).

18. C. Wong, J. D. Anderson, P. Brown, L. F. Hansen, J. L. Kammerdiener, C. Logan, and B. Pohl, "Livermore Pulsed Sphere Program: Program Summary Through July 1971," Lawrence Livermore National Laboratory report UCRL-51144, Rev.1 (1972). 
APPENDIX:

MCNP INPUT FILES 


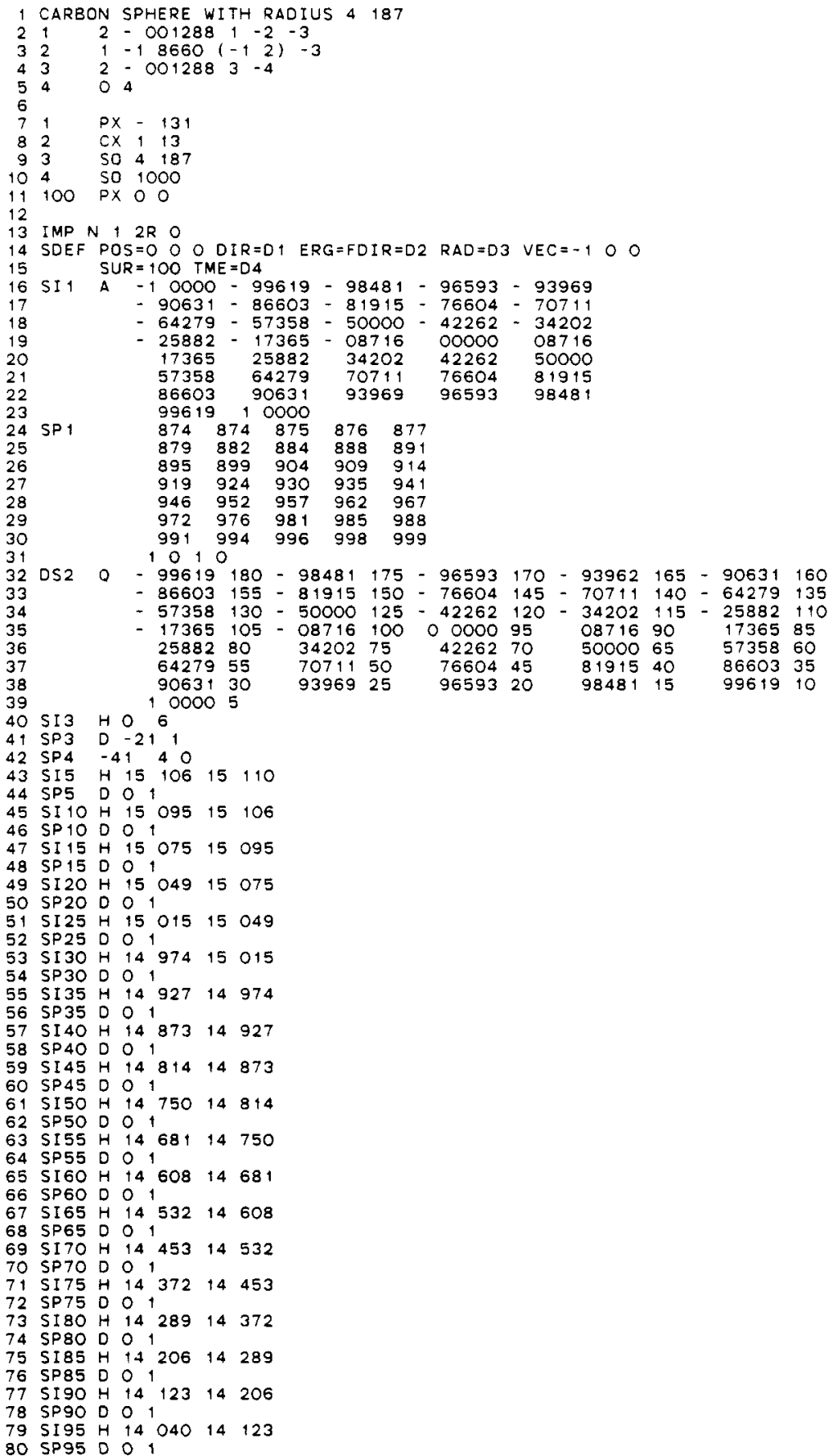

Table A1. Livermore pulsed sphere setup for .5 m.f.p. carbon, representative of the simple sphere problems. 


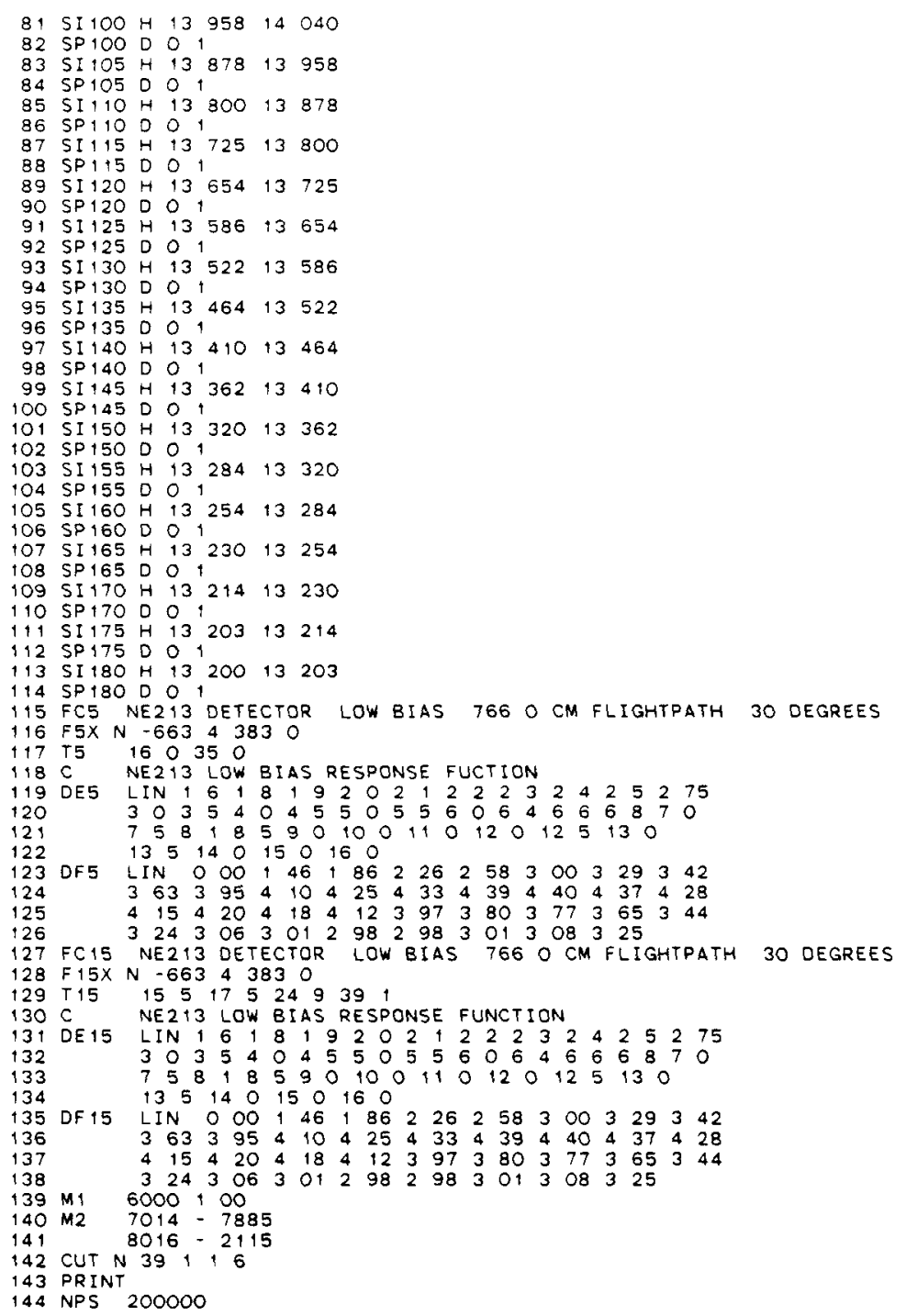

Table A1. (cont.) 


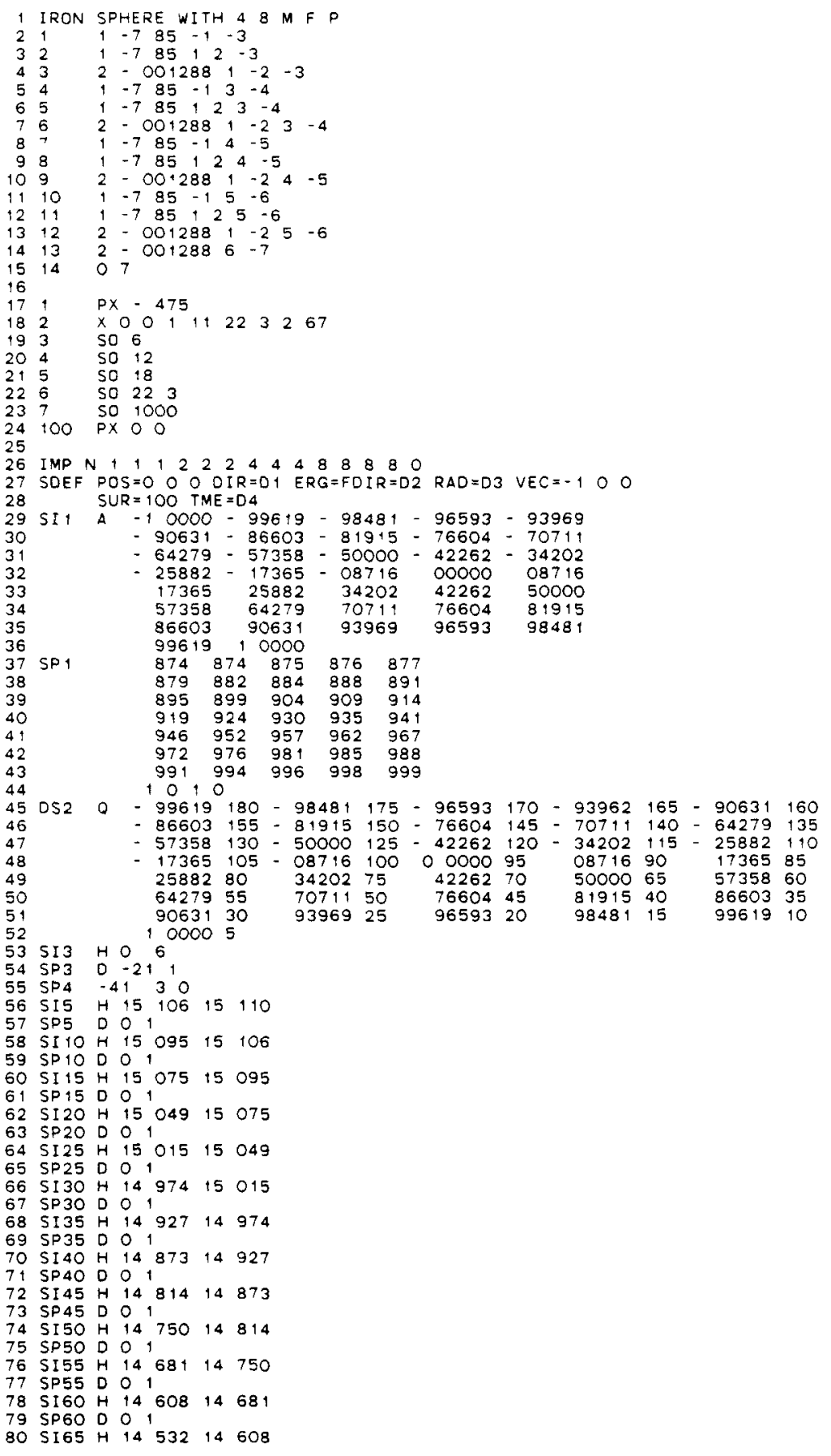

Table A2. Livermore pulsed sphere setup for 4.8 m.f.p. iron - the only sphere subdivided for importance sampling. 


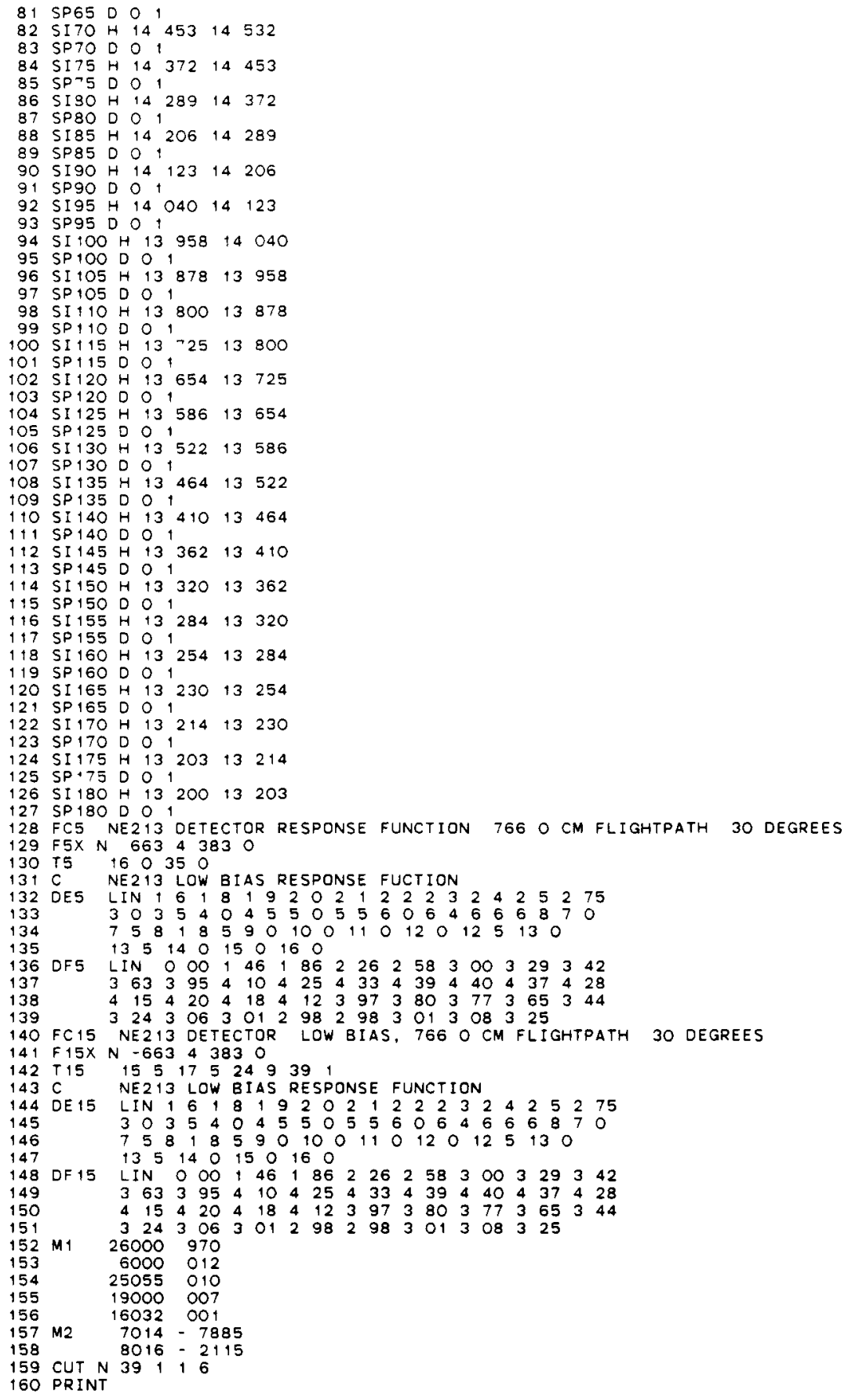

Table A2. (cont.) 


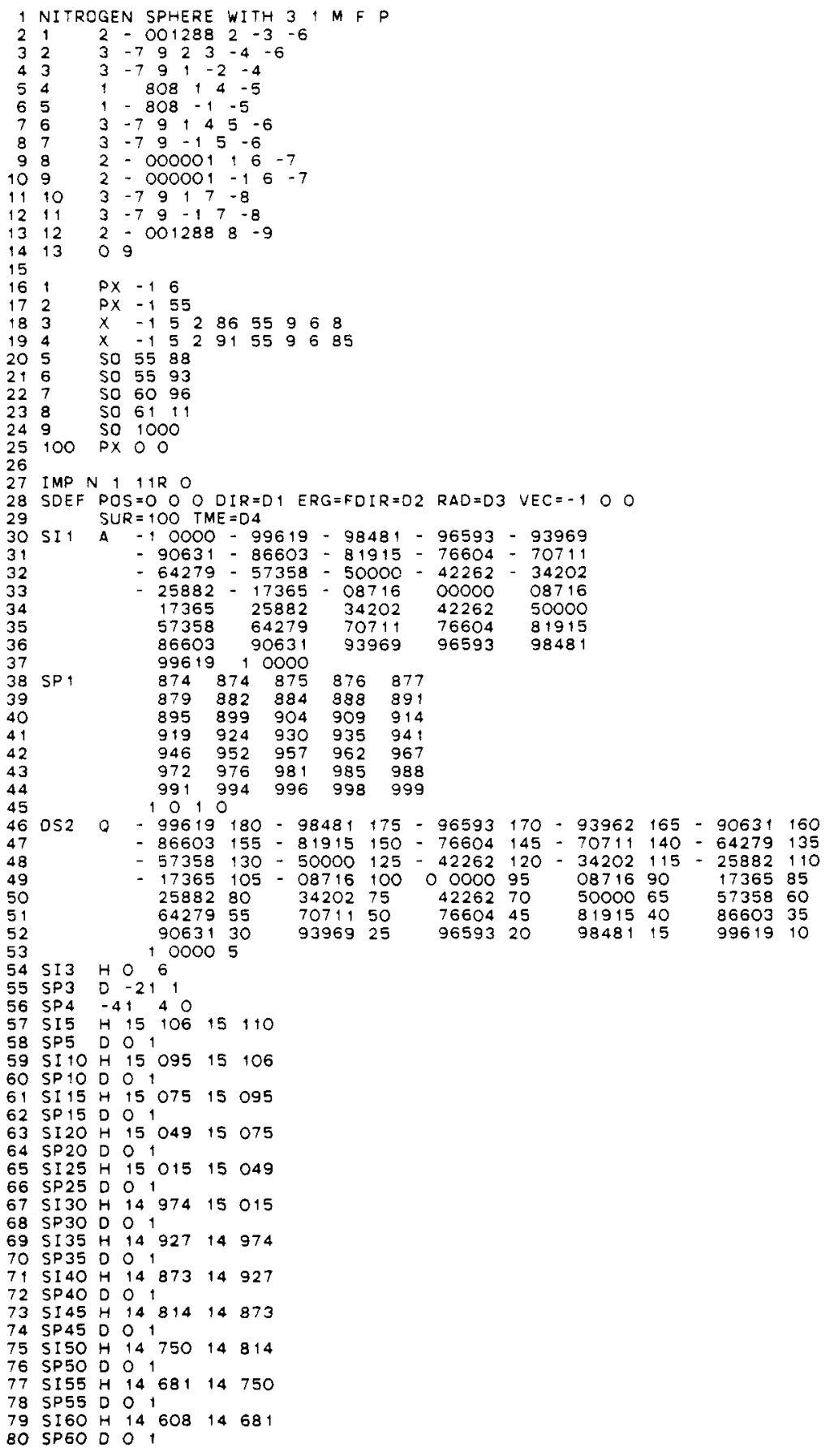

Table A3. Livermore pulsed sphere setup for 3.1 m.f.p. nitrogen, representative of the liquid spheres. 


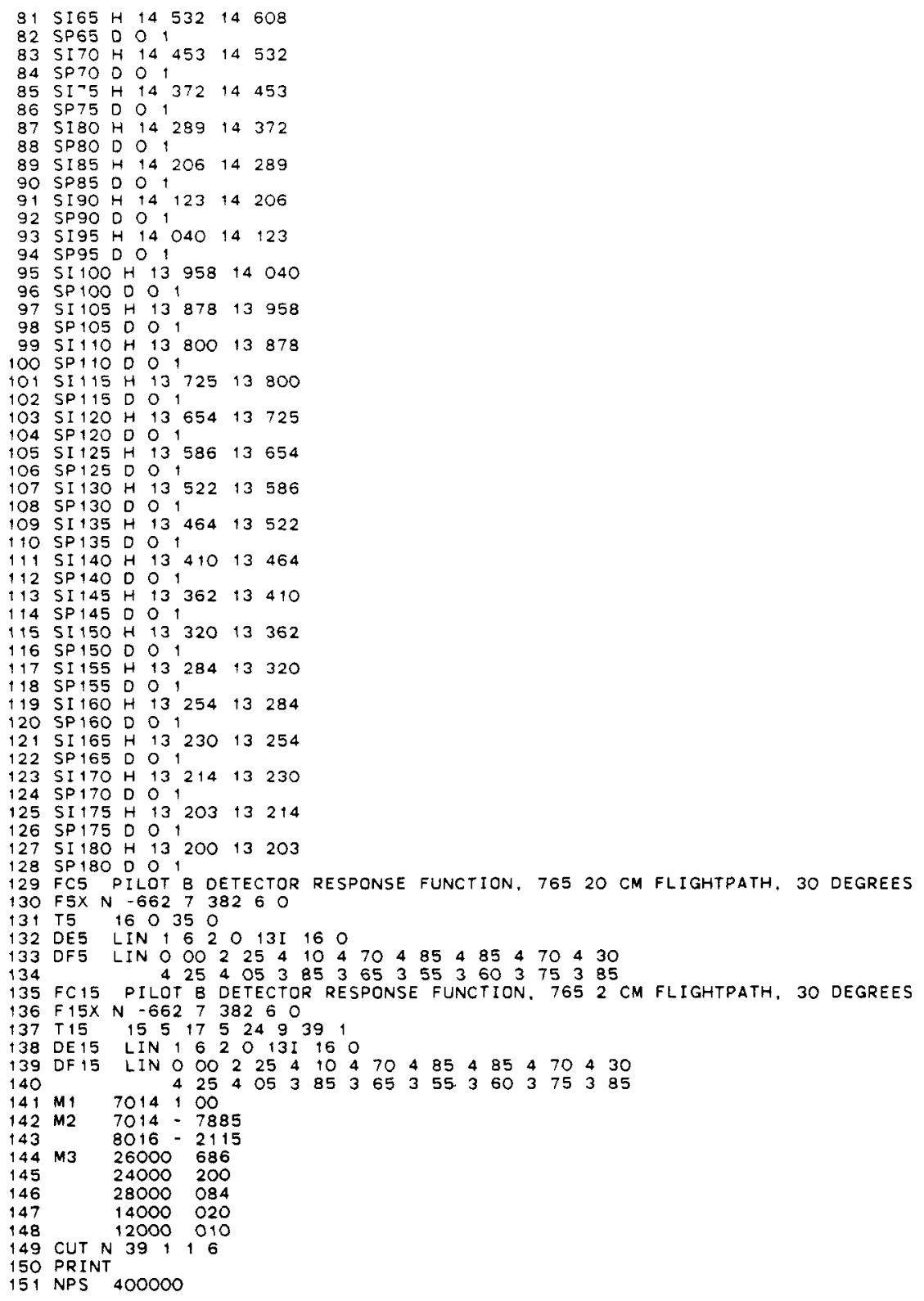

Table A3. (cont.) 


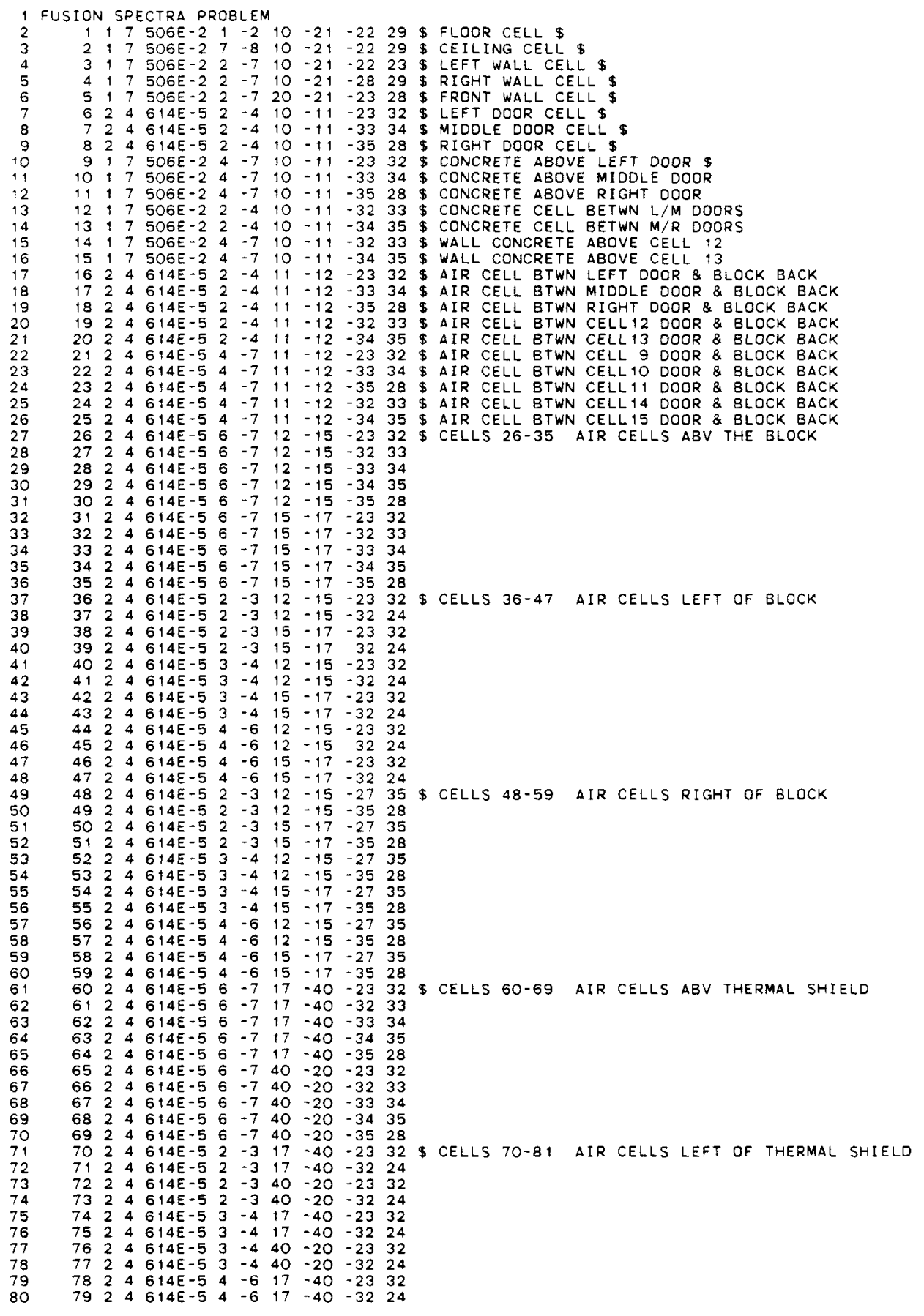

Table A4. Fusion shielding benchmark setup for configuration 3 with an on-axis neutron detector. 


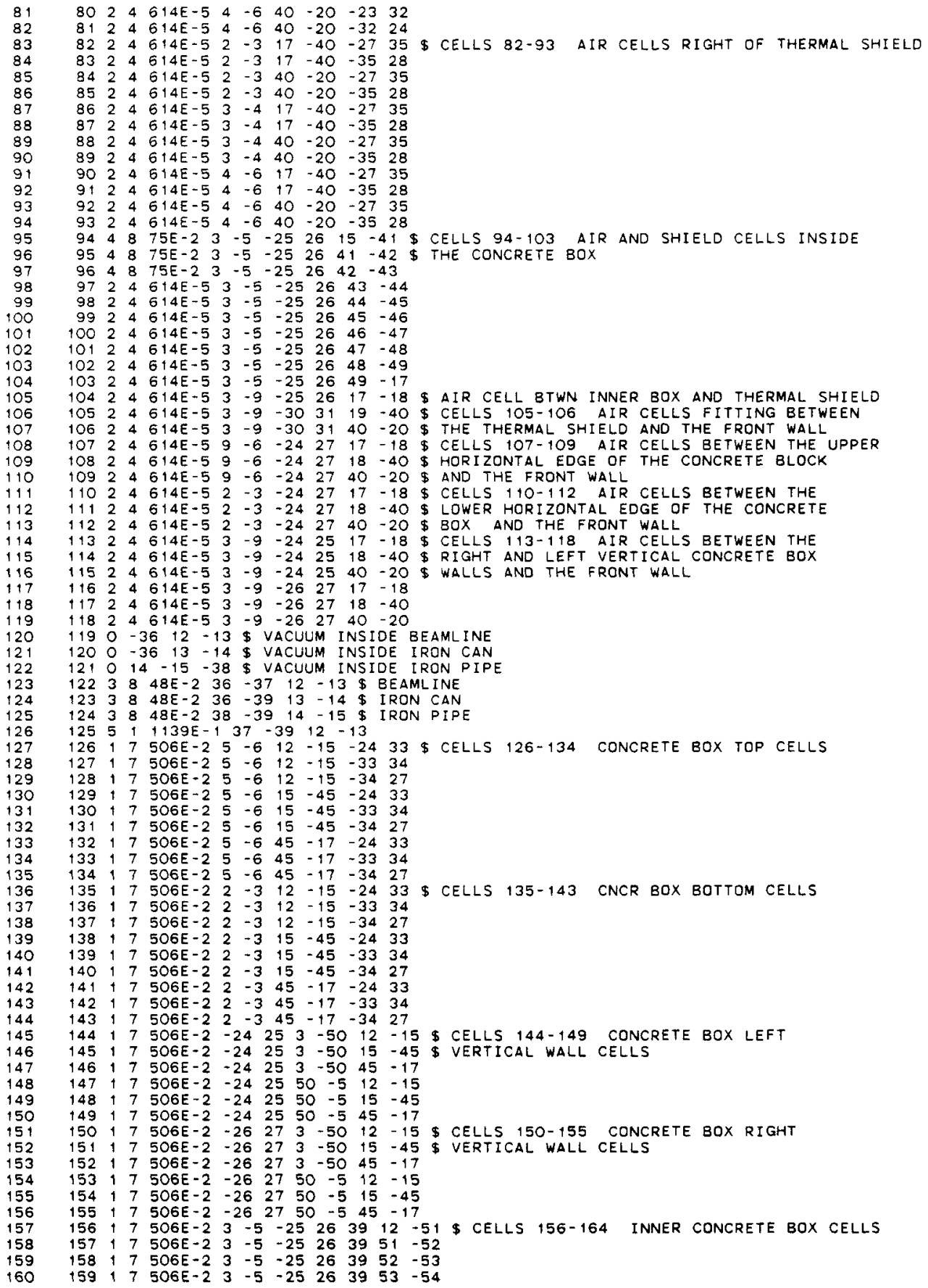

Table A4. (cont.) 


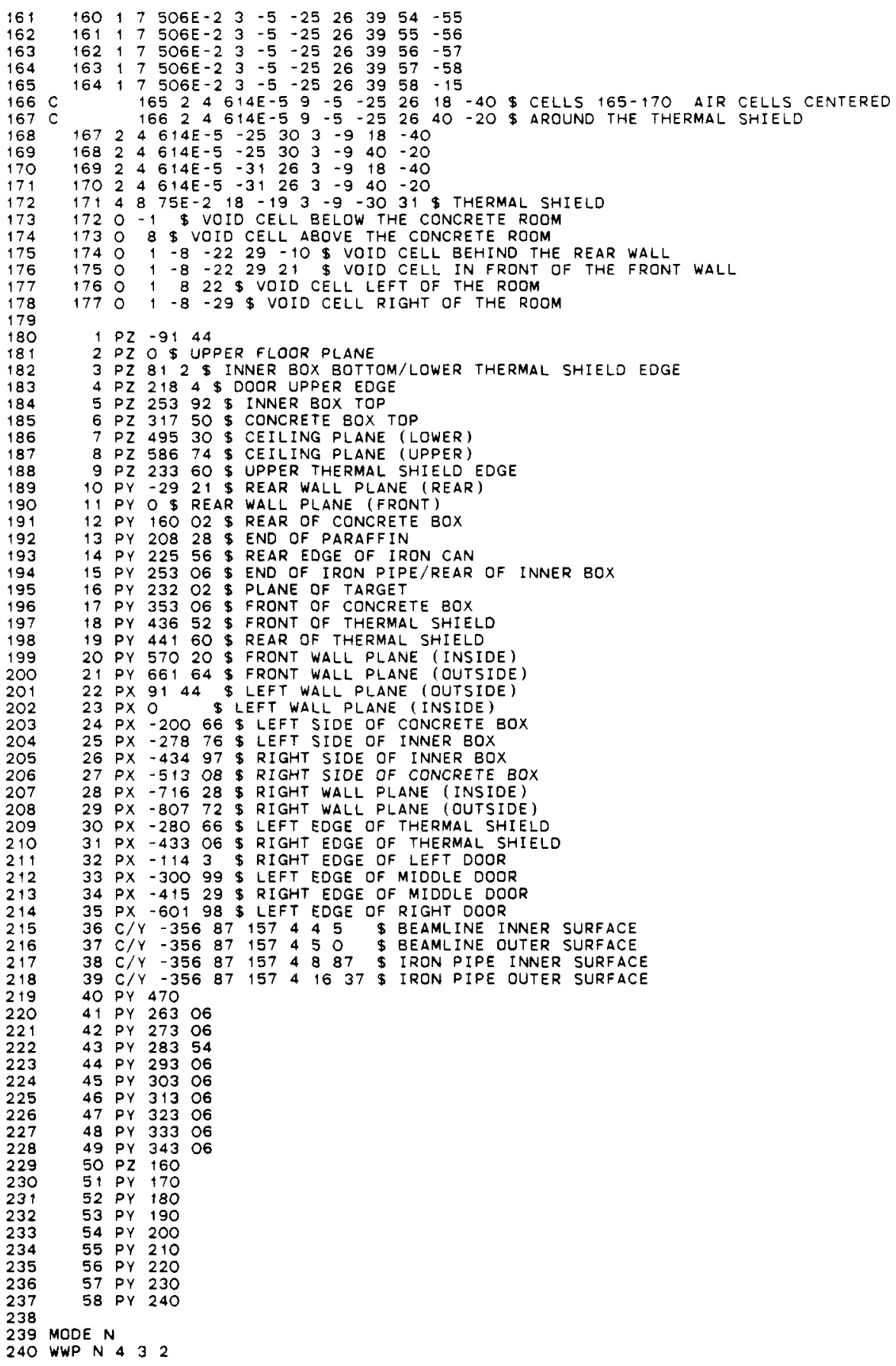

Table A4. (cont.) 


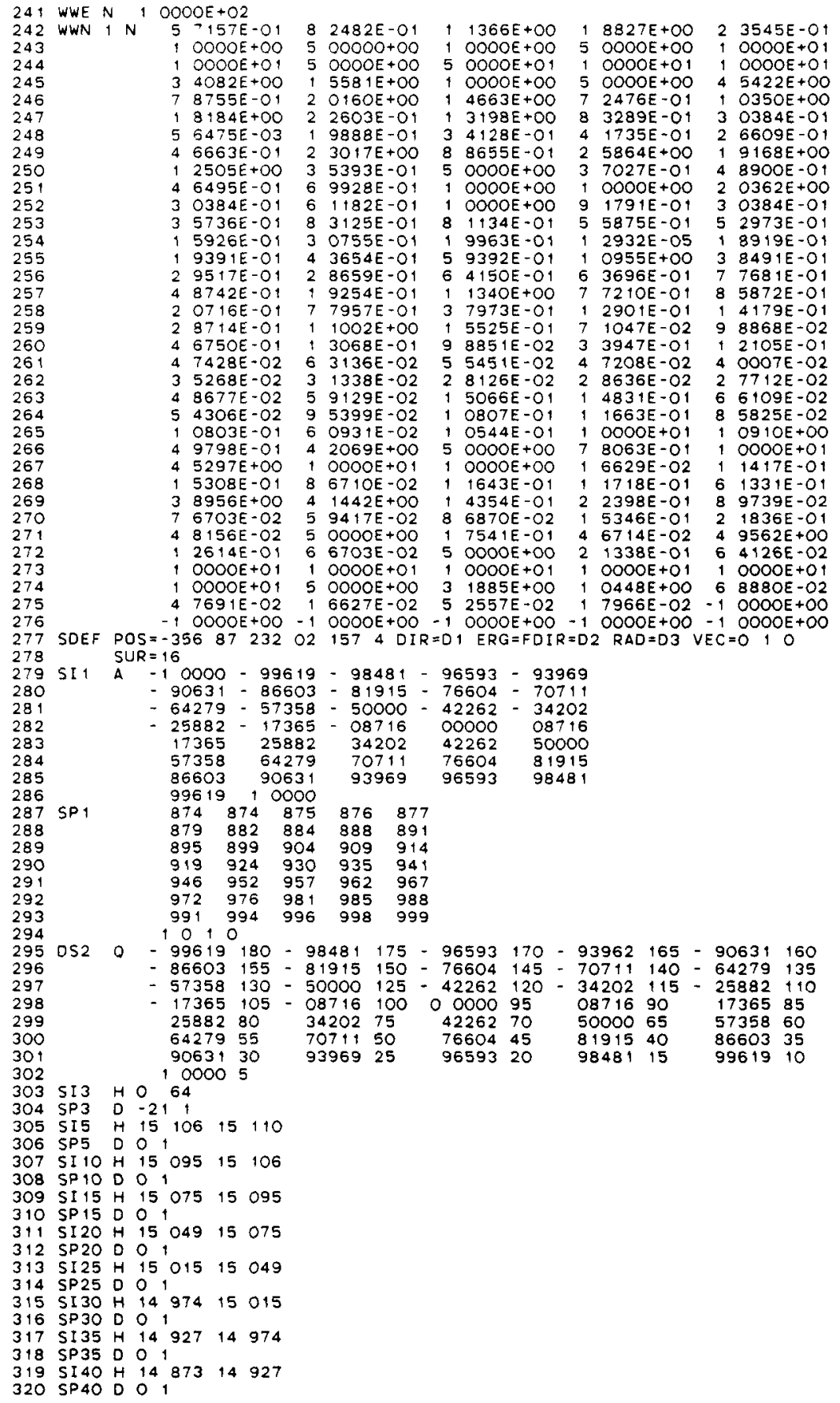

Table A4. (cont.) 
$321 \quad S I 45 \quad H \quad 14 \quad 814 \quad 14 \quad 873$

322 SP 45 D $O 1$

$\begin{array}{lllllll}323 & \text { SI } 50 & \mathrm{H} & 14 & 750 & 14 & 814\end{array}$

324 SP5O D $O 1$

325 SI 55 H 14 681 14750

326 SP55 0

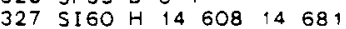

328 SP 60 O 0 ,

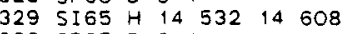

330 SP65 D 01

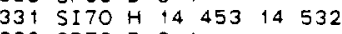

332 SP7O D $O$

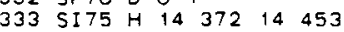

334 SP $75 \quad 0 \quad 0 \quad 1$

$\begin{array}{lllllll}335 & \text { SI } 80 & H & 14 & 289 & 14 & 372\end{array}$

$3365 P 80 \quad 0 \quad 0 \quad 1$

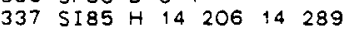

338 SP85 0

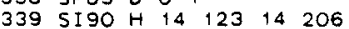

$3405 P 90$ D $O 1$

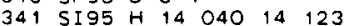

342 SP95 $D$

343 SI $100 \mathrm{H} \quad 13 \quad 958 \quad 14 \quad 040$

344 SP 100 O 0

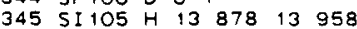

346 SP 105 D $O$

347 SI 110 H $13800 \quad 13878$

348 SP 110 D 0

349 SI 115 H $13 \quad 725 \quad 13 \quad 800$

351 SI 120 H $13654 \quad 13 \quad 725$

352 SP120

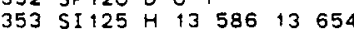

354 SP 125 D $O$

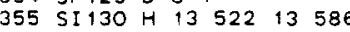

356 SP $130 \quad D \quad O$

$\begin{array}{lllllll}357 & \text { SI } 135 & H & 13 & 464 & 13 & 522\end{array}$

$3585 P 13500$

359 SI $140 \quad H \quad 13 \quad 410 \quad 13 \quad 464$

360 SP 140 D O

361 SI $145 \quad H \quad \$ 3 \quad 362$ 13 410

362 SP 145 D $O$

363 SI 150 H 13320 \$3 362

364 SP 150 D 0

$\begin{array}{llllll}365 & \text { SI } 155 \quad \mathrm{H} & 13 & 284 & 13 \quad 320\end{array}$

366 SP 155 O 0

$\begin{array}{lllllll}367 & \text { SI } 160 & H & 13 & 254 & 13 & 284\end{array}$

368 SP 160 D 013

36951165 H $13 \quad 230 \quad 13 \quad 254$

370 SP 165 0 - 13

37151770 H $13,21413 \quad 230$

$3712170 \mathrm{H} 13214$

372 SP 170 O 01

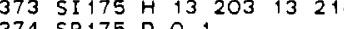

375 SI $180 \mathrm{H} 13 \quad 200 \quad 13203$

376 SP 180 D 0

$\begin{array}{lllllllll}377 & F 5 & N & -356 & 87 & 386 & 52 & 157 & 4\end{array}$

378 FTS GEB O3 08

379 FQ5 E D

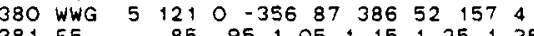

381 E5

382

$\begin{array}{llllllllllllllllllllll}85 & 95 & 1 & 05 & 1 & 15 & 1 & 25 & 1 & 35 & 1 & 45 & 1 & 55 & 1 & 65 & 1 & 75 & 1 & 85 & 1 & 95\end{array}$

$\begin{array}{llllllllllllllllllllllll}2 & 15 & 2 & 35 & 2 & 55 & 2 & 75 & 2 & 95 & 3 & 15 & 3 & 35 & 3 & 55 & 3 & 75 & 3 & 95 & 4 & 15 & 4 & 45\end{array}$

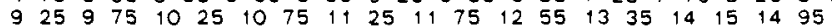

$384 \quad 92597515$

386 EM5 $\quad 110 \quad 10 R \quad 5 \quad 10 R \quad 3 \quad 33 \quad 8 R \quad 2 \quad 5 \quad 2 \quad 8 R \quad 1 \quad 25 \quad 5 R$

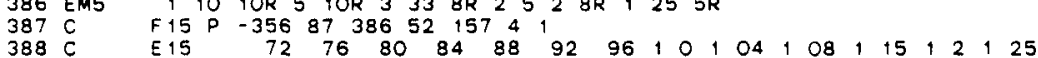

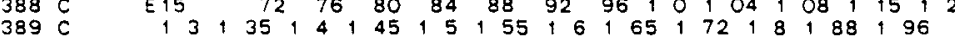

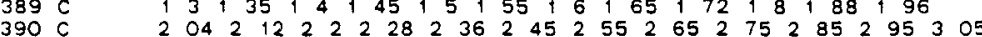

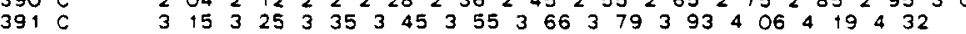

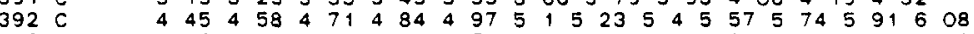

$393 \mathrm{C}$

$394 \mathrm{C}$

$395 \mathrm{C}$

$396 \mathrm{C}$

$\begin{array}{lllllllllllllllllllllllllllll}6 & 25 & 6 & 42 & 6 & 6 & 6 & 8 & 7 & 0 & 7 & 2 & 7 & 4 & 7 & 6 & 7 & 8 & 8 & 0 & 8 & 2 & 8 & 4 & 8 & 6 & 8 & 8 & 9\end{array}$

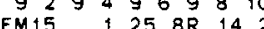

$\begin{array}{lllllllllllllllllllllllll} & 9 M 15 & 1 & 25 & 8 R & 14 & 286 & 20 & 9 R & 14 & 286 & 12 & 5 & 7 R & 11 & 111 & 10 & 10 R & 9 & 0909 & 7 & 6923\end{array}$

$\begin{array}{llllllllllll}7 & 1429 & 7 & 6923 & 9 R & 5 & 8824 & 6 R & 5 & 5556 & 5 & 16 R\end{array}$

398 PRDMP $1 E 33850$ \$ IGNORE NEUTRONS BELOW THE DETECTOR RESPONSE

$399 M 1 \quad 1001786 E-3$

$400 \quad 8016439 E-2$

Table A4. (cont.) 


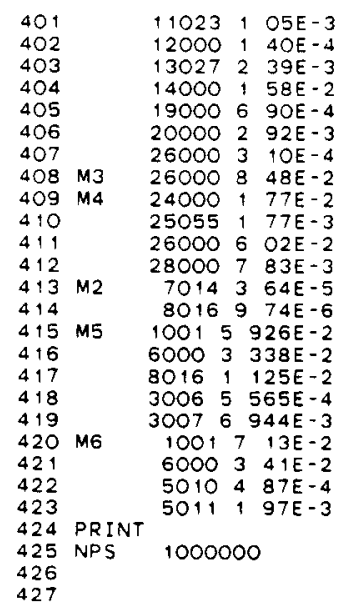

Table A4. (cont.) 


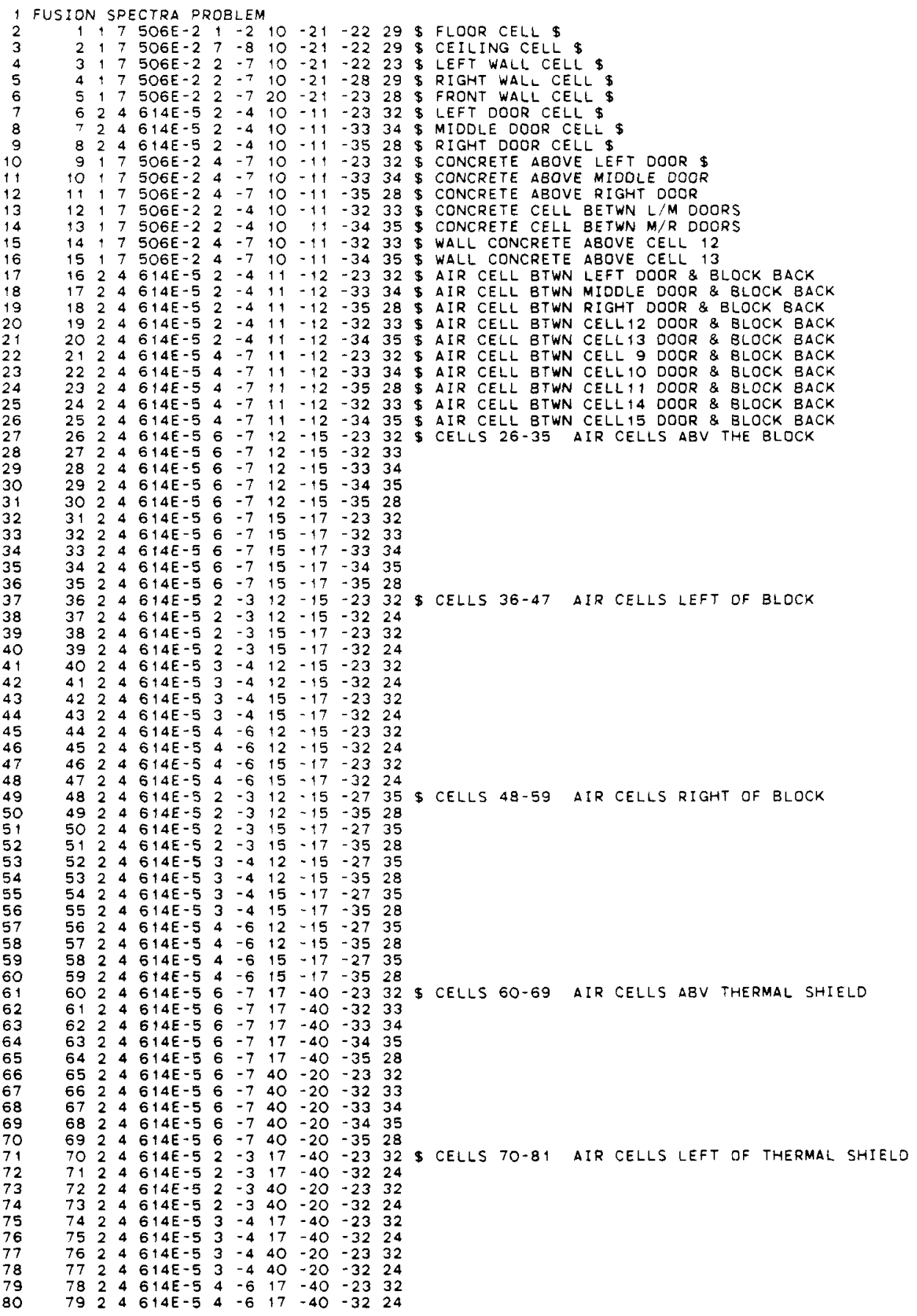

Table A5. Fusion shielding benchmark setup for configuration 7 with an off-axis photon detector. 


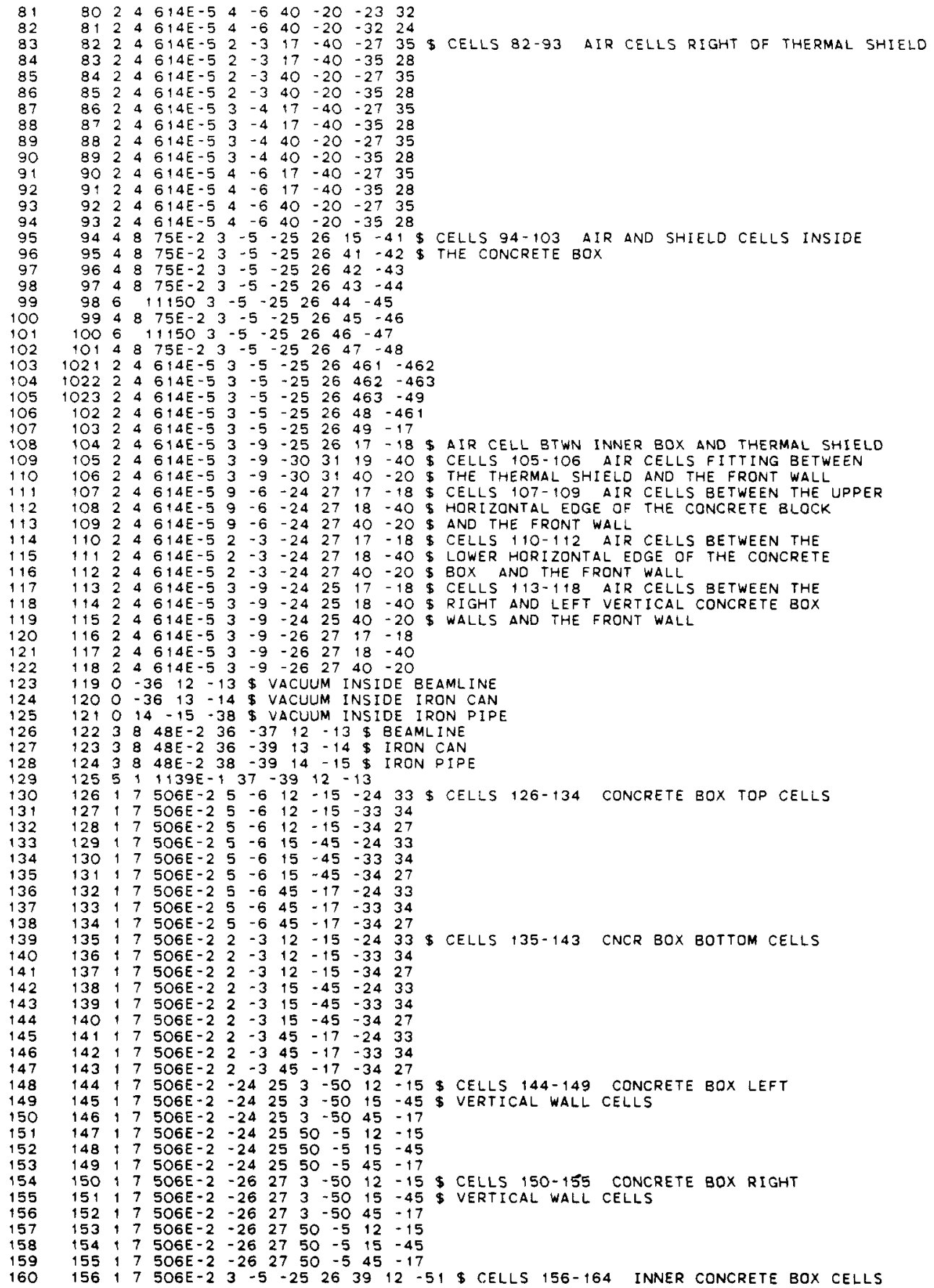

Table A5. (cont.) 
$\begin{array}{lllllllllll}157 & 1 & 7 & \text { SO6E }-2 & 3 & -5 & -25 & 26 & 39 & 51 & -52\end{array}$

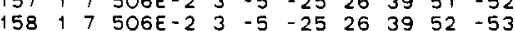

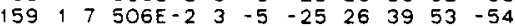

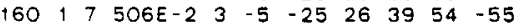

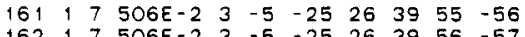

$16217506 \mathrm{E}-2$

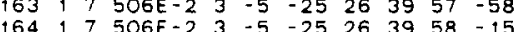

C $16524614 \mathrm{E}-590-5 \quad 2526 \quad 18-40$ CELLS $165-170$ AIR CELLS CENTERED

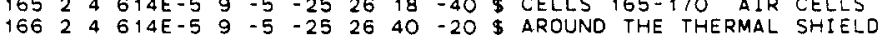

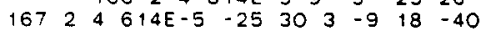

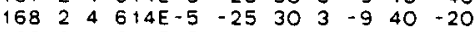

$1692 \quad 4 \quad 6 \uparrow 4 E-5-31$ 26 $3 \quad-9+8-40$

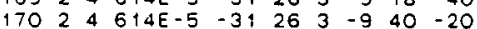

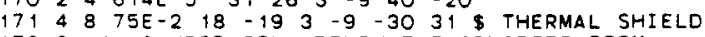

172 O 19 VOID CELL BELOW THE CONCRETE ROOM

$17308 \$$ VOID CELL ABOVE THE CONCRETE ROOM

4-8 -2229 - TO \$ VOID CELL BEHIND THE REAR WALL

$\begin{array}{llllllll}175 & 0 & 1 & -8 & -22 & 29 & 21 & \$\end{array}$

$1760-1-822 \$$ VOID CELL LEFT OF THE ROOM

$1770 \quad 1-8-29$ \$ VOID CELL RIGHT OF THE ROOM

$1 P Z-9+44$

2 PZ O \$ UPPER FLOOR PLANE

3 PZ 8122 \$ INNER BOX BOTTOM/LOWER THERMAL SHIELD EDGE

$\begin{array}{llllll}4 & P Z & 218 & 4 & \$ & \\ 5 & P O O R & \text { UPPER EDGE }\end{array}$

$\begin{array}{lllll}5 & P Z & 253 & 92 & \$ \text { INNER BOX TOP } \\ 6 & P Z & 317 & 50 & \$\end{array}$

7 PZ 49530 \$ CEILING PLANE (LOWER)

$8 \mathrm{PZ} 58674 \$$ CEILING PLANE (UPPER)

9 PZ 233 60 \$ UPPER THERMAL SHIELD EDGE

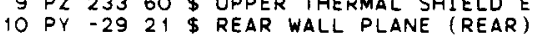

11 PY 0 \$ REAR WALL PLANE (FRONT)

12 PY 160 O2 \$ REAR OF CONCRETE BOX

12 PY 160 O2 \$ REAR OF CONCRETE

$\begin{array}{llllll}13 & \text { PY } & 208 & 28 & \$ \text { END OF PARAFFIN } \\ 14 & \text { PY } & 225 & 56 & \text { \$ REAR EDGE OF IRON CAN }\end{array}$

15 PY 2536 \$ REAR EDGE OF IRON CAN OF INNER BOX

15 PY 253 O6 \$ END OF IRON PIPE/ 16 PY 232 O2 \$ PLANE OF TARGET

16 PY 232 O2 \$ PLANE OF TARGET
17 PY 353 O6 \$ FRONT OF CONCRETE BOX

18 PY 43652 \$ FRONT OF THERMAL SHIELD

19 PY 44160 REAR OF THERMAL SHIELD

20 PY 57020 \$ FRONT WALL PLANE (INSIDE)

21 PY 66164 \& FRONT WALL PLANE (OUTSIDE)

22 PX 9144 \$ LEFT WALL PLANE (OUTSIDE)

24 PX -200 66 \$LEFT SIDE OF CONCRETE BOX

$25 \mathrm{PX}-278$ 76 LEFT SIDE OF INNER BOX

$26 \mathrm{PX}-434$ 97 RIGHT SIDE OF INNER BOX

$27 \mathrm{PX}-513$ O8 \$ RIGHT SIDE OF CONCRETE BOX

$\begin{array}{llllll}27 & P X & -513 & 08 & \$ & \text { RIGHT SIDE OF CONCRETE BOX } \\ 28 & P X & -716 & 28 & \$ & \text { RIGHT WALL PLANE (INSIDE) }\end{array}$

$\begin{array}{lllll}28 & P X & -716 & 28 & \$ R I G H T \\ 29 & P X & -807 & 72 & \text { RIGL }\end{array}$

29 PX -80772 \$ RIGHT WALL PLANE (OUTSIDE)

$31 \mathrm{PX}-433$ O6 \$RIGHT EDGE OF THERMAL SHIELD

32 PX -11433 \$ RIGHT EDGE OF LEFT DOOR

33 PX -30099 \$LEFT EDGE OF MIDDLE DOOR

34 PX -41529 \$ RIGHT EDGE OF MIODLE DODR

35 PX -60198 \$ LEFT EDGE OF RIGHT DOOR

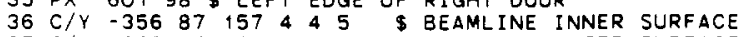

$37 \mathrm{C} / Y-356 \quad 87 \quad 1574450$ \$ BEAMLINE OUTER SURFACE

$\begin{array}{llllllllll}38 & C & Y & -356 & 87 & 157 & 4 & 8 & 87 & \$\end{array}$

$\begin{array}{lllllllll}39 & \mathrm{C} / Y & -356 & 87 & 157 & 4 & 16 & 37 & \$\end{array}$ IRON PIPE OUTER SURFACE

40 PY 470

41 PY 263 O6

42 PY 273 O6

43 PY 28354

44 PY 28862

45 PY 29370

46 PY 29878

47 PY 30386

48 PY 30894

461 PY 31306

462 PY 32306

463 Pr 333 O6

49 PY 34306

50 PZ 160

51 PY 170

52 PY 180

53 PY 190

54 PY 200
55 PY 210

Table A5. (cont.) 


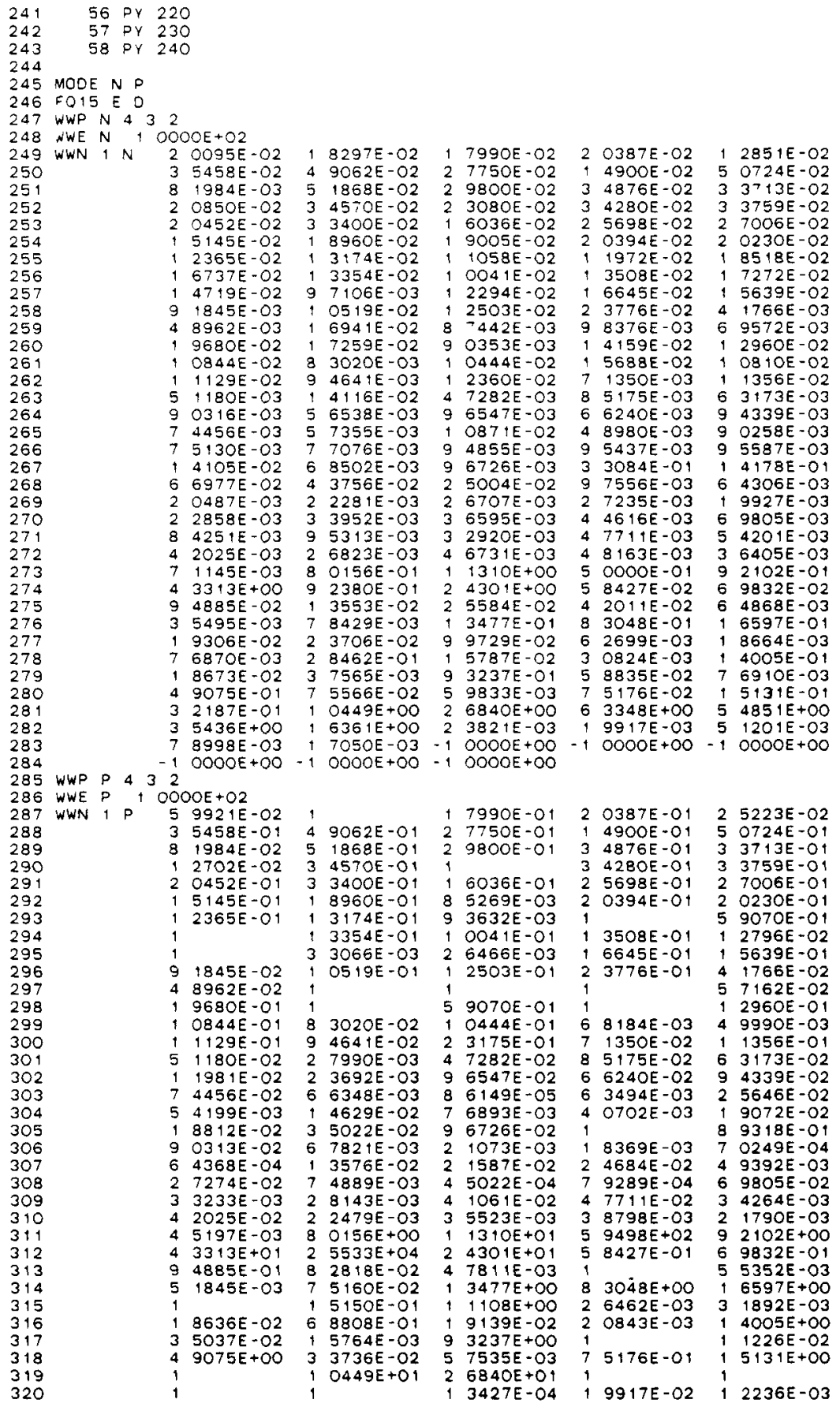

Table A5. (cont.) 


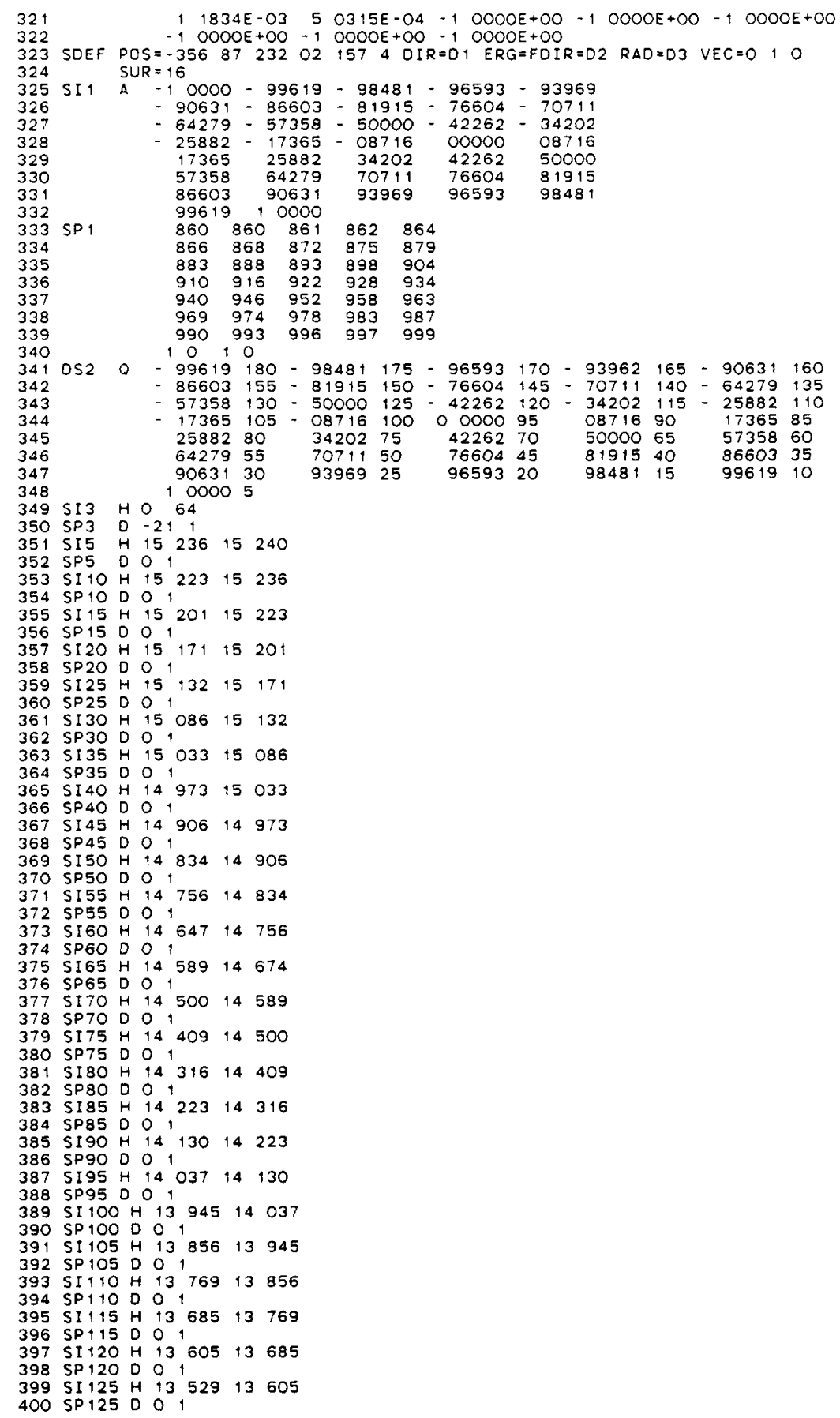

Table A5. (cont.) 


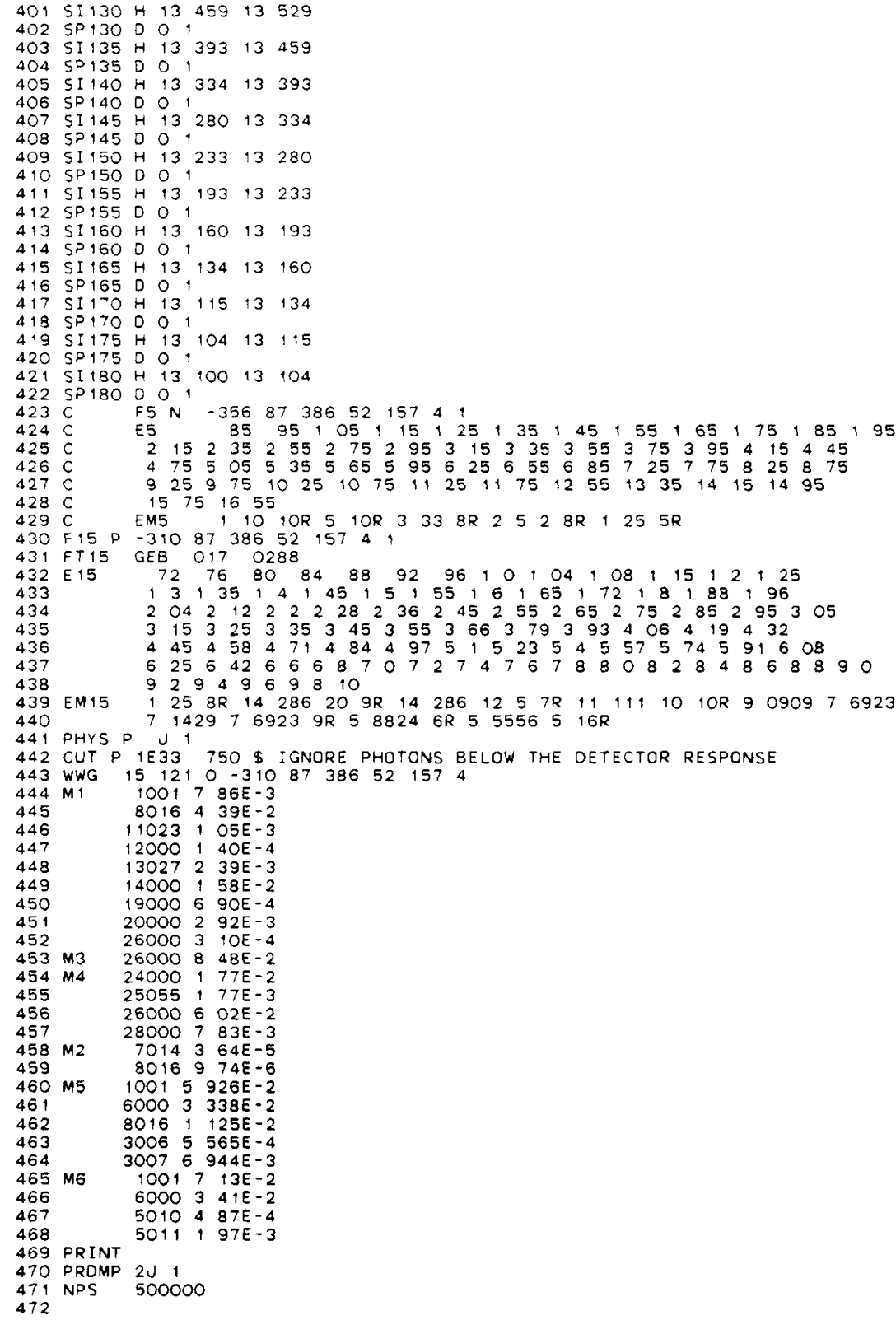

Table A5. (cont.) 


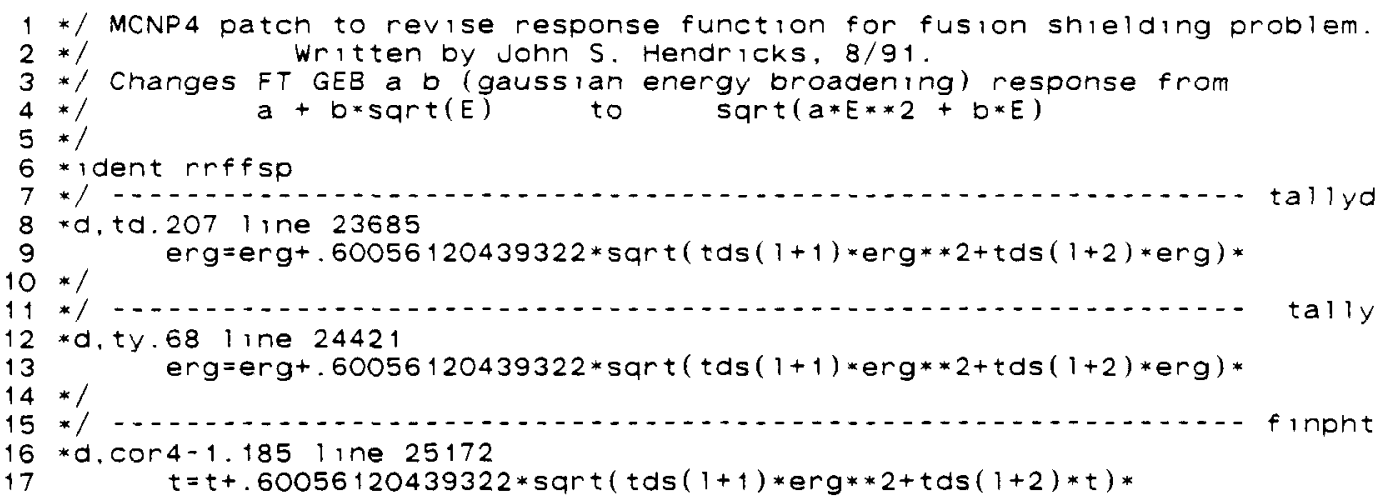

Table A6. Patch to modify the MCNP gaussian detector response function. 


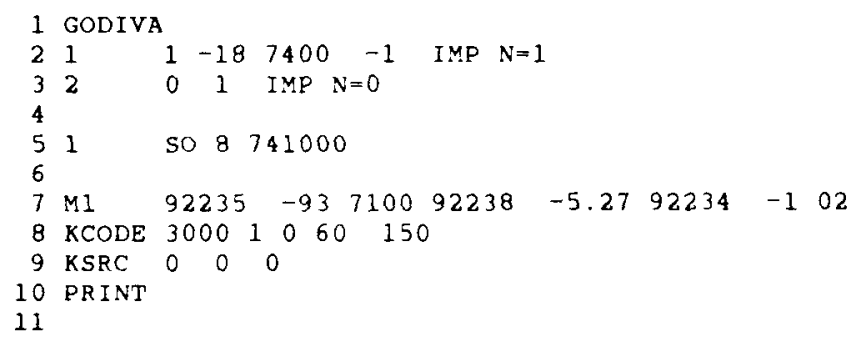

Table A7. Lady Godiva fast neutron critical assembly setup, $93.71 \%$ U-235 sphere. 


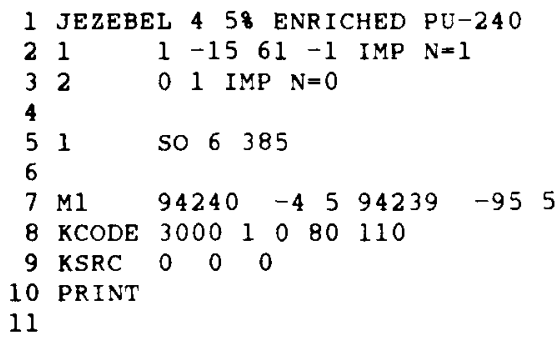

Table A8. Jezebel fast neutron critical assembly setup, 95.5\% Pu-239. 


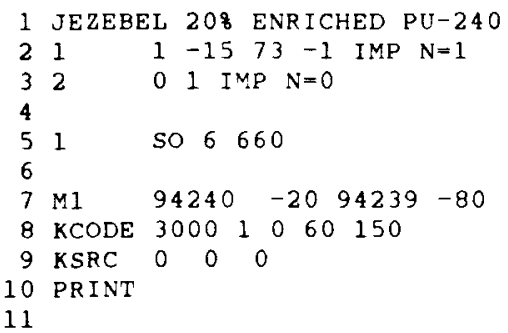

Table A9. Jezebel fast neutron critical assembly setup, 80\% Pu-239. 


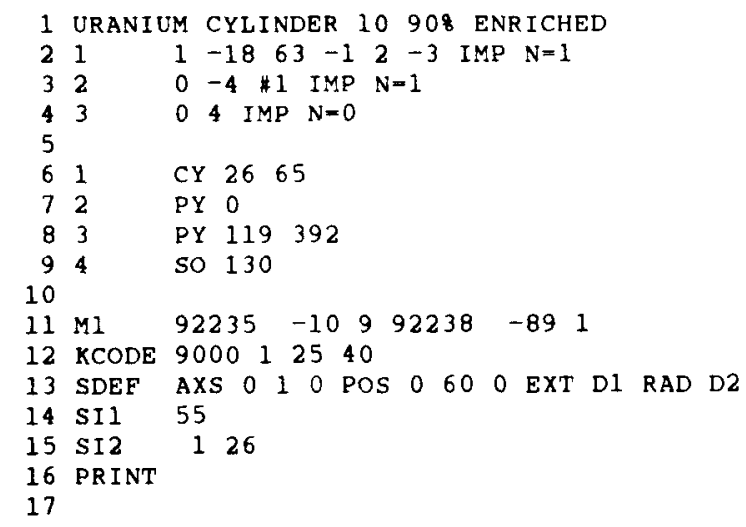

Table A10. Low-enrichment uranium cylinder critical assembly setup, 10.9\% U-235. 


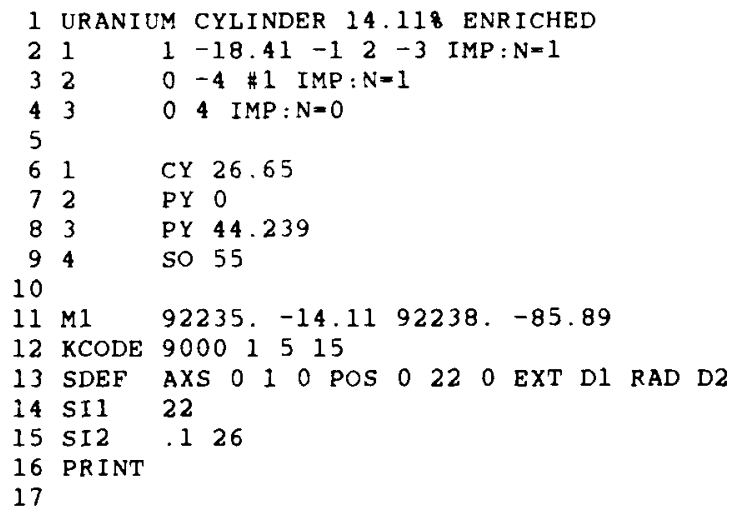

Table A11. Low-enrichment uranium cylinder critical assembly setup, 14.1\% U-235. 


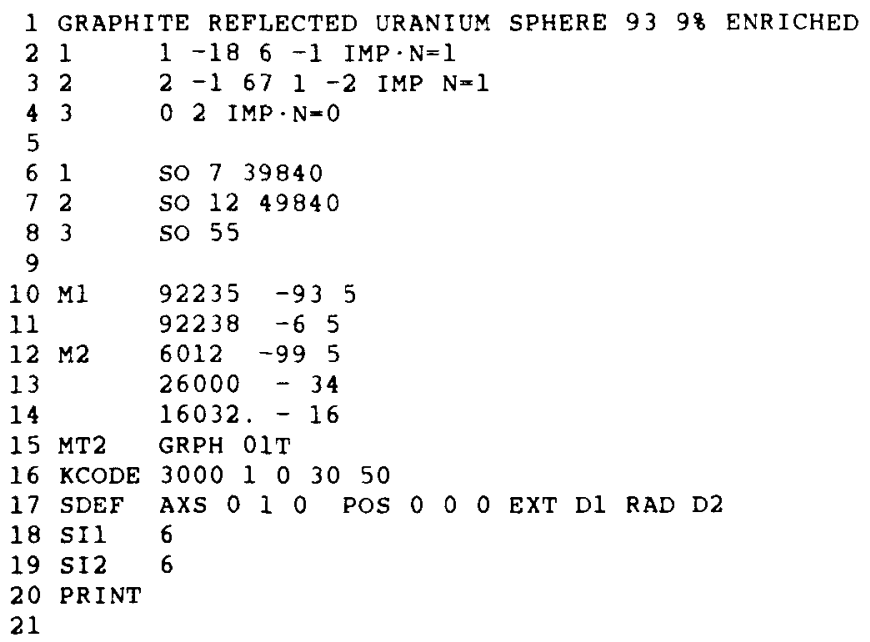

Table A12. Graphite-tamped reflected-uranium sphere critical assembly setup. 


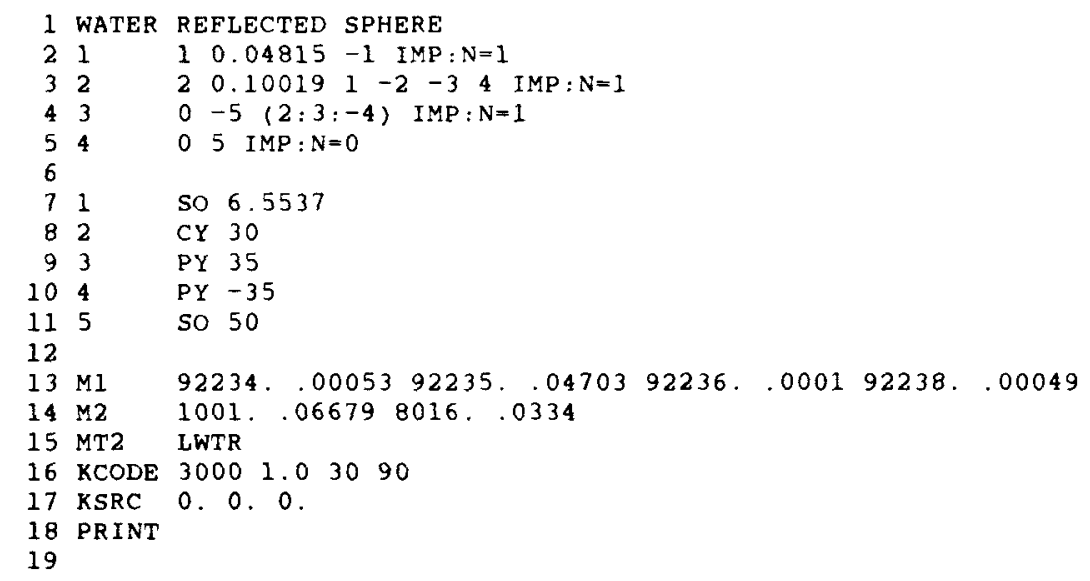

Table A13. Water-reflected uranium sphere critical assembly setup. 


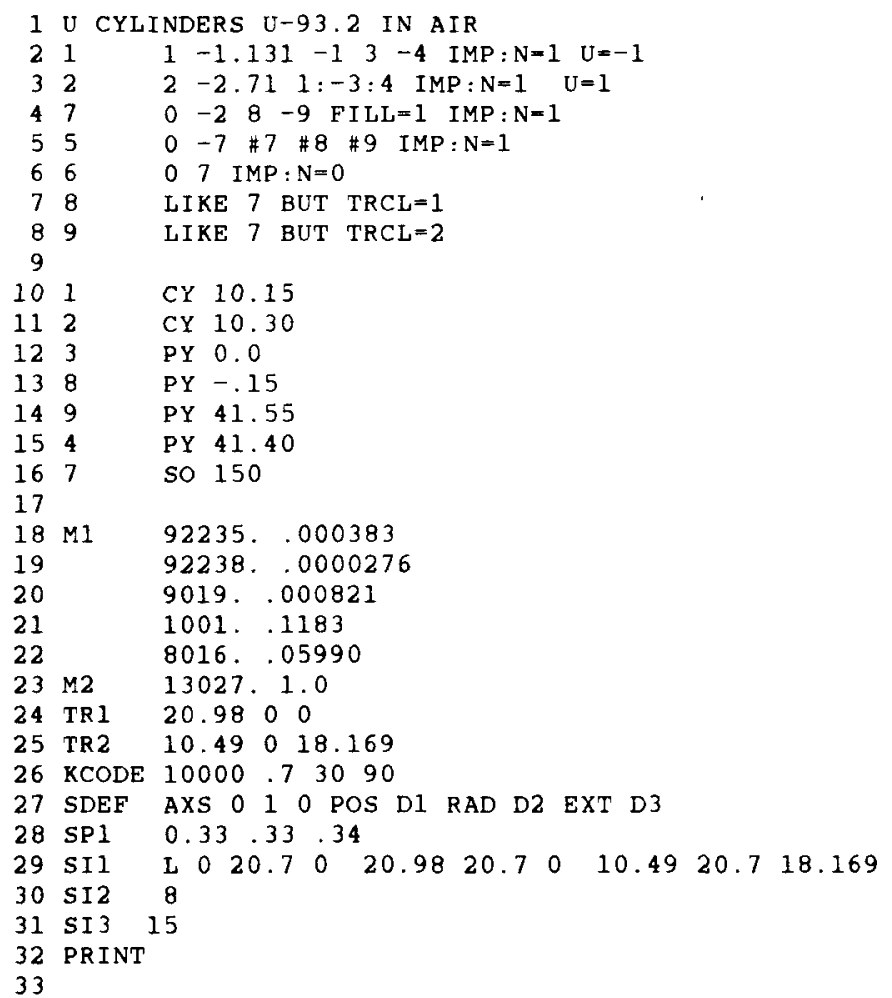

Table A14. Three interacting uranium cylinders critical assembly setup. 


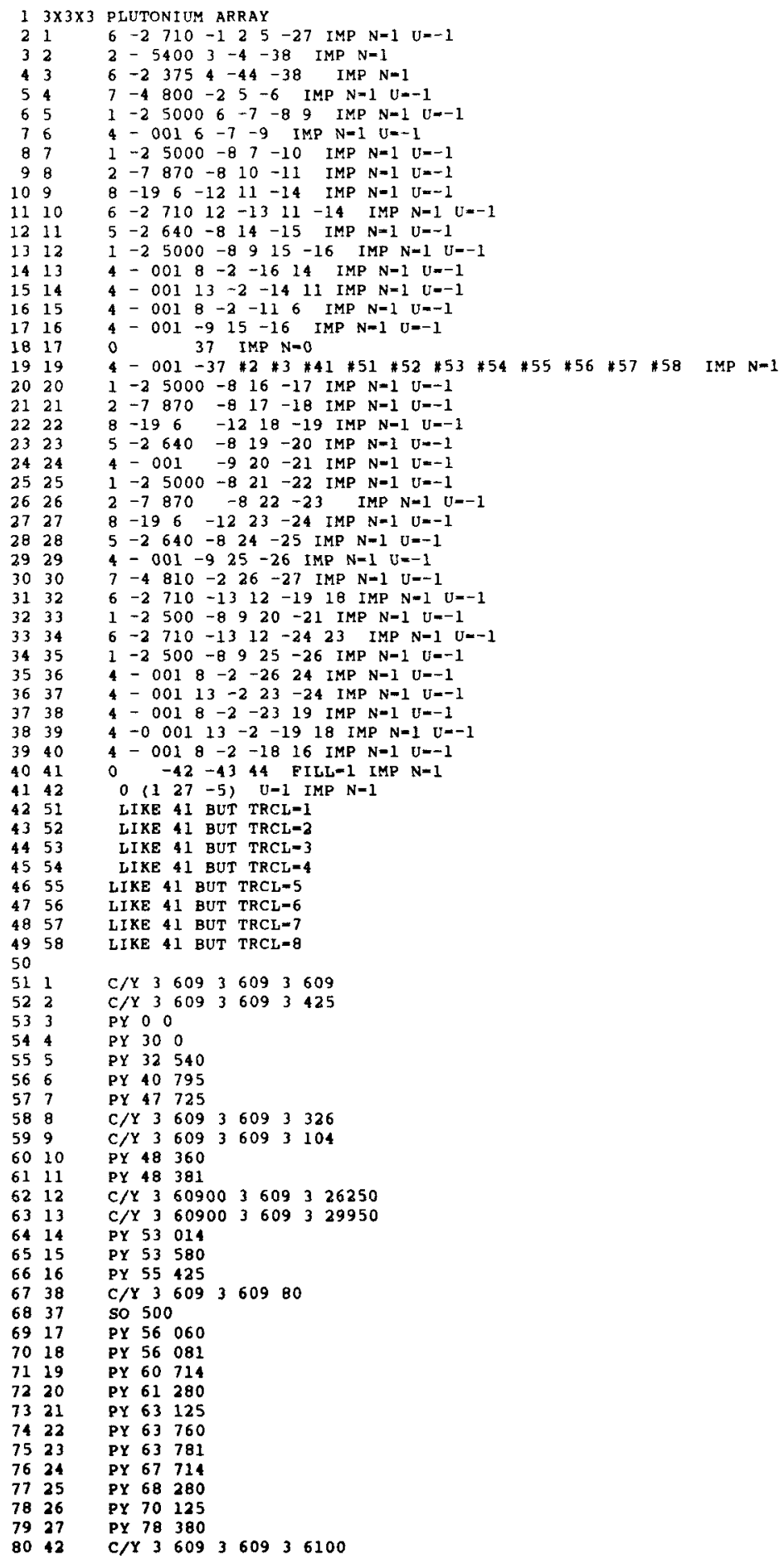

Table A15. 3 x 3 array of plutonium fuel rods critical assembly setup. 


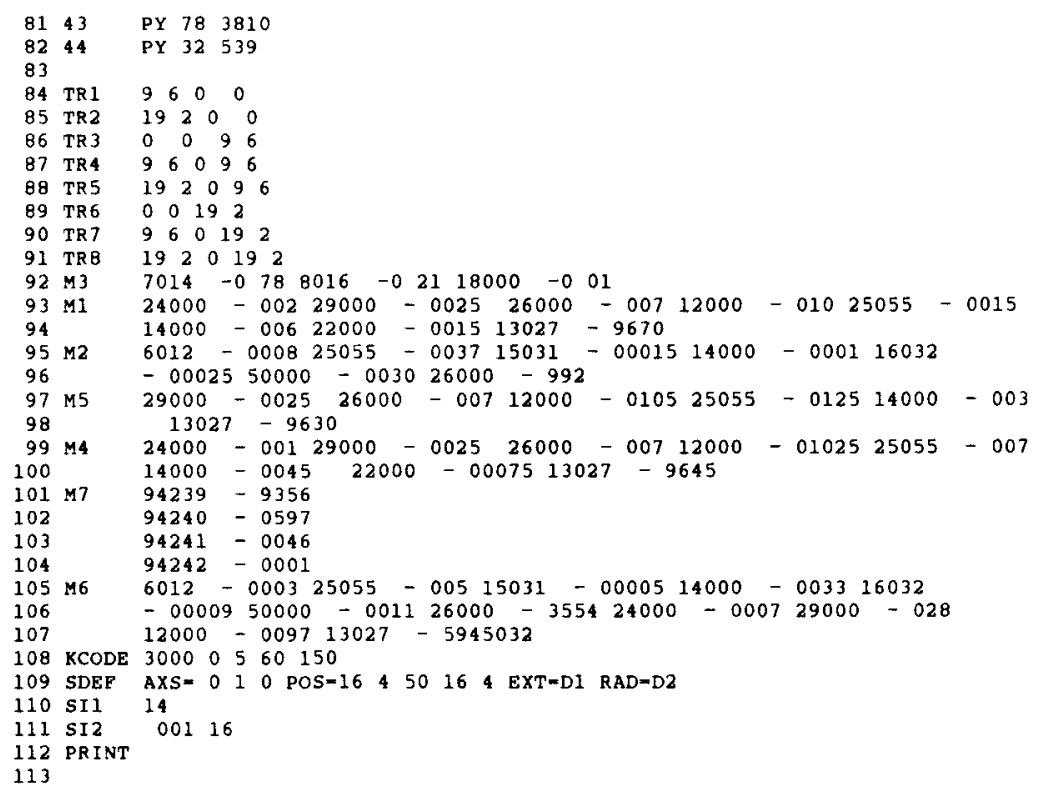

Table A15. (cont.) 